Aus dem Institut für Neuro- und Sinnesphysiologie

(Prof. Dr. S. O. Rizzoli)

im Zentrum Physiologie und Pathophysiologie

der Medizinischen Fakultät der Universität Göttingen

\title{
Dreidimensionale Analyse von Synapsen in hippocampalen Zellkulturen
}

\author{
INAUGURAL-DISSERTATION \\ zur Erlangung des Doktorgrades \\ für Zahnheilkunde \\ der Medizinischen Fakultät der \\ Georg-August-Universität zu Göttingen
}

vorgelegt von

Jan-Eike Ußling

aus

Herford

Göttingen 2019 
Dekan:

Prof. Dr. rer. nat. H. K. Kroemer

\section{Betreuungsausschuss}

Betreuer/in:

Ko-Betreuer/in:

\section{Prüfungskommission}

Referent/in:

Ko-Referent/in:

Drittreferent/in:
Prof. Dr. S. O. Rizzoli

Prof. Dr. S. O. Rizzoli

Prof. Dr. T. F. Outeiro

Prof. Dr. T. F. Outeiro

Datum der mündlichen Prüfung: 29.06.2020 
Hiermit erkläre ich, die Dissertation mit dem Titel „Dreidimensionale Analyse von Synapsen in hippocampalen Zellkulturen" eigenständig angefertigt und keine anderen als die von mir angegebenen Quellen und Hilfsmittel verwendet zu haben.

Göttingen, den

(Unterschrift) 


\section{Inhaltsverzeichnis}

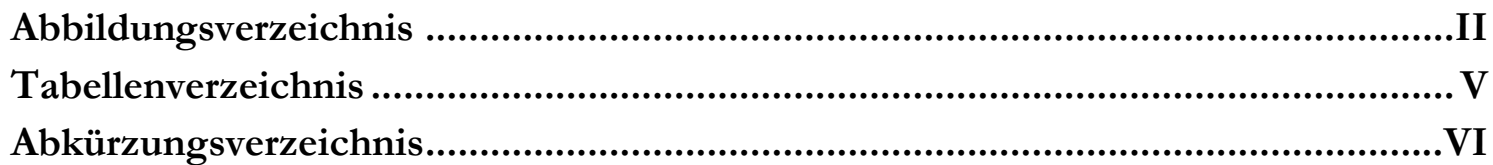

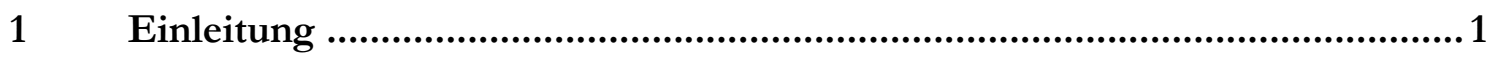

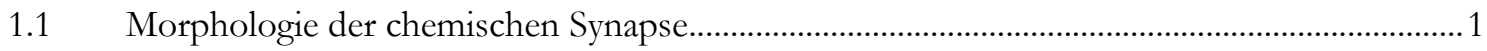

1.2 Bisheriger Forschungsstand: Vesikelanzahl und Morphologie der Synapsen in hippocampalen Zellkulturen ...........................................................................................................

1.3 Chemische Signalübertragung an Synapsen des Zentralnervensystems ...................................10

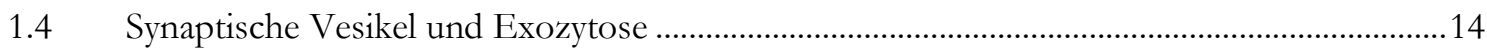

1.5 Medizinische Bedeutung chemischer Synapsen und des SNARE-Komplexes ........................21

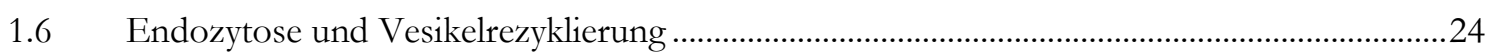

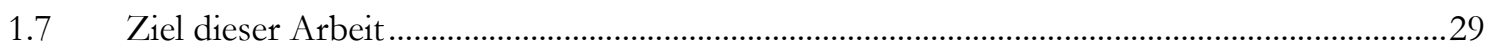

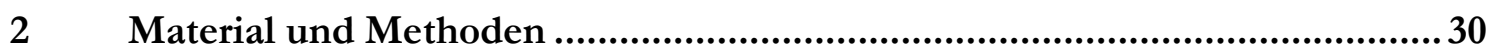

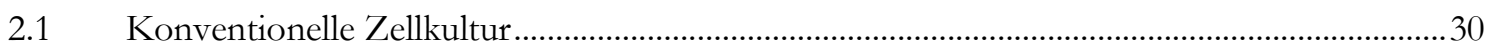

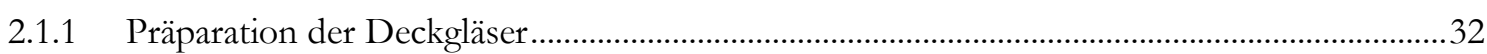

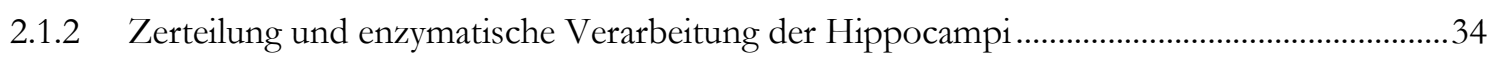

2.2 Fixation, Elektronenmikroskopie, Adobe Photoshop CS6, MatLab ..........................................36

2.3 Statistik: Korrelationskoeffizient nach Bravais-Pearson und Bonferroni-Korrektur..............41

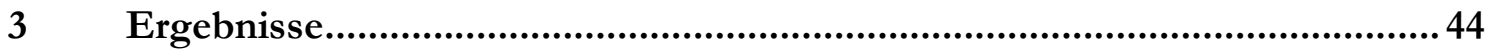

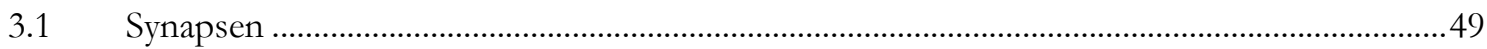

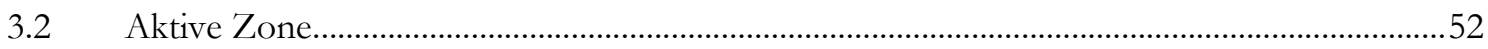

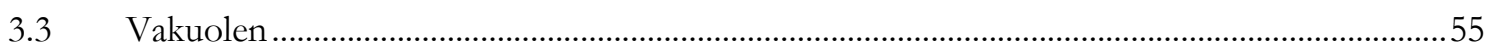

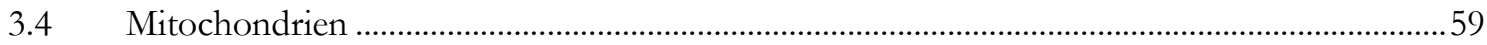

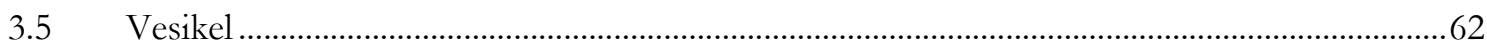

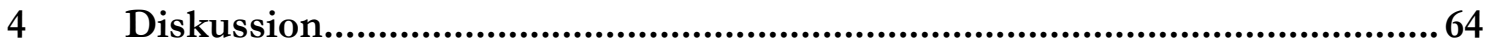

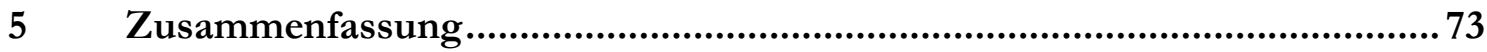

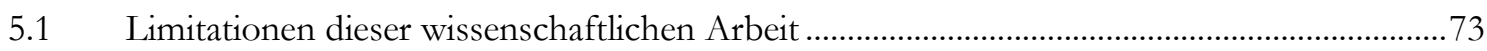

5.2 Ausblick für zukünftige Foschungsvorhaben ........................................................................

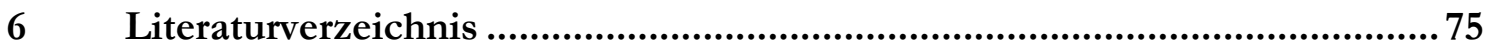




\section{Abbildungsverzeichnis}

Abbildung 1: Schematische Darstellung einer chemischen Synapse.

Abbildung 2: Elektronenmikroskopisches Bild einer chemischen Synapse und Schema-

Zeichnung. 3

Abbildung 3: Dreidimensionale Rekonstruktion von Synapsen.....

Abbildung 4: EM-Schnittbilder und dreidimensionale Rekonstruktion einer typischen Synapse.

Abbildung 5: Schematische Darstellung einer Nervenzelle (links) und einer chemischen Synapse mit chemischer Signalübertragung (rechts) .................................................... 11

Abbildung 6: Überblick über den Vesikelkreislauf ....

Abbildung 7: Die V-ATPase pumpt unter ATP-Verbrauch Protonen in den synaptischen Vesikel, die dann im Austausch gegen den Neurotransmitter wieder ausgeschleust werden.

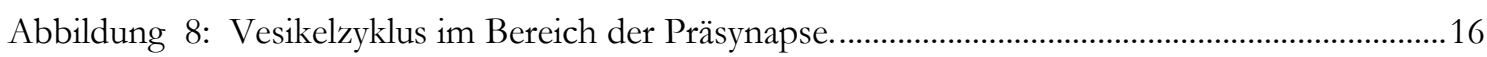

Abbildung 9: Molekulare Mechanismen der Vesikelfusion..............................................................17

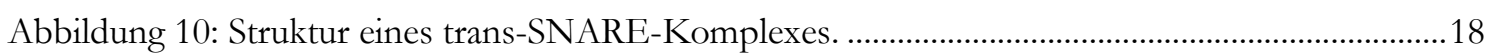

Abbildung 11: Ein Modell, wie SNARE-Proteine die Membranfusion katalysieren.

Abbildung 12: NSF-vermittelte Dissoziation der SNARE-Paare nach einem Membranfusionszyklus.

Abbildung 13: Angriffspunkte der Botulinum- und Tetanustoxine an den Komponenten des SNARE-Komplexes.

Abbildung 14: Sir Charles Bells Porträt eines Mannes mit generalisiertem Tetanus.

Abbildung 15: Die Ansammlung verschiedener Moleküle des synaptischen Vesikels in der Plasmamembran triggert die Rekrutierung von Adapterproteinen.

Abbildung 16: Jedes Triskelion besteht aus drei schweren und drei leichten Ketten .........................25

Abbildung 17: Zusammenlagerung und Auflösung einer Clathrinhülle 26

Abbildung 18: Abschnürvorgang des clathrinbeschichteten Vesikels durch Dynamin und assoziierte Proteine ......................................................................................................26

Abbildung 19: Ablösung der Clathrinhülle durch Hsc70 und Auxillin...............................................28

Abbildung 20: Das Flowchart zeigt das dreiteilige Protokoll für die Präparation hippocampaler Zellkulturen nach Kaech und Banker.

Abbildung 21: Dargestellt ist der beispielhafte Aufbau einer „Neubauer Cell Counting Chamber"

Abbildung 22: Ausschnitt eines elektronenmikroskopischen Bildes, das mit Adobe Photoshop geöffnet wurde und den Bereich der Synapse abbildet. .38

Abbildung 23: Die in Abbildung 22 gezeigte Synapse ist im Detail vergrößert dargestellt 38

Abbildung 24: Dargestellt ist die Befehlskette „Edit $\rightarrow$ Transform $\rightarrow$ Rotate“, mit deren Hilfe die einzelnen Schichten exakt übereinandergelegt wurden .39

Abbildung 25: Auf der rechten Leiste sind die verschiedenen Ebenen („Layer 1-3“) abgebildet. Ebenfalls zu erkennen ist die Schaltfläche „Opacity“

Abbildung 26: Abgebildet ist der Arbeitsschritt des manuellen Zeichnens der synaptischen Strukturen mit dem Programm MatLab. 
Abbildung 27: Abgebildet ist der Arbeitsschritt der dreidimensionalen Rekonstruktion des präsynaptischen Bereichs.

Abbildung 28: Darstellung der 30 dreidimensional rekonstruierten Synapsen. Die Größe eines Vesikels beträgt in allen Bildern einheitlich 42 Nanometer

Abbildung 29: Zwei Detailbilder von dreidimensionial rekonstruierten Synapsen............................48

Abbildung 30: Dargestellt ist das Volumen der einzelnen Synapsen .................................................49

Abbildung 31: Mittelwert der Vesikelanzahl pro Synapse .................................................................50

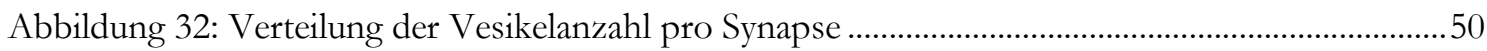

Abbildung 33: Anteil des Gesamtvolumens der Vesikel am jeweiligen Synapsenvolumen.................50

Abbildung 34: Mittelwert der Vakuolenanzahl pro Synapse .............................................................51

Abbildung 35: Gezeigt ist die Vakuolenanzahl pro Synapse ...............................................................51

Abbildung 36: Mittelwert der Oberfläche der aktiven Zone ..................................................................52

Abbildung 37: Verteilung der Oberflächengrößen der aktiven Zonen................................................52

Abbildung 38: Gezeigt ist das Verhältnis vom Volumen der Synapsen zur Oberfläche der

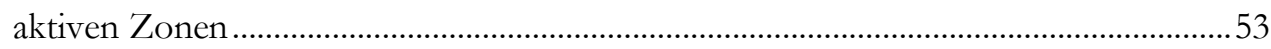

Abbildung 39: Anzahl der Vesikel im Verhältnis zur Oberfläche der aktiven Zone..........................53

Abbildung 40: Anzahl der Vakuolen im Verhältnis zur Oberfläche der aktiven Zone........................54

Abbildung 41: Oberfläche der aktiven Zonen im Verhältnis zum Volumen der Mitochondrien.......55

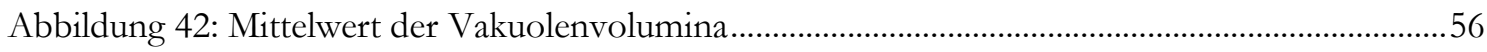

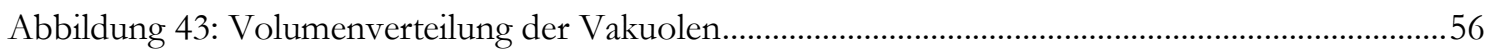

Abbildung 44: Anzahl der Vakuolen im Verhältnis zum Volumen der Synapsen..............................57

Abbildung 45: Volumen der Vakuolen im Verhältnis zum Volumen der Synapse .............................57

Abbildung 46: Anzahl der Vakuolen im Verhältnis zur Anzahl der Vesikel ......................................58

Abbildung 47: Anzahl der Vesikel im Verhältnis zum Volumen der Vakuolen...................................59

Abbildung 48: Mittelwert der Volumina der Mitochondrien ...............................................................60

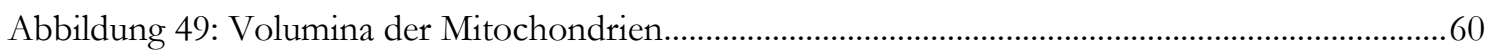

Abbildung 50: Volumen der Mitochondrien im Verhältnis zum Volumen der Synapse....................61

Abbildung 51: Anzahl der Vesikel im Verhältnis zum Volumen der Mitochondrien.........................61

Abbildung 52: Mittelwert des Gesamtvolumens der Vesikel .............................................................62

Abbildung 53: Anzahl der Vesikel im Verhältnis zum Volumen der Synapse ...................................63

Abbildung 54: Gesamtvolumen der Vesikel im Verhältnis zum Volumen der Synapse.....................63

Abbildung 55: Position und mögliche Funktion endosomähnlicher Strukturen im Bereich der Präsynapse. Gezeigt sind die vier Hauptendozytosemodelle synaptischer Vesikel. 


\section{Tabellenverzeichnis}

Tabelle 1: Auflistung der Materialien für die Herstellung der Zellkultur und deren Anwendung... 


\section{Abkürzungsverzeichnis}

$\begin{array}{ll}\text { ATP } & \text { Adenosintriphosphat } \\ \text { DAB } & \text { Diaminobenzidine } \\ \text { Grip } & \text { Glutamate receptor interacting protein } \\ \text { Hsc70 } & \text { Heat shock cognate } 70 \\ \text { Munc } & \text { Mammalian uncoordinated-18 protein } \\ \text { NSF } & \text { N-ethylmaleimide-sensitive factor } \\ \text { PSD-95 } & \text { Postsynaptic density protein } 95 \\ \text { RIMs } & \text { Rab3-interacting molecules } \\ \text { SNAP-25 } & \text { Synaptosomal-associated protein 25 } \\ \text { SNARE } & \text { Soluble N-ethylmaleimide-sensitive-factor attachment receptor }\end{array}$




\section{$1 \quad$ Einleitung}

\subsection{Morphologie der chemischen Synapse}

Das Wort Synapse (griech.: „zusammen“; „Verbindung“) beschreibt morphologisch speziell aufgebaute Kontaktstellen zwischen zwei Nervenzellen, die der Übertragung von Informationen zwischen diesen dienen (Dudel und Heckmann 2005). Die Verbindung kann hierbei entweder zwischen zwei Nervenzellen oder aber einer Nervenzelle und einer muskulären oder sekretorischen Effektorzelle bestehen.

Das zentrale Nervensystem des Menschen enthält ungefähr 100 Milliarden Neuronen. Die Anzahl der Synapsen, die von einem einzelnen Neuron ausgebildet werden, variiert sehr stark und liegt je nach Zelltyp zwischen einer und mehr als 100.000. Im Durchschnitt lassen sich circa 1.000 Synapsen pro Nervenzelle detektieren (Jahn 2016). Daraus ergibt sich somit eine Gesamtanzahl von ungefähr 100 Billionen Synapsen im gesamten Zentralnervensystem.

Generell unterscheidet man zwischen elektrischen Synapsen, die über sogenannte Gap Junctions, also eine direkte Verbindung der beiden Membranen, eine elektrische Kommunikation ermöglichen, und chemischen Synapsen, bei denen das Eintreffen eines elektrischen Signals zur Freisetzung von Neurotransmittern führt, die danach zur postsynaptischen Membran diffundieren und dort auf spezifische Rezeptoren treffen. Als Reaktion auf diese Bindung öffnen sich Membrankanäle, durch die dann Ionenströme fließen, welche die postsynaptische Zelle durch die Beeinflussung ihres Membranpotentials depolarisieren und ein Aktionspotential auslösen (Dudel und Heckmann 2005).

Synapsen zeigen bei ihrem Aufbau folgende drei Hauptkomponenten: die Präsynapse, also der Endbereich des präsynaptischen Neurons, den synaptischen Spalt, der jedoch nur bei chemischen Synapsen vorhanden ist, und die Postsynapse (vergleiche Abbildung 1 und Abbildung 2). 


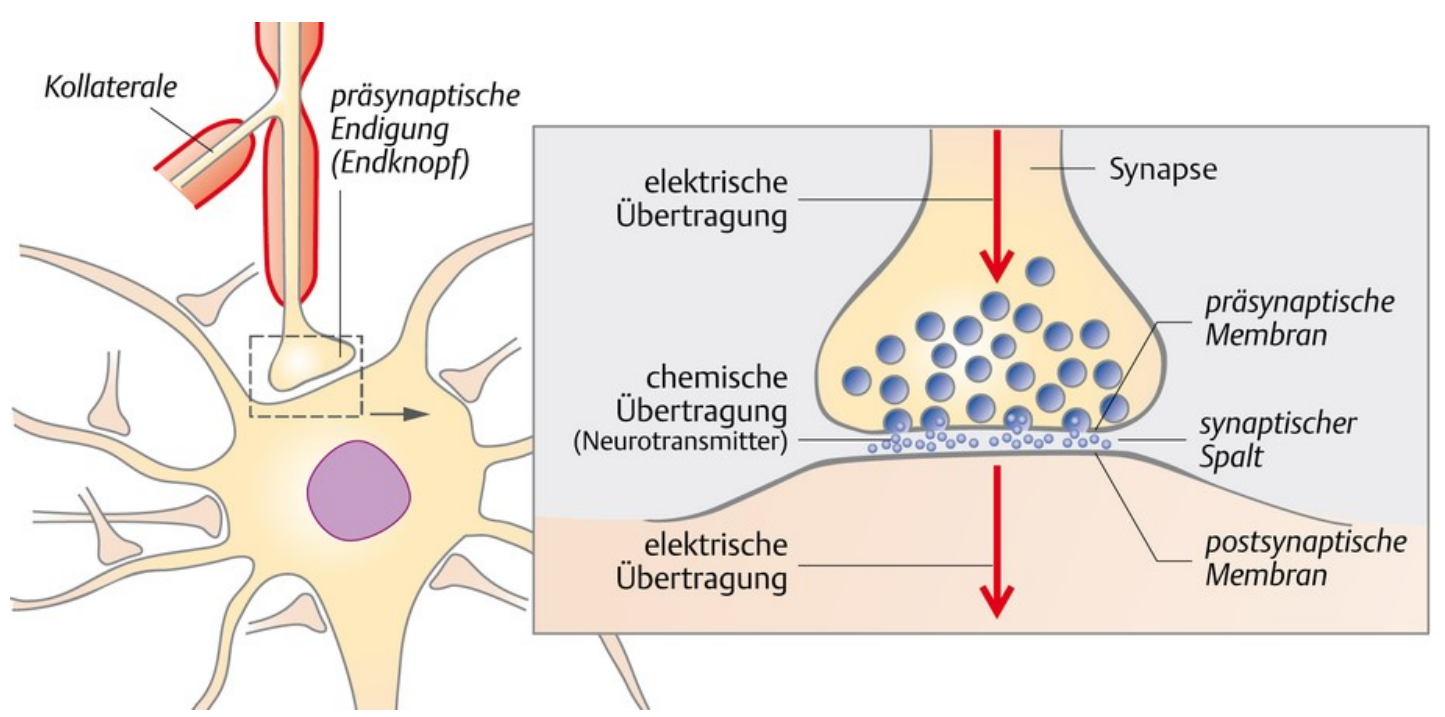

Abbildung 1: Schematische Darstellung einer chemischen Synapse (entnommen aus Kühnel 2008; die Verwendung erfolgt mit freundlicher Genehmigung des Georg Thieme Verlags)

Bei genauerer Betrachtung beinhalten sowohl die Prä- als auch die Postsynapse verschiedene Strukturen, die von elementarer Bedeutung für die Funktion der Synapse sind. Im Bereich der Präsynapsen findet man zahlreiche synaptische Vesikel, die mit Botenstoffen (Neurotransmittern) gefüllt sind. Ein ausgeprägtes Zytoskelett aus Mikrotubuli und Aktinfilamenten ermöglicht den Transport der Vesikel, die Mitochondrien dienen der Energiebereitstellung. Die wahrscheinlich komplexeste, aber auch am besten organisierte Struktur der Präsynapse stellt die aktive Zone dar, ein elektronendichter Bereich, an den Vesikel binden und fusionieren (Rizzoli und Tabares 2016).

Hier findet man zusätzlich spannungsabhängige Calciumkanäle, durch die während der Depolarisation Calciumionen aus dem extrazellulären Raum in das Innere der Präsynapse einströmen. Vermutlich besteht darüber hinaus eine Verbindung der aktiven Zone mit der sogenannten periaktiven Zone, einem Bereich, in dem die synaptischen Vesikel, die gerade die Exozytose durchlaufen haben, für die Endozytose vorbereitet werden (Rizzoli und Tabares 2016).

Die physiologische Funktion der Präsynapse umfasst sowohl die Speicherung als auch die aktivitätsabhängige Freisetzung von Neurotransmittern (Draguhn 2014). Sie wird in den folgenden Kapiteln detailliert erläutert und findet daher hier keine weitere Berücksichtigung.

Die Trennung der prä- und der postsynaptischen Membran erfolgt durch den ungefähr $20 \mathrm{~nm}$ breiten synaptischen Spalt. 


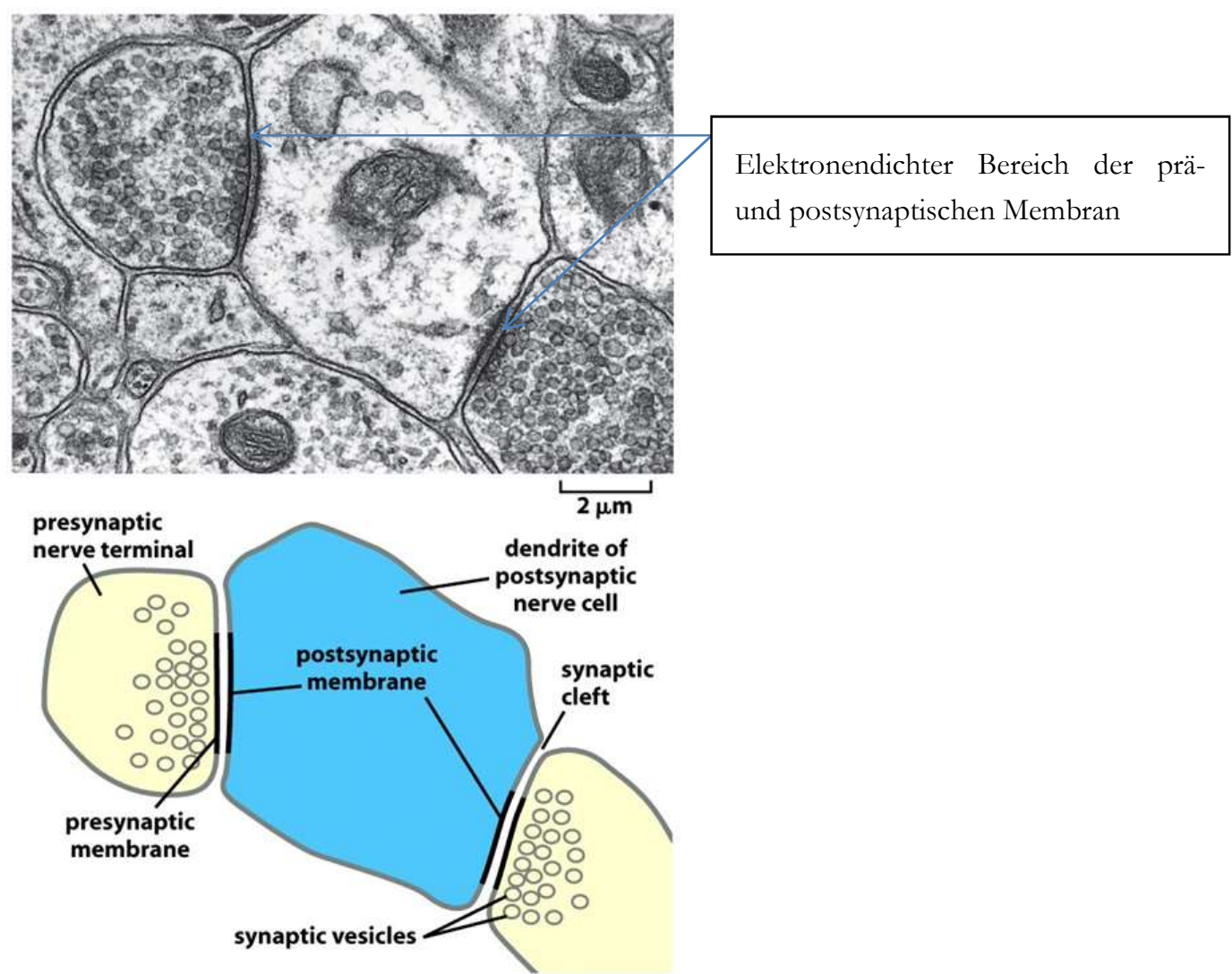

Abbildung 2: Elektronenmikroskopisches Bild einer chemischen Synapse und Schemazeichnung. Dargestellt sind zwei präsynaptische Nervenendigungen und ihre synaptischen Verbindungen mit dem Dendriten der postsynaptischen Nervenzelle. Gut zu erkennen sind die elektronendichten Bereiche, die die Region der prä- und postsynaptischen aktiven Zone markieren (Pfeile) (entnommen und modifiziert aus Alberts et al. 2008; die Verwendung erfolgt mit freundlicher Genehmigung durch Dr. C. S. Raine).

Im Bereich der Postsynapse findet man ebenfalls ein aus Mikrotubuli und Aktinfilamenten aufgebautes Zytoskelett und Mitochondrien, die der Energiegewinnung dienen. Im Bereich der postsynaptischen aktiven Zone liegen die Rezeptoren für die in den synaptischen Spalt freigesetzten Neurotransmitter. Die Einteilung der postsynaptischen Rezeptoren erfolgt in iono- beziehungsweise metabotrope Rezeptoren. Zytoskelettale Ankerproteine wie PSD95, Gephyrin, Grip und weitere sorgen für die Fixierung der Rezeptoren an der postsynaptischen Membran. Die präsynaptischen aktiven Zonen und die postsynaptische Membran mit ihren Rezeptoren sind direkt vis-à-vis positioniert und ermöglichen somit eine äußerst effektive Signalübertragung (Richter 2013). Des Weiteren beherbergt die Postsynapse Ribosomen und raue endoplasmatische Retikula, denen eine wichtige Funktion bei der Produktion der Rezeptoren zukommt. 


\subsection{Bisheriger Forschungsstand: Vesikelanzahl und Morphologie der Synapsen in hippocampalen Zellkulturen}

Seit der Pionierarbeit von Bernhard Katz bezüglich der Funktion der Synapse ist der morphologisch anatomische Aufbau zentraler Synapsen wichtiger Bestandteil der neurobiologischen Forschung. Das Erkennen der synaptischen Struktur und die Assoziation dieser mit der physiologischen Funktion bilden hierbei den Kern zahlreicher Forschungsvorhaben. Bezüglich der in dieser Arbeit untersuchten anatomischen Strukturen der Synapse leisteten Prof. Dr. Thomas Schikorski und Prof. Dr. Charles F. Stevens vom „Salk Institute for Biological Studies“ in La Jolla, San Diego umfangreiche Vorarbeit.

In ihrer 1997 erschienenen Übersichtsarbeit „Quantitative Ultrastructural Analysis of Hippocampal Excitatory Synapses“ leiteten sie anhand dreidimensionaler Rekonstruktionen exzitatorischer Synapsen aus der CA1-Region des Nager-Hippocampus und in Zellkulturen die Größe der aktiven Zone und der Postsynapse, die Anzahl der aktiven Zonen pro präsynaptischer Endigung, die Anzahl der gebundenen Vesikel pro aktiver Zone und die Gesamtanzahl synaptischer Vesikel in der präsynaptischen Endigung ab (Schikorski und Stevens 1997). Als Untersuchungsmaterial dienten hippocampale Neuronen erwachsener Mäuse (sieben Monate alt). Da sich ein Großteil der wissenschaftlichen Arbeiten zu der Zeit auf den Bereich der Postsynapse konzentrierte, war es Ziel ihrer Arbeit, die statistische Verteilung jener präsynaptischen Eigenschaften zu bestimmen, die mit hoher Wahrscheinlich von physiologischer Bedeutung für Synapsen im Hippocampus sind.

Der Bereich einer Synapse wurde anhand folgender Parameter festgelegt: Die aktive Zone und die Postsynapse konnten mit Hilfe elektronendichten Materials identifiziert werden. Gebundene Vesikel, ein synaptischer Spalt und eine parallele Ausrichtung der prä- und postsynaptischen Membran dienten als definitive Marker der Synapse. Die dreidimensionale Rekonstruktion erfolgte dann durch die Analyse 29 aufeinanderfolgender Schnittbilder und ist in Abbildung 3 gezeigt.

Schikorski und Stevens fanden heraus, dass 64 der 71 untersuchten Hirn-Synapsen nur eine aktive Zone zeigten; das entspricht $90 \%$. Sechs Synapsen (8\%) präsentierten zwei und eine $(2 \%)$ sogar drei aktive Zonen. Waren mehrere aktive Zonen im Bereich einer Synapse vorhanden, kommunizierten diese nie mit der gleichen Postsynapse. Die Untersuchung der Synapsen in der Zellkultur zeigte statistisch nicht relevant abweichende Ergebnisse. $69 \%$ der Synapsen hatten eine aktive Zone, 31 \% besaßen zwei. 
Übereinstimmend wurde eine enge Lagebeziehung und Verknüpfung der aktiven Zone und der Postsynapse beobachtet. Die Fläche der aktiven Zone variierte jedoch erheblich, stand dabei aber stets in einer linearen Beziehung zu dem Volumen ,ihrer“ Synapse. Die größte aktive Zone zeigte eine Länge von $0,8 \mu \mathrm{m}$ und eine Breite von $0,26 \mu \mathrm{m}$, wohingegen die kleinste $0,12 \mu \mathrm{m}$ lang und $0,06 \mu \mathrm{m}$ breit war. Die durchschnittliche Oberfläche einer aktiven Zone betrug $0,027 \mu \mathrm{m}^{2}$.

Die Anzahl der an der jeweiligen aktiven Zone gebundenen Vesikel zeigte ebenfalls eine große Spannweite. Im Durchschnitt waren 10,3 Vesikel an eine der 79 untersuchten aktiven Zonen gebunden. Das Minimum waren zwei, das Maximum 27 angedockte Vesikel. Obwohl sowohl die Fläche der aktiven Zone als auch die Menge der Vesikel, die an einer aktiven Zone lagen, sehr unterschiedlich waren, bestand immer eine starke Korrelation dieser beiden Größen an der jeweiligen Synapse. Die Position, an der die Vesikel an die aktive Zone gebunden waren, schien hingegen zufällig zu sein. Ein Problem bezüglich dieser Beobachtung entstand dadurch, dass es keine präzise Definition für an die aktive Zone „gebundene Vesikel“ (im Folgenden: „AZ-gebundene Vesikel“) im elektronenmikroskopischen Bild gibt. Daher wurde als Kriterium eine enge Lagebeziehung der Vesikel und der Plasmamembran zur Identifikation AZ-gebundener Vesikel verwendet.

Die Gesamtanzahl der Vesikel betrug im Durchschnitt 270 Vesikel pro Synapse.

Im Vergleich mit den Synapsen in der Zellkultur zeigte sich lediglich ein statistisch signifikanter Unterschied. Die Anzahl der gebundenen Vesikel pro aktiver Zone war in der Zellkultur deutlich geringer und nur ungefähr halb so groß.

Zusammenfassend präsentieren die Daten von Schikorski und Stevens die Synapse als eine Struktur mit reichlich Variabilität bezüglich der Größe und Form der aktiven Zone, der Fläche der Postsynapse, der Anzahl gebundener Vesikel pro aktiver Zone und der Größe des Reservepools nicht gebundener Vesikel. Nichtsdestoweniger gab es einheitliche Merkmale, nämlich das Vorhandensein von überwiegend einer aktiven Zone pro Synapse und die enge Beziehung zwischen der Fläche der aktiven Zone und der Anzahl der daran gebundenen Vesikel.

Im Verlauf ihres Papers zogen Schikorski und Stevens den Vergleich zu vorherigen Untersuchungen synaptischer Strukturen, die sich jedoch auf spinale Synapsen beschränkten. Die primären Unterschiede bezogen sich hierbei auf die Fläche der aktiven Zone, die in spinalen Synapsen zweieinhalbmal größer war als in Synapsen des Hippocampus. 

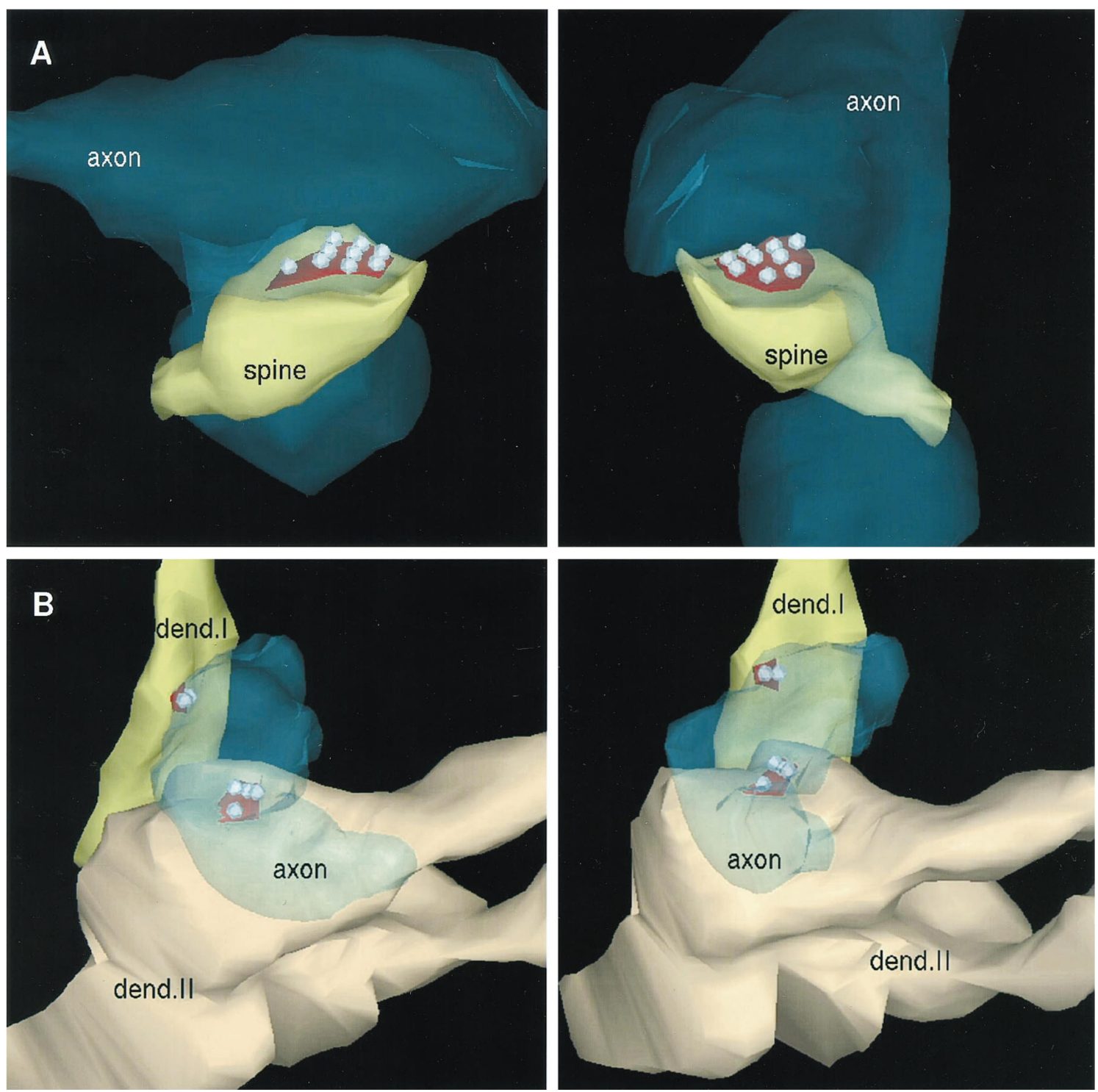

Abbildung 3: Dreidimensionale Rekonstruktion von Synapsen. Abbildung 3A zeigt zwei Ansichten einer Synapse aus dem Gehirn. Die aktive Zone ist rot, die neun gebundenen Vesikel sind grau markiert. Abbildung 3B präsentiert die Rekonstruktion zweier axodendritischer Synapsen aus einer Zellkultur des Hippocampus. Die Farbgebung entspricht der in Abbildung 3A (entnommen aus Schikorski und Stevens 1997; die Verwendung erfolgt mit freundlicher Genehmigung des Journals of Neuroscience)

Des Weiteren fand man im Rückenmark im Durchschnitt sechs aktive Zonen pro Synapse, im Vergleich zu einer pro Synapse im Hippocampus. Die Unterschiede zwischen spinalen Synapsen und denen im Hippocampus waren anhand des deutlich kleineren Synapsenvolumens im Hippocampus (10- bis 100-mal kleiner) zu erklären.

Interessanterweise zeigten jedoch alle Studien eine lineare Beziehung zwischen der Gesamtfläche der aktiven Zone und dem Volumen der Synapse. 
Zum Abschluss ihres Artikels zogen Schikorski und Stevens drei primäre Schlussfolgerungen bezüglich der Verknüpfung der präsynaptischen Struktur und der Freisetzung der Neurotransmitter. Erstens entsprach die Anzahl der Plätze für die Neurotransmitterfreisetzung der der aktiven Zonen. Zweitens stimmte die Größe des Pools der gebundenen Vesikel, die morphologisch bestimmt wurde, annähernd mit der Größe des Pools der sogenannten readily releasable Vesikel überein, die wiederum durch physiologische Testung festgelegt wurde. Abschließend bestand darüber hinaus eine Beziehung zwischen der Anzahl gebundener Vesikel und der Freisetzungswahrscheinlichkeit, die proportional zur Anzahl der gebundenen Vesikel war. Im Jahr 1999 untersuchten die beiden Wissenschaftler olfaktorische, kortikale exzitatorische Synapsen anhand von elektronenmikroskopischen Schnittbildern aus dem Gehirn von Mäusen und verglichen die Ergebnisse mit denen aus der Hippocampusregion (Schikorski und Stevens 1999). Die Versuchstiere waren, wie bereits 1997, erwachsene Mäuse (sieben Monate alt.) Sie stellten fest, dass es eindeutige Unterschiede zwischen der CA1-Hippocampusregion und den olfaktorischen Kortexschichten 1a und 1b gab.

Schikorski und Stevens wählten den piriformen, olfaktorischen Kortex bewusst als Vergleichsregion zum Hippocampus aus, da er ebenfalls über einen recht simplen Aufbau und Synapsen mit unterschiedlichen physiologischen Funktionen verfügt. Sie fokussierten sich bei ihrer Arbeit auf die Betrachtung exzitatorischer Synapsen in der Kortexschicht 1a, die Informationen aus dem Bereich des Riechkolbens bekommen, und Synapsen der Kortexschicht 1b, die wiederum rückläufig vom piriformen Kortex selbst angesteuert werden. Diese Auswahl ermöglichte die Untersuchung zweier getrennter Leitungsbahnen, die in unterschiedlichen Regionen ihren Ursprung haben und verschiedene physiologische Funktionen abbilden: Axone vom Riechkolben projizieren spezifisch in die 1a-Schicht und zeigen das Phänomen der „Paired Pulse Facilitation“, das bei Synapsen rückläufiger kortikaler Fasern nicht zu beobachten ist.

Die Betrachtung der Synapsen erbrachte folgende Ergebnisse: Der generelle Aufbau exzitatorischer Synapsen im olfaktorischen Kortex unterscheidet sich nicht von dem anderer exzitatorischer Synapsen. Er zeigt klassisch eine präsynaptische aktive Zone mit gebundenen Vesikeln und einer korrespondierenden Postsynapse. Die Breite des synaptischen Spaltes lag einheitlich zwischen 18 und $20 \mathrm{~nm}$. Olfaktorische Synapsen präsentierten sich in beiden Schichten circa zweieinhalbmal größer als die Synapsen des Hippocampus. Das Vorkommen von zwei oder mehr aktiven Zonen pro Synapse war häufiger als im Hippocampus. Das Volumen kortikaler, olfaktorischer Synapsen war vier- 
bis siebenmal größer als im Hippocampus. Im Vergleich der Schichten 1a und 1b zeigte sich, dass die durchschnittliche Fläche der aktiven Zonen einheitlich bei 0,095 $\mu \mathrm{m}^{2}$ lag und mit dem Gesamtvolumen der Synapse korrelierte. Die Fläche der aktiven Zone war höchst selten größer als 0,4 $\mu \mathrm{m}^{2}$. Im Vergleich zu ihrer Arbeit aus dem Jahr 1997, in der sie eine durchschnittliche Oberfläche der aktiven Zone von $0,027 \mu \mathrm{m}^{2}$ beschrieben, waren die Flächen bei dieser Untersuchungsreihe somit größer. Große Synapsen schienen dazu zu neigen, eher mehrere aktive Zonen auszubilden, anstatt dieses „Flächenlimit“ zu überschreiten. Deutliche Unterschiede zwischen den beiden Schichten waren bei der Dichte gebundener Vesikel (dreimal höher in Schicht 1b) und der Gesamtvesikelanzahl festzustellen (1a: $354 \pm 436$; 1b: $656 \pm 423$ ). Die absolute Anzahl der an den jeweiligen aktiven Zonen gebundenen Vesikel war für die Hippocampus-Synapsen und die Synapsen in Region 1a nahezu identisch, wohingegen die Dichte der gebundenen Vesikel in der 1a-Schicht geringer war. Die Dichte gebundener synaptischer Vesikel in der 1b-Schicht entsprach der des Hippocampus, die Gesamtanzahl gebundener Vesikel war aufgrund der größeren aktiven Zonen dementsprechend ebenfalls höher.

Im Vergleich zu den Ergebnissen, die Schikorski und Stevens in ihrer 1997 erschienenen Arbeit präsentieren, zeigten die hier untersuchten Synapsen eine höhere Anzahl synaptischer Vesikel.

Anhand dieser Ergebnisse zogen Schikorski und Stevens Rückschlüsse bezüglich der physiologischen Funktion der einzelnen Synapsen. Synapsen in der 1a-Region wurde, im Gegensatz zu denen in der 1b-Region, lange die Fähigkeit der Fazilitation zugeschrieben, die eine Beziehung zu der Vesikeldichte aufzuzeigen schien. Synapsen in der 1b-Schicht hatten eine höhere Vesikeldichte und zeigten keine „Paired Pulse Facilitation“, wohingegen Synapsen der 1a-Schicht mit einer geringeren Vesikeldichte dieses taten. Schikorski und Stevens kamen somit zu dem Schluss, dass das Vorkommen von „Paired Pulse Facilitation" nicht allein anhand der Vesikeldichte zu erklären war. Vielmehr schien die Anzahl der gebundenen Vesikel von entscheidender Bedeutung für die „Paired Pulse Facilitation“"zu sein.

Abschließend zogen Schikorski und Stevens aufgrund ihrer Beobachtungen die Schlussfolgerung, dass der Hippocampus eine gute Forschungsgrundlage für das Studium zentraler Synapsen bietet, Verallgemeinerungen bezüglich der physiologischen Funktion auf Synapsen in anderen Regionen aber nur bedingt erfolgen sollten.

In ihrem 2001 veröffentlichten Paper „Morphological correlates of functionally defined synaptic vesicle populations“ untersuchten Schikorski und Stevens die Hypothese, dass der 
anhand der physiologischen Funktion bestimmte „Readily Releasable Pool (RRP)“ mit dem morphologisch bestimmten Pool gebundener Vesikel (Vesikel, die im elektronenmikroskopischen Bild der aktiven Zone direkt anliegen) übereinstimmt. Als Material dienten Synapsen von Hippocampuszellen der Ratte. Anders als bei ihren Untersuchungen aus den Jahren 1997 und 1999 (siehe oben) waren die Versuchstiere nur einen Tag alt. Mit Hilfe der Photokonversion von mit FM1-43 markierten Vesikeln, die nach der Konversion den elektronendichten DAB-Marker (Diaminobenzidin-Marker) enthalten, definierten Schikorski und Stevens den sogenannten Recycling Pool als maximale Vesikelanzahl, die durch verlängerte Stimulation mit FM1-43 angefärbt werden konnte. Hierfür wurden die hippocampalen Neuronen mit dem fluoreszierenden FM1-43Marker befüllt. Werden diese fluoreszierenden Farbstoffe erregt, kommt es zur Freisetzung von Photonen. Durch diesen Vorgang entstehen freie Radikale, die Diaminobenzidine (DAB) oxidieren und so in stabile Präzipitate polymerisieren, die dann im elektronenmikroskopischen Bild sichtbar werden (Sandell und Masland 1988).
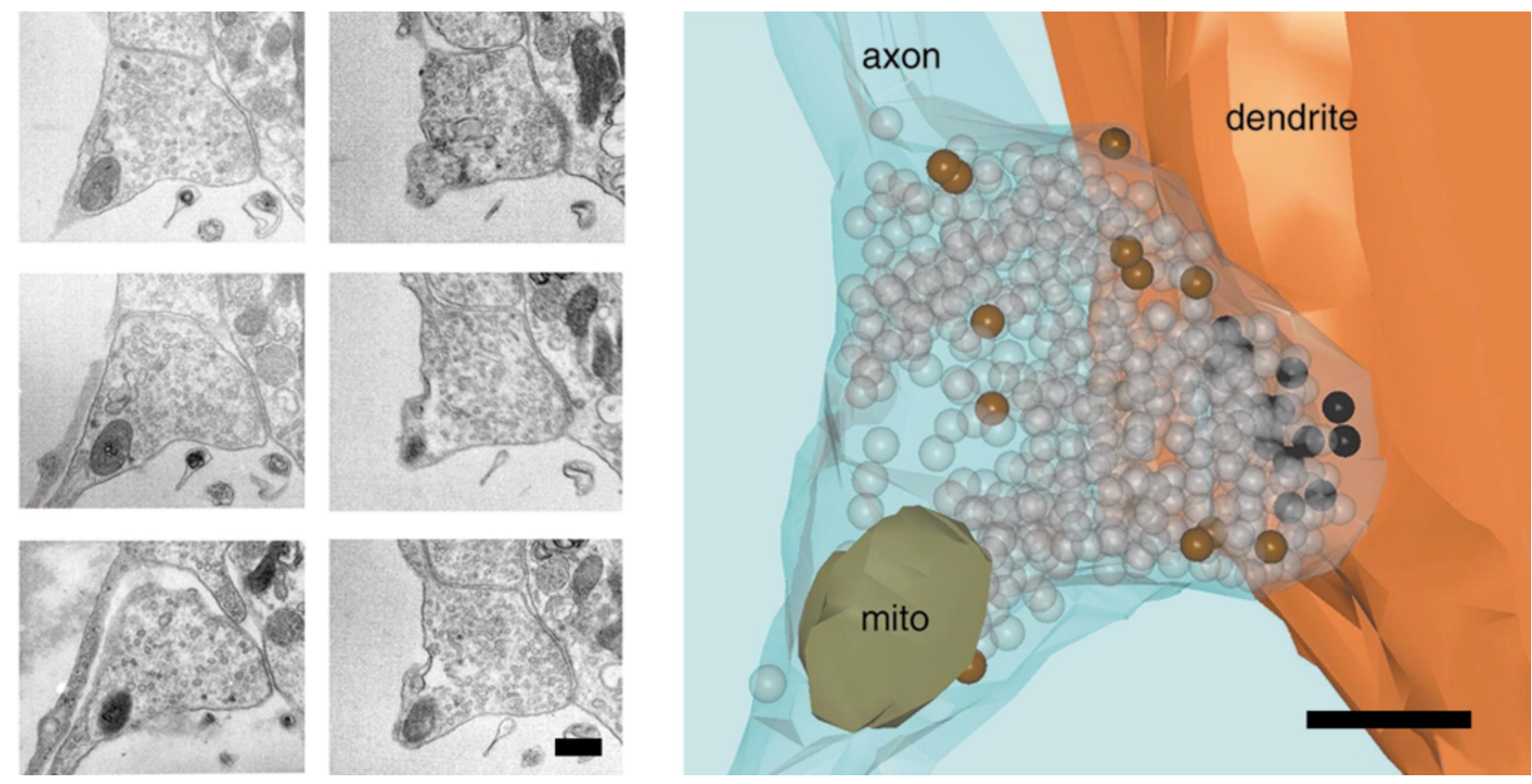

Abbildung 4: EM-Schnittbilder und dreidimensionale Rekonstruktion einer typischen Synapse. Rechts sieht man die Rekonstruktion und auf der linken Seite eine Serie von sechs Schnitten, die für die Rekonstruktion verwendet wurden. Dargestellt sind das Axon, der Dendrit und ein Mitochondrium. Die gebundenen Vesikel sind schwarz und die angefärbten Vesikel braun markiert. Der Maßstabsbalken entspricht 0,1 $\mu \mathrm{m}$ (entnommen aus (Schikorski und Stevens 2001; die Verwendung erfolgt mit freundlicher Genehmigung des Springer Nature Verlags).

Aus physiologischen Experimenten ist bekannt, dass ein kontinuierlicher Stimulus mit 40 Aktionspotentialen mit $20 \mathrm{~Hz}$ das sogenannte Quantum des „Readily Releasable Pool“ 
freisetzt (Rosenmund und Stevens 1996; Murthy und Stevens 1999). Schikorski und Stevens verwendeten in ihrer Versuchsreihe den gleichen Stimulus und stellten fest, dass der Pool der an die aktiven Zone gebundenen Vesikel das morphologische Gegenstück zum physiologisch bestimmten „Readily Releasable Pool“ ist. Des Weiteren fanden sie heraus, dass die Vesikel des „Recycling Pool“ nicht gleichmäßig zwischen der Gesamtpopulation der Vesikel verteilt waren, sondern zu $50 \%$ in der Nähe der aktiven Zone lagen. Gemäß dem damaligen aktuellen Forschungsstandes konnten nur gebundene und speziell vorbereitete Vesikel an der Exozytose teilhaben (Fernández-Chacón und Südhof 1999).

Zusammenfassend lässt sich festhalten, dass Unterschiede sowohl hinsichtlich der Größe der Synapsen und der aktiven Zone als auch der Anzahl der synaptischen Vesikel zwischen den Arbeiten von Schikorski und Stevens festzustellen sind. Nicht nur die Oberfläche der aktiven Zone, sondern auch die Anzahl der in einer Synapse registrierten Vesikel war in der 1999 veröffentlichten Untersuchung größer als bei den Ergebnissen aus dem Jahr 1997. Als Versuchstiere dienten damals erwachsene Nager, die sieben Monate alt waren. Hinsichtlich der in dieser Arbeit untersuchten hippocampalen Strukturen von neugeborenen Ratten sind somit nicht unbedingt übereinstimmende Ergebnisse mit den vorherigen Untersuchungen zu erwarten, da bereits die Werte von Schikorski und Stevens in ihren verschiedenen Experimenten unterschiedlich waren.

\subsection{Chemische Signalübertragung an Synapsen des Zentralnerven- systems}

Durch das Eintreffen eines Aktionspotentials in der Präsynapse erfolgt hier eine Depolarisation. Spannungsabhängige Calciumkanäle im Bereich der präsynaptischen aktiven Zone werden aktiviert und ermöglichen daraufhin einen Einstrom von Calciumionen aus dem Extrazellularraum in die Präsynapse.

Die synaptischen Vesikel besitzen spezifische Calciumsensoren, die die Fusion mit der Plasmamembran im Bereich der aktiven Zone triggern. Die Exozytosewahrscheinlichkeit ist im zentralen Nervensystem relativ gering, sodass nur auf jedes dritte bis zehnte Aktionspotential die Freisetzung eines synaptischen Transmitters erfolgt. Nach erfolgreicher Fusion werden die Neurotransmitter in den synaptischen Spalt entlassen und diffundieren zur postsynaptischen Membran. Im Bereich der Präsynapse werden nun durch Endozytose die fusionierten Vesikelmoleküle gesammelt und neue Vesikel gebildet. Zur 
gleichen Zeit erfolgt die Repolarisation der Präsynapse. Die Neurotransmitter aktivieren spezifische postsynaptische Rezeptoren und lösen je nach Rezeptortyp eine De- oder eine Hyperpolarisation aus, die in der postsynaptischen Membran elektrotonisch weitergeleitet wird. Die Empfängerzelle verarbeitet die Spannungsänderung sehr schnell, sodass zwischen dem Eintreffen des Impulses in der Präsynapse bis zur Spannungsänderung auf postsynaptischer Seite nur etwa eine tausendstel Sekunde vergeht (Jahn 2016). Abbildung 5 zeigt eine schematische Darstellung des beschriebenen Ablaufs.
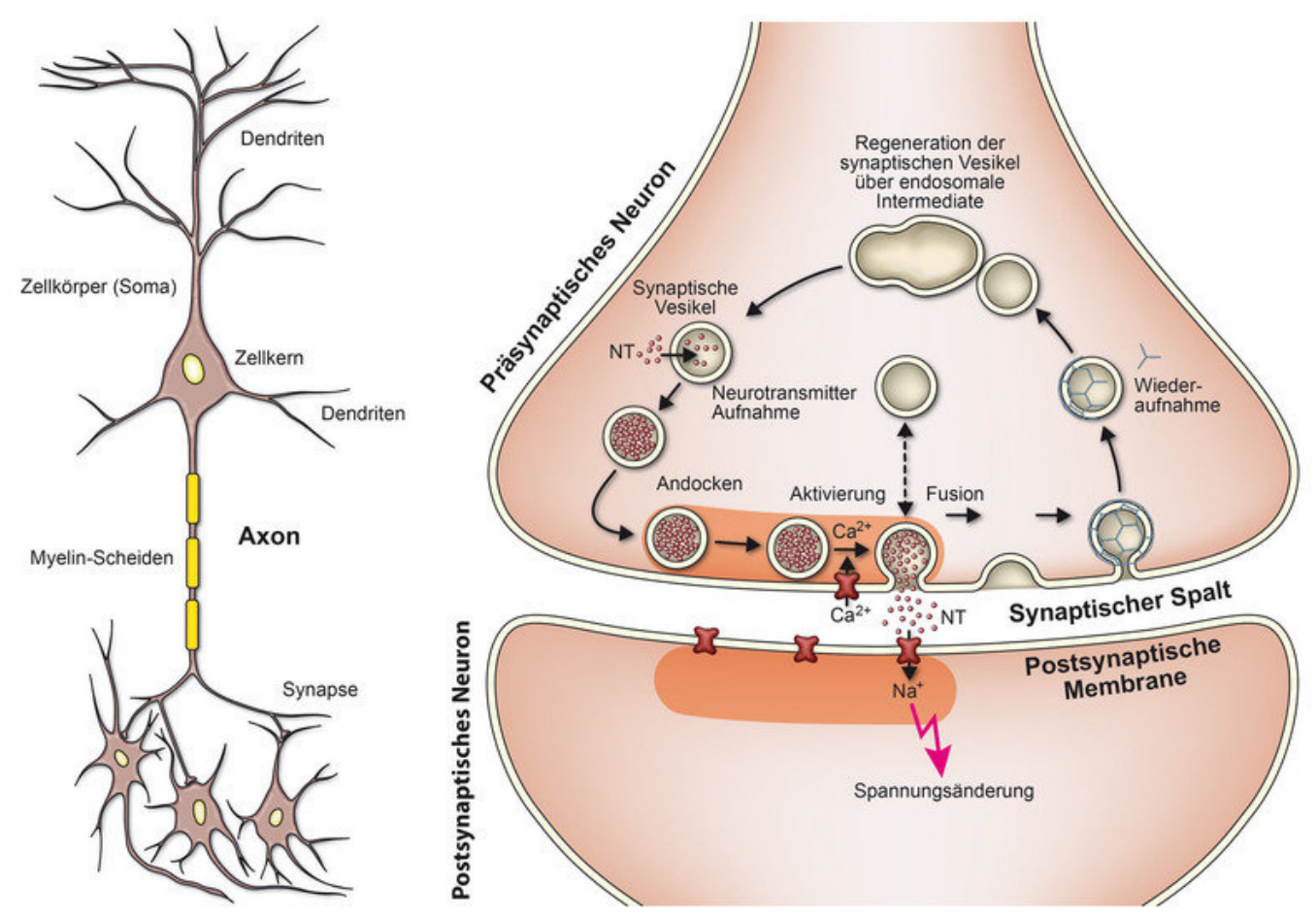

Abbildung 5: Schematische Darstellung einer Nervenzelle (links) und einer chemischen Synapse mit chemischer Signalübertragung (rechts) (entnommen aus Jahn 2016; die Verwendung erfolgt mit freundlicher Genehmigung durch Herrn Professor Reinhard Jahn)

Sowohl die Prozesse der Vesikelfusion und Exozytose als auch der Endozytose und Vesikelrezyklierung müssen gut ausbalanciert und aufeinander abgestimmt sein, um die langfristige Funktion der Synapse sicherzustellen (Rizzoli und Tabares 2016). Die Abbildung 6 zeigt den gesamten Vesikelkreislauf, dessen genaue Vorgänge in den nächsten Kapiteln ausführlich beschrieben werden. 


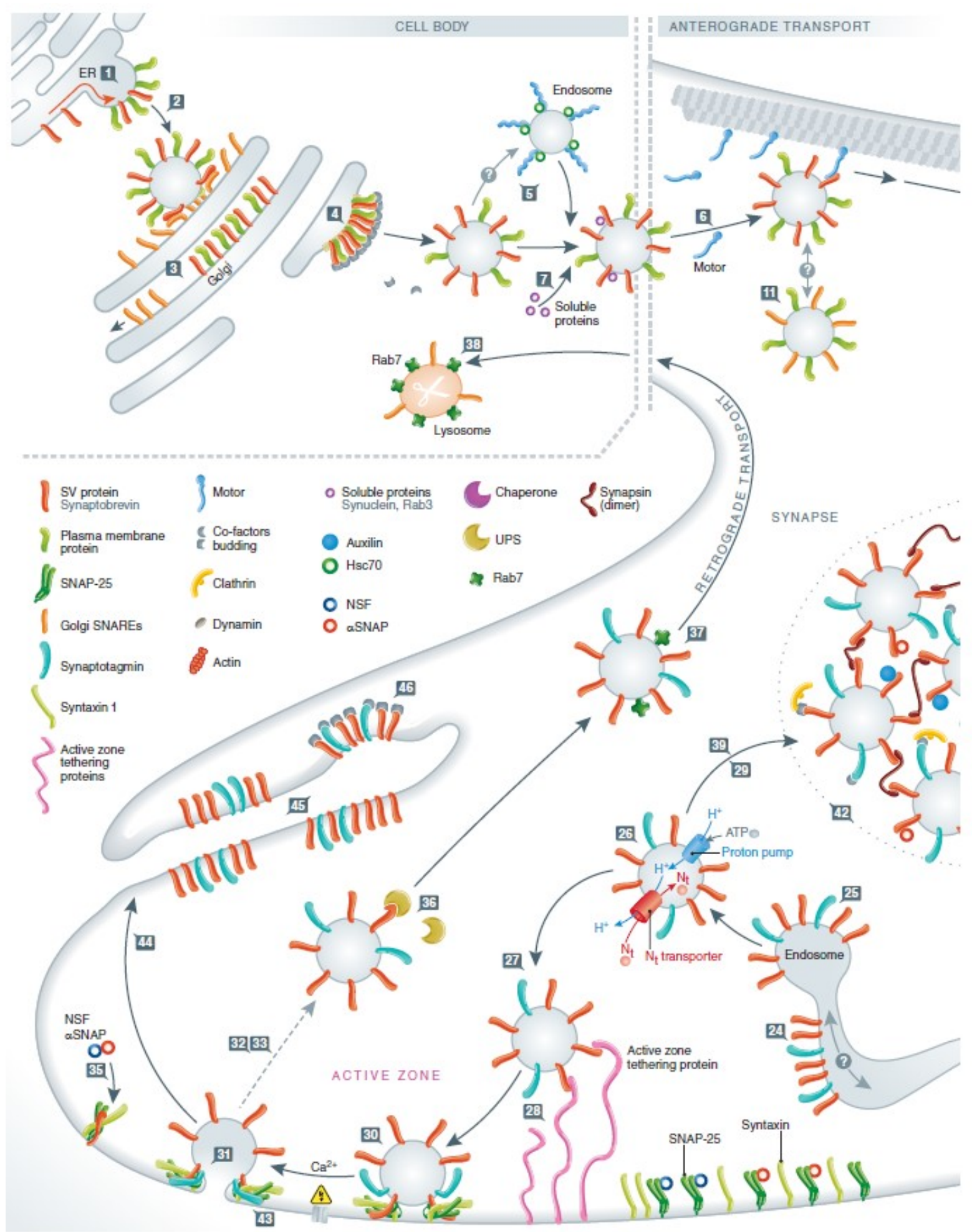




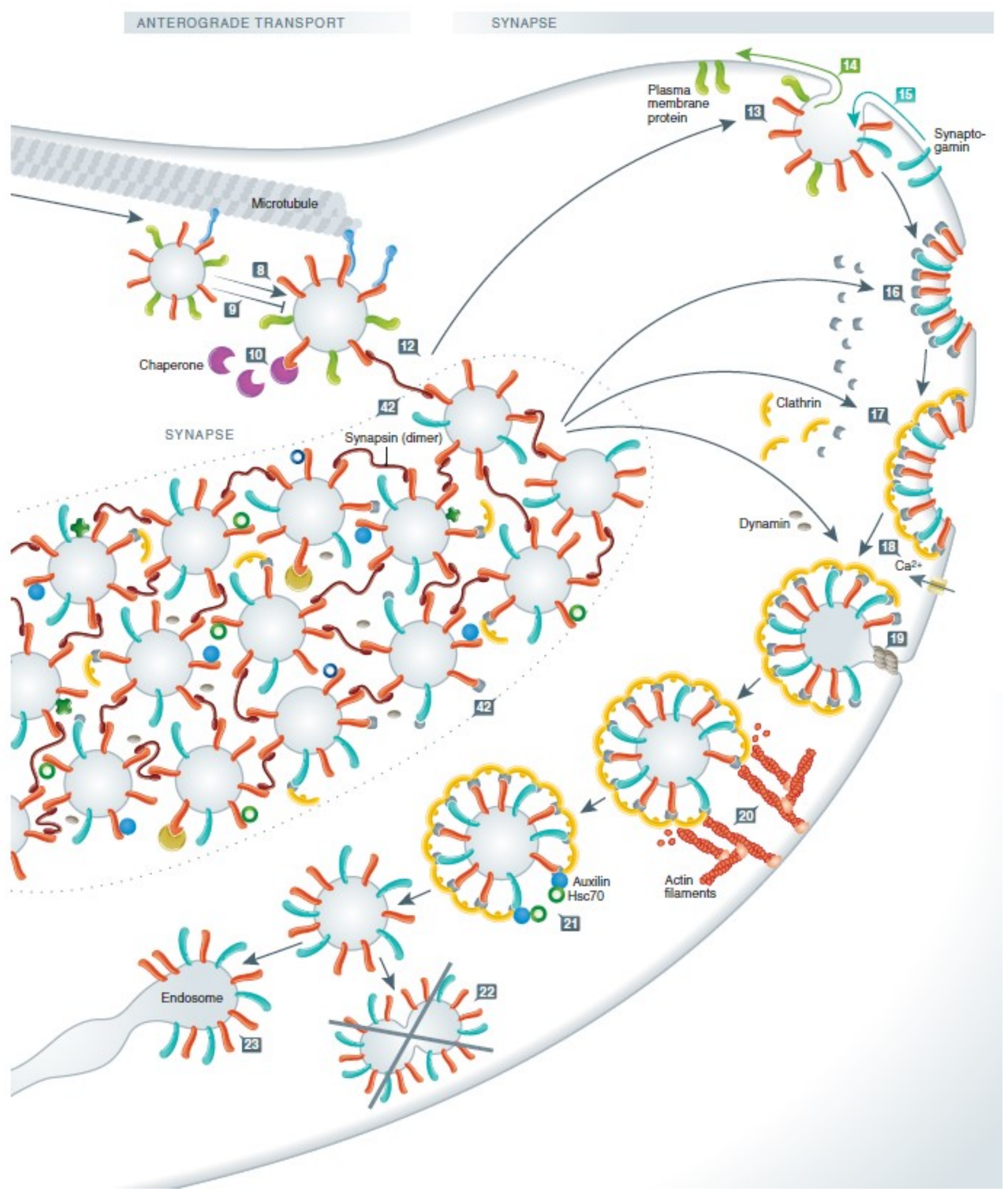

Abbildung 6: Überblick über den Vesikelkreislauf (entnommen aus Rizzoli 2014a; die Verwendung erfolgt mit freundlicher Genehmigung durch Herrn Professor Silvio Rizzoli) 


\subsection{Synaptische Vesikel und Exozytose}

Der synaptische Vesikel dient primär dem Transport von Neurotransmittern, die nach der klassischen Definition Substanzen sind, die vom präsynaptischen Neuron synthetisiert und aktivitätsabhängig freigesetzt werden und dann über spezifische Rezeptoren an der postsynaptischen Membran eine messbare Reaktion auslösen (Draguhn 2014). Bekannte Beispiele für Neurotransmitter sind Acetylcholin, $\gamma$-Aminobuttersäure (GABA), L-Glutamat, Glycin sowie die Catecholamine Adrenalin, Noradrenalin, Dopamin und die Monoamine Histamin und Serotonin.

Der Vesikelzyklus in der Präsynapse ist in Abbildung 8 dargestellt. Man unterscheidet zwischen sofort verfügbaren (readily releasable) und sogenannten Reserve Pools von Vesikeln (Richter 2013). Um ihre Aufgabe erfüllen zu können, beherbergt die Vesikelmembran verschiedene Proteinkomplexe, die der Aufnahme der Botenstoffe aus dem Plasma der Zelle dienen. Die dafür notwendige Energie wird von einer ProtonenATPase (V-ATPase), einem weiteren Proteinmolekül der Vesikelmembran, das wahrscheinlich durch die Interaktion mit Synaptophysin (Galli et al. 1996) oder Synaptobrevin (Di Giovanni et al. 2010) in die Membran integriert wird, bereitgestellt. Unter Verbrauch von Adenosintriphosphat pumpt sie dann Protonen in die Vesikel (Jahn 2016). Durch diesen Prozess bildet sich ein Konzentrationsgefälle, das für die Aufnahme der Neurotransmitter genutzt wird.

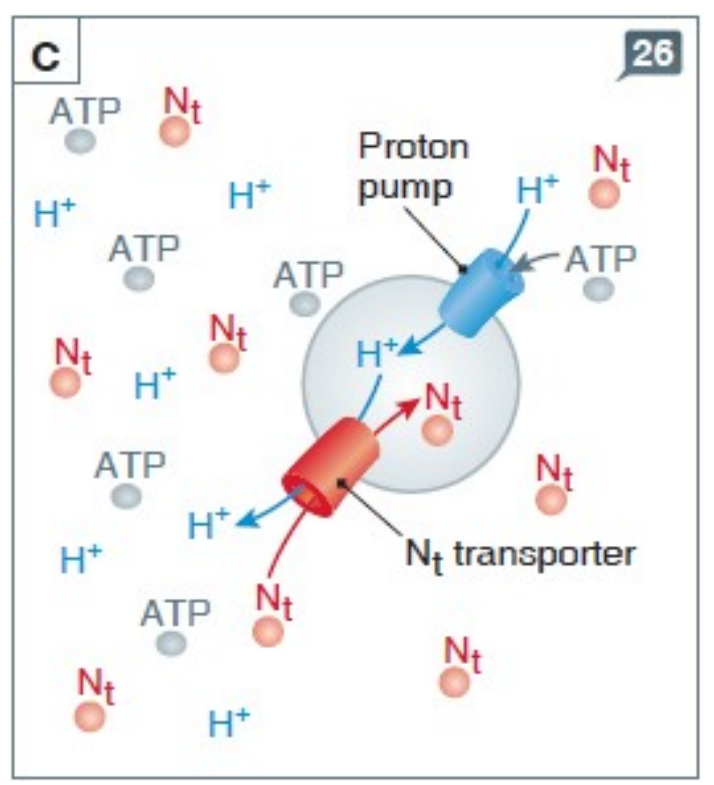

Abbildung 7: Die V-ATPase pumpt unter ATP-Verbrauch Protonen in den synaptischen Vesikel, die dann im Austausch gegen den Neurotransmitter wieder ausgeschleust werden (entnommen aus Rizzoli 2014a; die Verwendung erfolgt mit freundlicher Genehmigung durch Herrn Professor Silvio Rizzoli). 
Dabei werden im Antiport zwei Vesikelprotonen gegen ein Neurotransmittermolekül ausgetauscht (Edwards 2007). Die Aufnahme der Transmitter in die Vesikel erfolgt somit sekundär aktiv (Draguhn 2014) und ist in Abbildung 7 dargestellt.

Für die Fusion der Vesikel mit der Plasmamembran im Rahmen der Exozytose besitzt die Vesikelmembran weitere Proteine, die dem sogenannten SNARE-Komplex (,soluble Nethylmaleimide-sensitive-factor attachment receptor"-Komplex) zugeordnet werden. Der einfachen Fusion zweier Membranen stehen nach Rizzoli jedoch folgende Fakten entgegen: Die Doppelmembranstruktur ist sehr stabil und daher nur bedingt prädisponiert, ihre Struktur zu verändern. Des Weiteren kommt es durch polare Gruppen auf den Membranaußenseiten zu Abstoßungsreaktionen zwischen den beiden Membranen (Rizzoli 2014a). Für die Destabilisierung und anschließende Verschmelzung der zwei Membranen wird daher Energie benötigt.

Trotz jahrelanger intensiver Forschung ist es bis heute nicht abschließend geklärt, wie es die für die Membranfusion verantwortlichen Proteine schaffen, innerhalb von weniger als einer Millisekunde nach Einstrom der Calciumionen die Membranen verschmelzen zu lassen (Jahn 2016).

Die Sequenzen der Exozytose (vergleiche Abbildung 8) sind das „Docking“, „Priming“ und schließlich die Fusion mit Exozytose der Neurotransmitter (Richter 2013). Die synaptischen Vesikel werden nach ihrem Eintritt in die Präsynapse im Bereich der aktiven Zone gebunden. Dieser Prozess wird wahrscheinlich durch die Bindung der Vesikel an sogenannte RIMs (Rab3-interacting molecules) (Haucke et al. 2011) oder RIM-bindingProteine (Liu et al. 2011) gefördert. Die Positionierung der synaptischen Vesikel an der aktiven Zone in unmittelbarer Nachbarschaft der spannungsabhängigen Calciumkanäle ermöglicht den Vesikeln ein sofortiges Erkennen des Eintritts von Calciumionen in die Präsynapse (Rizzoli 2014a).

Forschungsergebnisse von Harlow et al. legen nahe, dass die synaptischen Vesikel nur an einer spezifischen Position an die aktive Zone binden können und stets die gleiche Domäne in Kontakt mit der Maschinerie der aktiven Zone tritt (Harlow et al. 2013).

Dies unterstreicht die enorme Bedeutung einer gewissen „Strukturkonstanz“ der aktiven Zone und wird durch die Ergebnisse von Matz et al. gestützt, die herausfanden, dass sich eine Strukturveränderung der aktiven Zone in einer Abweichung der Freisetzung synaptischer Vesikel widerspiegelt (Matz et al. 2010). 
Die Fusion beginnt, nachdem die präsynaptische Membran durch ein Aktionspotential depolarisiert wurde, worauf sich in Folge spannungsabhängige Calciumkanäle öffnen (Draguhn 2014). Die Konzentration der Calciumionen steigt danach im Bereich der aktiven Zonen rasant an.

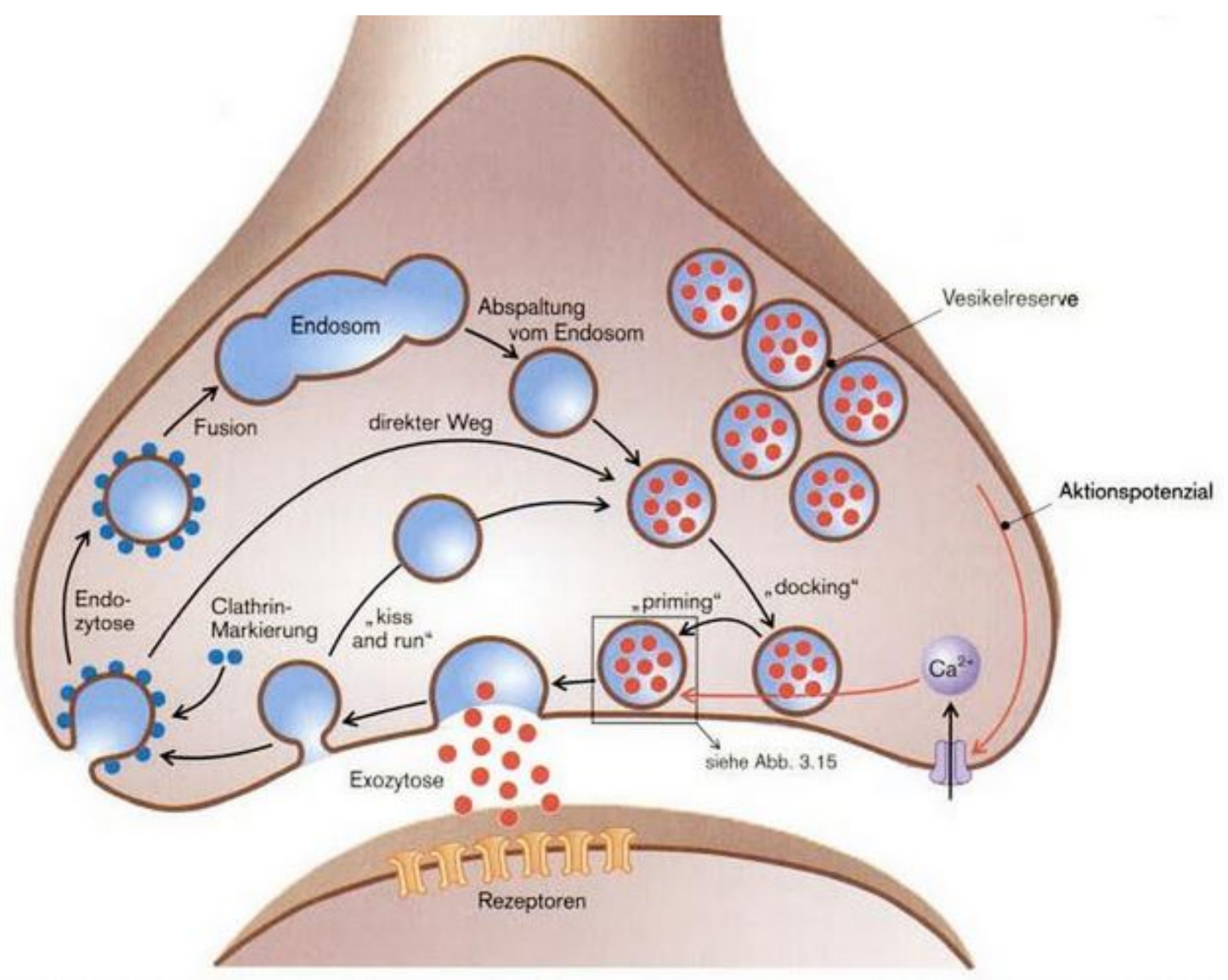

Abbildung 8: Vesikelzyklus im Bereich der Präsynapse. Mit Clathrin markierte Vesikel werden nach Abschluss der Fusion durch die Endozytose wieder in die Präsynapse aufgenommen. Des Weiteren besteht die Möglichkeit, dass die Vesikel nach unvollständiger Fusion sofort erneut abgeschnürt werden („Kiss and Run“). Die Rückkehr in die Vesikelreserve erfolgt entweder über das Endosom oder den direkten Weg. Hier können die Vesikel durch Bindung und Vorbereitung des Fusionskomplexes erneut in den freisetzungsbereiten Zustand versetzt werden (entnommen aus Draguhn 2014; die Verwendung erfolgt mit freundlicher Genehmigung des Georg Thieme Verlags).

Das Vesikelprotein Synaptotagmin, das als Calciumsensor fungiert, ändert nach der kooperativen Bindung von vier Calciumionen seine Konformation und hebt vermutlich die sterische Blockade des SNARE-Komplexes durch Complexin auf (vergleiche Abbildung 9). Vermutlich werden die Membranen der Vesikel und der Präsynapse durch die Interaktion 
mit Synaptotagmin zusätzlich destabilisiert und somit eine Fusion ermöglicht (Chapman 2008; Jahn und Fasshauer 2012).
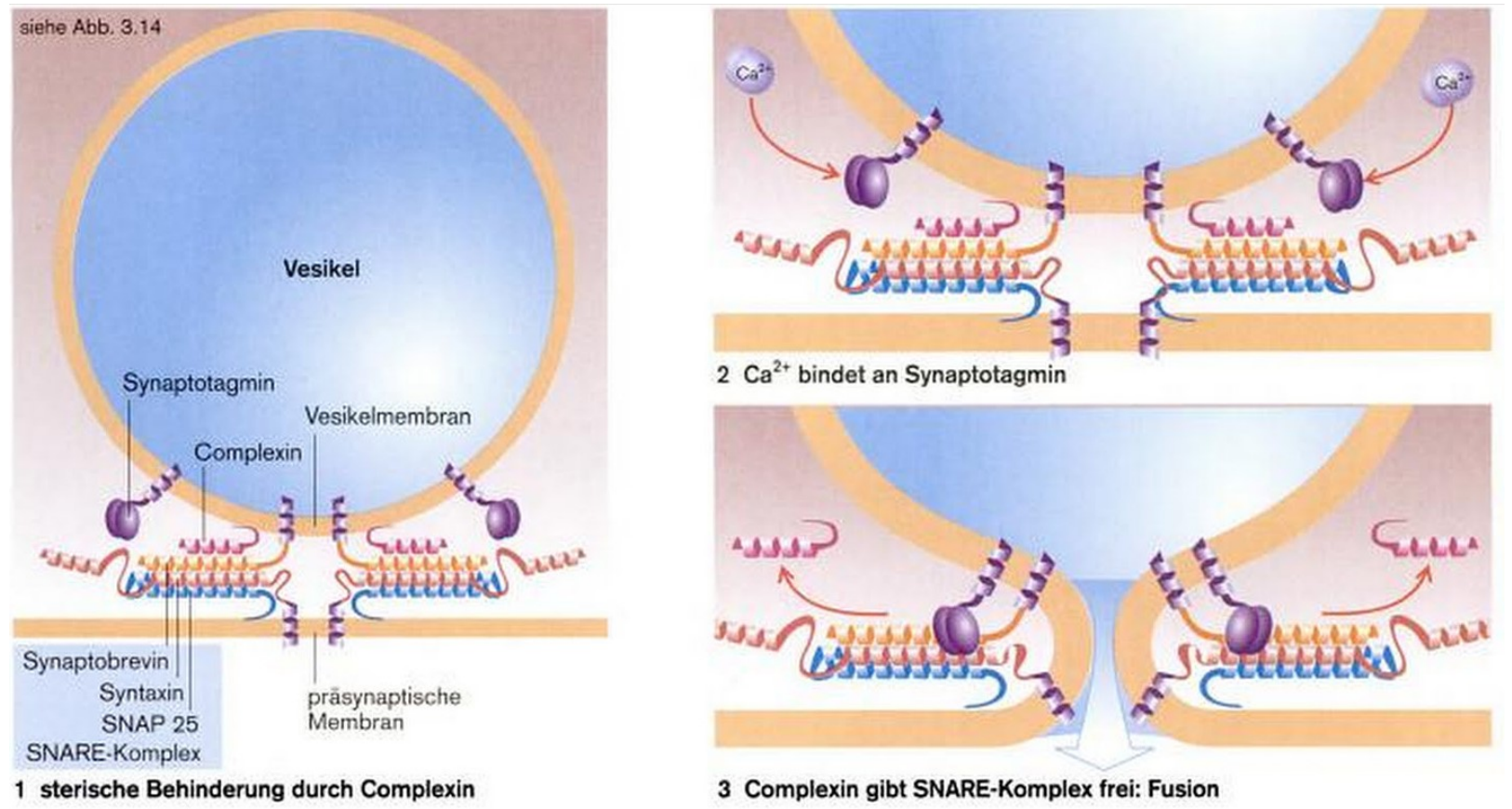

3 Complexin gibt SNARE-Komplex frei: Fusion

Abbildung 9: Molekulare Mechanismen der Vesikelfusion. Der SNARE-Komplex ist die zentrale Komponente der Fusion (1 und 2). Die Proteine Synaptobrevin und SNAP-25 bringen die Vesikelund die Zellmembran in eine enge räumliche Beziehung, wodurch der Prozess der Fusion ermöglicht wird (3). Entscheidend für diesen Prozess ist Synaptotagmin. Es bindet vier Calciumionen und hebt auf diese Weise die sterische Blockade des SNARE-Komplexes durch Complexin auf (entnommen aus Draguhn 2014; die Verwendung erfolgt mit freundlicher Genehmigung des Georg Thieme Verlags).

Bewerkstelligt wird die Exozytose durch die SNARE-Proteine Synaptobrevin, Syntaxin und SNAP-25 (Synaptosomal-associated protein 25). Synaptobrevin ist ein Transmembranprotein und liegt als sogenanntes ${ }^{2}$-SNARE in der Membran des synaptischen Vesikels.

Sein Gegenspieler ist das „t-SNARE“ $(\mathrm{t}=$ target $=$ Zielmembran $)$ Syntaxin, ein Transmembranprotein der Plasmamembran. Das zweite „t-SNARE“ SNAP-25 ist hingegen ein peripheres Membranprotein.

Die SNARE-Proteine erkennen sich gegenseitig, verdrillen sich bei ihrer Interaktion umeinander und lösen den sogenannten Reißverschlusseffekt („Zipper“) aus (Richter 2013). Dabei bilden sie ein Bündel aus, das bis in die Membran reicht (Jahn 2016). Der sich ergebende trans-SNARE-Komplex (vergleiche Abbildung 10) nähert die beiden 
Membranen einander an und verbindet sie schließlich miteinander (Alberts et al. 2011) (Alberts et al. 2011). Bei diesem Prozess kommt es zu einer hohen Energiefreisetzung, die für die Membranfusion genutzt wird. Möglich ist die Membranfusion letztendlich erst dann, wenn sich die beiden Lipiddoppelschichten auf 1,5 $\mathrm{nm}$ angenähert haben und somit Lipide aus einer Doppelschicht in die andere fließen können (Alberts et al. 2011). Abbildung 11 zeigt und erklärt, wie SNARE-Proteine die Membranfusion katalysieren.

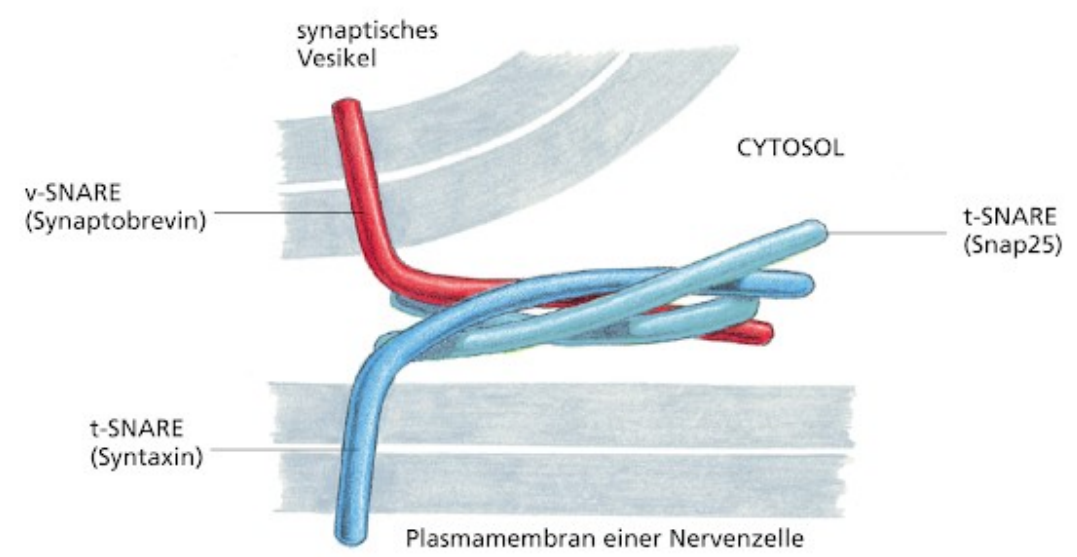

Abbildung 10: Struktur eines trans-SNARE-Komplexes. Rot dargestellt sieht man das Transmembranprotein Synaptobrevin, ausgehend vom synaptischen Vesikel. Dunkelblau gefärbt ist Syntaxin, das Transmembranprotein der Plasmamembran, und hellblau SNAP-25, als peripheres Membranprotein (entnommen aus Alberts et al. 2011; die Verwendung erfolgt mit freundlicher Genehmigung des Verlags W.W. Norton \& Company).

Neben den beschriebenen SNARE-Proteinen sind zwei weitere Proteine an der Interaktion des SNARE-Komplexes beteiligt, nämlich Munc 18 (Mammalian uncoordinated-18 Protein) und Munc 13, die die Fusion dahingehend beeinflussen, dass sie Syntaxin in einer vom SNARE-Komplex bevorzugten Form halten (Ma et al. 2013).

Beim Vesikelzyklus unterscheidet man verschiedene Formen, die in Abbildung 8 schematisch dargestellt sind. Während der sogenannten Kiss and Run-Exozytose entsteht kurzzeitig eine Fusionspore, bevor die Vesikel nach dieser unvollständigen Fusion direkt wieder abgeschnürt und für einen neuen Zyklus bereitgestellt werden. Andere Vesikel werden nach der Fusion mit Clathrin markiert und finden ihren Weg in die Vesikelreserve entweder über das Endosom oder den direkten Weg (Draguhn 2014). Der genaue Ablauf dieser Vorgänge wird in Kapitel 1.6 im Detail beschrieben. 
Nach erfolgter Fusion müssen die stabilen SNARE-Komplexe zerlegt werden, damit sie für weitere Transportprozesse zur Verfügung stehen. Burgalossi et al. fanden heraus, dass dabei das Protein NSF (N-ethylmaleimide-sensitive factor) eine wichtige Rolle spielt, das in Kooperation mit $\alpha$-SNAP (alpha-soluble NSF attachment protein) den SNARE-Komplex zerlegt (Burgalossi et al. 2010; Ryu et al. 2015).

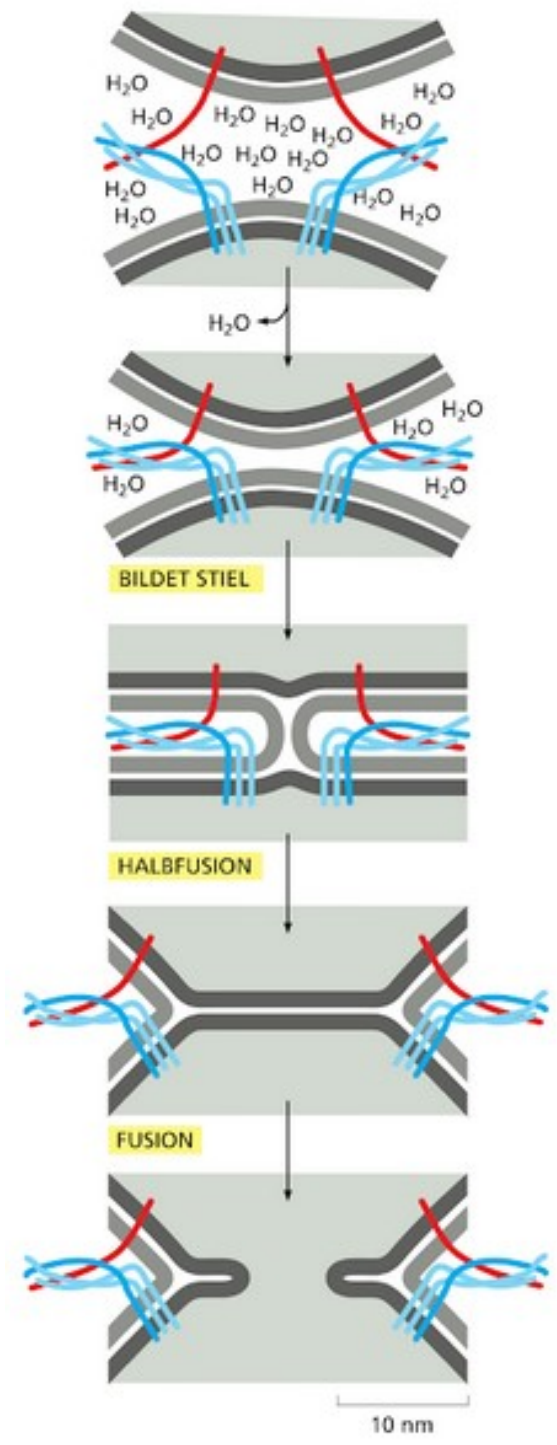

Abbildung 11: Ein Modell, wie SNARE-Proteine die Membranfusion katalysieren können. Die Fusion der Doppelmembranen verläuft in mehreren Schritten. Die enge Paarung von v-SNARE und t-SNARE zwingt die Lipiddoppelschichten, sich eng aneinanderzulagern, und vertreibt dadurch Wassermoleküle aus dem Zwischenraum. Die Lipidmoleküle der beiden betroffenen Membranseiten fließen dann zwischen den Membranen, um einen verbindenden Stiel zu bilden. Die Lipide der beiden anderen Lipidschichten berühren einander und bilden eine neue Doppelschicht, die die Fusionszone erweitert (Hemi- oder Halbfusion). Die Fusion wird durch Bruch der neuen Doppelschicht vollzogen (entnommen aus Alberts et al. 2011; die Verwendung erfolgt mit freundlicher Genehmigung des Verlags W.W. Norton \& Company). 
Das Vorhandensein der verschiedenen SNARE-Proteine erhöht dabei die Wahrscheinlichkeit, dass sich NSF in ihrer Nähe anreichert (Bar-On et al. 2009). Kawasaki und Kollegen sowie Littleton et al. konnten nachweisen, dass die Blockade von NSF zu einer Hemmung der synaptischen Freisetzung führt (Kawasaki et al. 1998; Littleton et al. 2001). Es wurde beobachtet, dass die Existenz von SNARE-Komplexen sowohl in der Vesikel- als auch in der Plasmamembran zu einer lokalen Anreicherung von NSF und $\alpha$ SNAP im Bereich der Synapse führt (Takamori et al. 2006; Sieber et al. 2007; Bar-On et al. 2012), was für eine enge funktionelle Verknüpfung dieser Proteine spricht. Der genaue molekulare Ablauf der Aufspaltung ist jedoch weitestgehend unbekannt.

NSF ist eine ATPase, die zwischen den Membranen und dem Zytosol zirkuliert und die Energie der ATP-Hydrolyse nutzt, um die engen Wechselwirkungen zwischen den helikalen Domänen der gepaarten SNARE-Proteine zunichtezumachen (Alberts et al. 2011). Ryu et al. fanden heraus, dass NSF nach der Spaltung des Adenosintriphosphats (ATP) eine „interne Spannung“ aufbaut, Phosphationen abspaltet und nach einer Latenzzeit von wenigen Zehntelsekunden die aufgebaute „Spannung“ freisetzt. Dies führt zur Spaltung des SNARE-Komplexes mit sofortiger Freisetzung der SNARE-Proteine (Ryu et al. 2015). Abbildung 12 zeigt die Bindung von NSF an den SNARE-Komplex, die anschließende ATP-Hydrolyse und die resultierende Spaltung des SNARE-Komplexes.

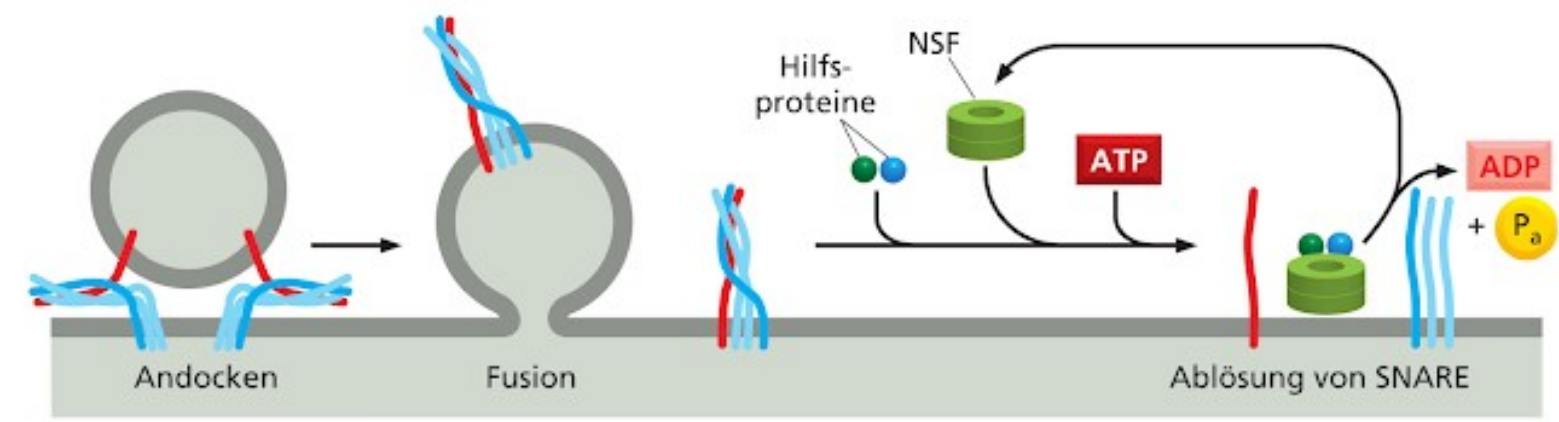

Abbildung 12: NSF-vermittelte Dissoziation der SNARE-Paare nach einem Membranfusionszyklus (entnommen aus Alberts et al. 2011; die Verwendung erfolgt mit freundlicher Genehmigung des Verlags W.W. Norton \& Company) 


\subsection{Medizinische Bedeutung chemischer Synapsen und des SNARE-Komplexes}

Die Funktion der chemischen Synapse ist von besonderem Interesse, da sie äußerst komplexe Interaktionen zwischen Nervenzellen erlaubt. Medizinische Relevanz gewinnt sie dadurch, dass hier auf der einen Seite spezifische pathologische Prozesse beobachtet werden können und auf der anderen Seite eine gute Möglichkeit der pharmakologischen Intervention besteht (Dudel und Heckmann 2005). Bevorzugtes „Angriffsziel“ ist hierbei häufig der Vesikelzyklus, bestehend aus Exo- und Endozytose.

Im Folgenden werden die durch Clostridien ausgelösten Erkrankungen Botulismus und Tetanus in ihrer Pathophysiologie genauer betrachtet (vergleiche Übersichtsartikel (Veit 1999). Clostridiale Neurotoxine, Tetanus und die Botulinumtoxine A-G sind Peptidasen, welche die an der Exozytose beteiligten SNARE-Proteine zerstören (Richter 2013). Sie bestehen aus zwei über Disulfidbrücken verbundenen Polypeptiden: einer schweren Kette $(100 \mathrm{kDa})$, zuständig für die Penetration der Toxine in die Zellen und die spezifische Bindung an bestimmte Nervenzelltypen, und einer leichten Kette $(50 \mathrm{kDa})$, die eine zinkabhängige proteolytische Aktivität besitzt (Ahnert-Hilger und Bigalke 1995; Rossetto et al. 1995). Die schwere Kette spaltet sich ab, lagert sich an der jeweiligen Membran an und erlaubt der leichten Kette somit die Durchquerung der Lipiddoppelschicht und den Eintritt in das Zytoplasma (Boujard et al. 2014).

Abbildung 13 zeigt die Angriffspunkte der Botulinum- und Tetanustoxine an den Komponenten des SNARE-Komplexes. Synaptobrevin wird durch die Tetanus- und Botulinumtoxine B, D, F und G gespalten, wohingegen Syntaxin durch das Botulinumtoxin C1 und SNAP-25 durch die Botulinumtoxine $\mathrm{A}$ und $\mathrm{E}$ abgebaut wird. Das als Calciumsensor fungierende Vesikelprotein Synaptotagmin ist das einzige Protein, das nicht direkt von einem Toxin beeinträchtigt wird.

Obwohl alle clostridialen Neurotoxine die Proteine des SNARE-Komplexes mit ihren leichten Ketten angreifen, unterscheiden sie sich deutlich in der Ausprägung ihrer klinischen Symptome. Der Grund hierfür sind Unterschiede in der Struktur der schweren Ketten, die dadurch verschiedene Transportwege beschreiten, um die leichten Ketten von ihrer Eintrittspforte zum Ort der Wirkungsentfaltung zu transportieren (Ahnert-Hilger und Bigalke 1995). 
Die proteolytische Aktivität der Tetanus- und Botulinumtoxine entfaltet sich somit an unterschiedlichen Neuronentypen und führt $\mathrm{zu}$ stimulatorischen beziehungsweise inhibitorischen Einflüssen auf die Muskelzellen. Die selektiven Abbauvorgänge an den SNARE-Komplexen erklären somit die unterschiedlichen klinischen Bilder des Tetanus mit Muskelkrämpfen im Gegensatz zum Botulismus mit paralytischen Symptomen (Veit 1999).

\section{synaptischer Spalt}
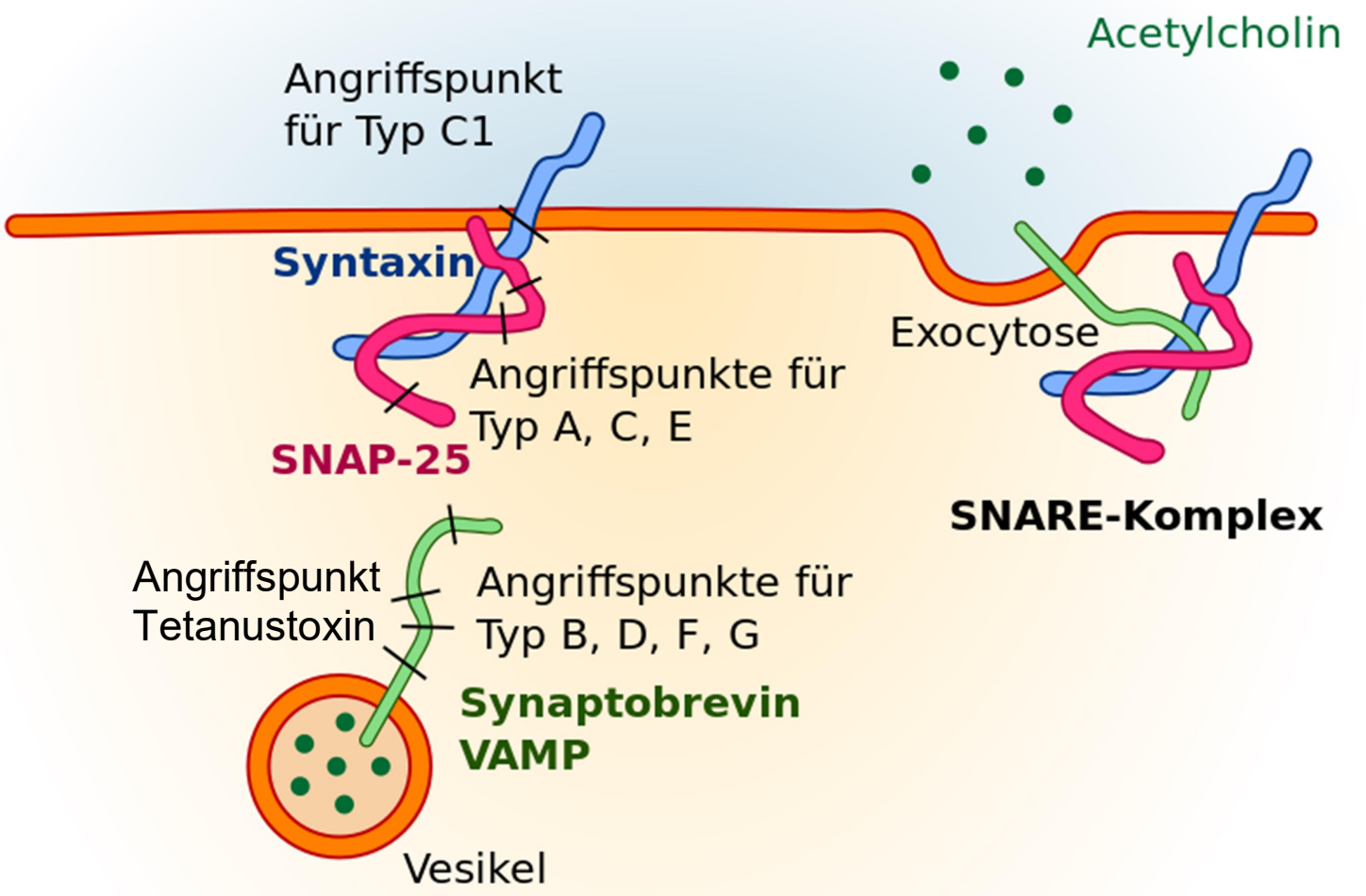

SNARE-Komplex

Abbildung 13: Angriffspunkte der Botulinum- und Tetanustoxine an den Komponenten des SNARE-Komplexes (modifiziert nach Scarlatos et al. 2005; die Verwendung erfolgt mit freundlicher Genehmigung des Journals of Food Science)

Der Auslöser des Tetanus ist das Clostridium tetani, ein anaerobes, sporenbildendes Bakterium. Die umgangssprachliche Bezeichnung „Wundstarrkrampf“ impliziert die pathologische Wirkung des Toxins, das nach der Aufnahme in die Motoneuronen im Bereich infizierter Wunden retrograd axonal transportiert wird und schlussendlich nach Transzytose die hemmenden Interneuronen des Rückenmarks erreicht (Dudel und Heckmann 2005). Dort angelangt, stört es das Gleichgewicht von Hemmung und Erregung des motorischen Systems. 
Wie der Abbildung $13 \mathrm{zu}$ entnehmen ist, spaltet es dort Synaptobrevin und verhindert somit die Transmitterfreisetzung aus den synaptischen Vesikeln. Daraus resultiert eine zunehmende Muskelsteifigkeit mit Muskelkrämpfen, die in dem Opisthotonus ihre maximale Ausprägung erreichen. Ein weiteres klassisches Symptom ist das sogenannte sardonische Grinsen (vergleiche Abbildung 14). Die Therapie bei einer Tetatnusintoxikation besteht in einer chirurgischen Wundsanierung und der Gabe von Antibiotika (Dudel und Heckmann 2005). Penicillin und Tetrazykline stehen hierbei im Vordergrund. Ergänzend erfolgt die Verabreichung von Antitoxin (humanes TetanusImmunglobulin) und es erfolgt eine Immunisierung mit dem inaktivierten Toxin Toxoid, das auch zur prophylaktischen Impfung eingesetzt wird (Dudel und Heckmann 2005). Bei therapieresistenten oder nichttherapierten Fällen kommt es im Endstadium zu generalisierten Spasmen mit letalem Ausgang.

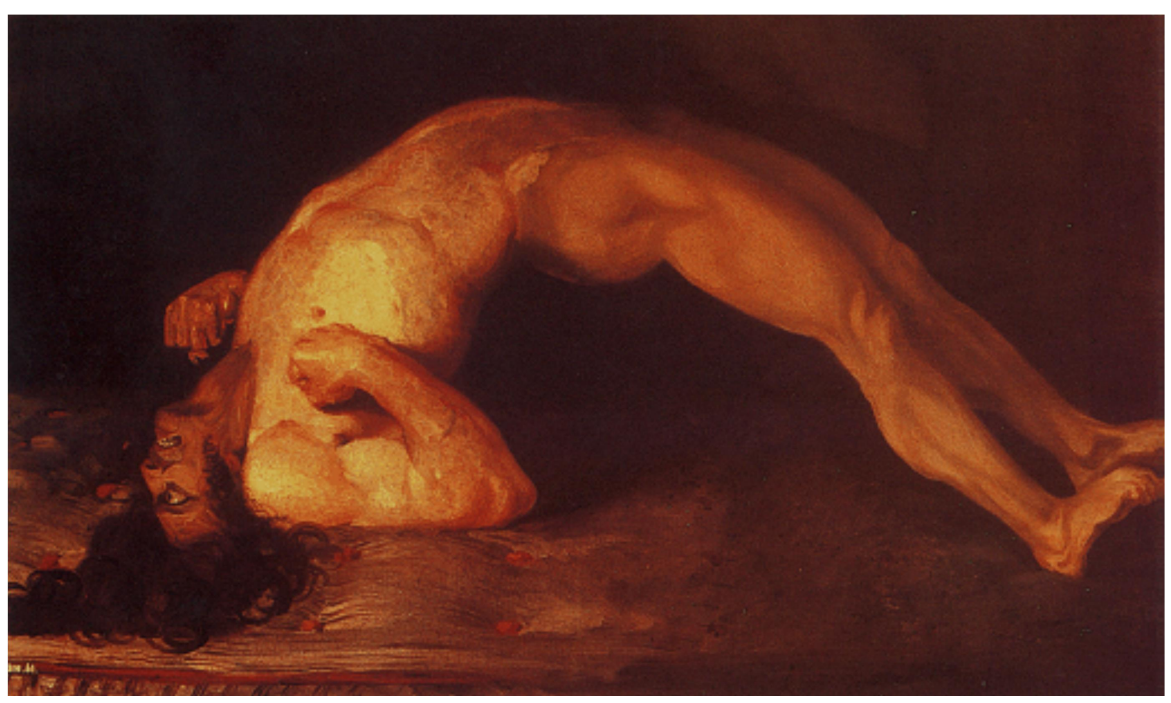

Abbildung 14: Sir Charles Bells Porträt eines Mannes mit generalisiertem Tetanus. Opisthotonus und Risus sardonicus sind deutlich zu erkennen (entnommen aus Richter 2013).

Der Erreger des Botulismus ist das ebenfalls anaerobe, sporenbildende Bakterium Clostridium botulinum, das in der Regel über verunreinigte Nahrungsmittel in den menschlichen Organismus gelangt. Die klinischen Symptome wie Sehstörungen, Schwindel und Muskelschwäche treten 24 Stunden nach Aufnahme des Toxins auf, in schweren Fällen kann es bei intakter Sensibilität zu Ausfällen der Muskeleigenreflexe kommen, schlimmstenfalls zum Atemstillstand als Folge der Muskelschwäche (Dudel und Heckmann 2005). 
Botulinumtoxine sind Neurotoxine und entfalten ihre Wirkung ausschließlich im Nervensystem. Sie sind nicht in der Lage, die Bluthirnschranke zu überwinden, somit manifestieren sich die paralytischen Ausfälle nur im peripheren Nervensystem (Boujard et al. 2014). Die Injektion kleiner Dosen des Botulinumtoxins findet im klinischen Alltag zum Beispiel Anwendung bei der Therapie des Torticollis (muskulärer Schiefhals) oder bei vegetativen Störungen wie pathologischer Schweiß- und Speichelbildung. Die paralysierende Wirkung des in der Kosmetikindustrie eingesetzten Botox entsteht durch Spaltung von Syntaxin und wird zur vorübergehenden Faltenreduktion durch Relaxation der mimischen Muskulatur genutzt (Dudel und Heckmann 2005; Draguhn 2014).

Darüber hinaus scheint der Verlust verschiedener präsynaptischer Proteine des SNAREKomplexes eine funktionelle Abweichung bei der Neurotransmitterfreisetzung zu verursachen, die für die Entstehung der Symptome degenerativer Erkrankungen wie der Chorea Huntington verantwortlich sein könnte (Reiner et al. 2011).

Daher bleibt die vollständige Entschlüsselung der Fusionsmaschinerie in der Synapse zentraler Bestandteil der neurowissenschaftlichen Forschung, da die berechtigte Hoffnung besteht, dass dadurch ein besseres Verständnis neurodegenerativer Erkrankungen wie Parkinson, Alzheimer und Chorea Huntington erzielt werden kann (Jahn 2016).

\subsection{Endozytose und Vesikelrezyklierung}

Nach erfolgter Fusion mit der Plasmamembran müssen die synaptischen Vesikel wieder in den Bereich der Präsynapse aufgenommen werden. Dieses geschieht durch die Endozytose, die für die Entfernung der Bestandteile der synaptischen Vesikel aus dem Bereich der aktiven Zone unerlässlich ist, da sie diese so für weitere Vesikelfusionen „reinigt“ (Neher 2010). Laut Rizzoli gibt es drei Möglichkeiten, was mit den Proteinen der synaptischen Vesikel nach der Fusion passieren kann. Die erste Möglichkeit beschreibt eine geringe Öffnung der Fusionspore, die dann wieder schließt und als „Kiss and Run“ bezeichnet wird (vergleiche Abbildung 8). Bei der zweiten Variante verbleiben die Moleküle des Vesikels nach der Verschmelzung mit der Plasmamembran in einer Gruppe, abgesondert vom Rest der Membran. Die dritte Möglichkeit ist die Verteilung und Vermischung der Moleküle in der Plasmamembran nach erfolgter Verschmelzung (Rizzoli 2014b). Unabhängig davon, welche der aufgeführten Möglichkeiten der Realität entspricht, sind bestimmte Vorgänge unabdingbar, um die einzelnen Moleküle von der Plasmamembran zu lösen und wieder in den Bereich der Präsynapse aufzunehmen. Dazu zählt laut Rizzoli das 
Erkennen der Vesikelproteine Synaptotagmin oder Synaptobrevin. Bei diesem als „Coincidence Detection“ beschriebenen Vorgang binden Adapterproteine zeitgleich eines der Membranproteine und Lipide aus der Plasmamembran (vergleiche Abbildung 15).

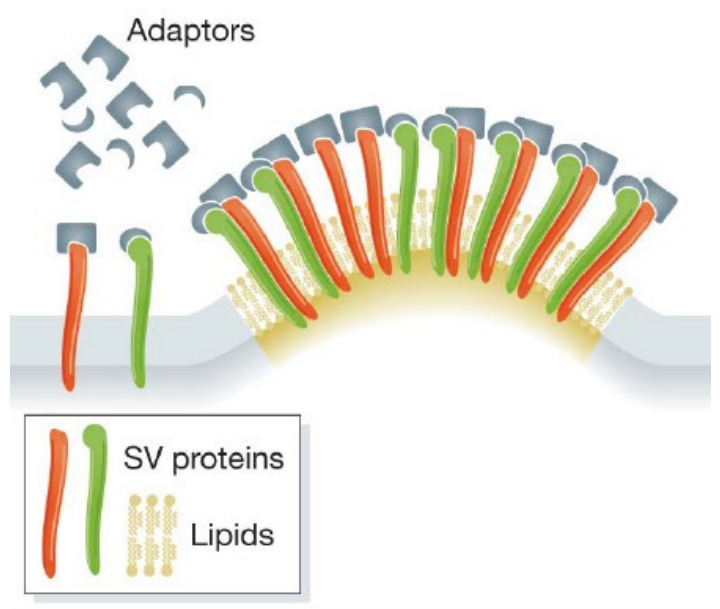

Abbildung 15: Die Ansammlung verschiedener Moleküle des synaptischen Vesikels in der Plasmamembran triggert die Rekrutierung von Adapterproteinen (entnommen aus Rizzoli 2014a; die Verwendung erfolgt mit freundlicher Genehmigung durch Herrn Professor Silvio Rizzoli).

Der Prozess der Endozytose beginnt mit dem sogenannten Clathrin Coating. Dieser Vorgang ist von fundamentaler Bedeutung für die Signalübertragung und die Regulation zahlreicher Aktivitäten der Plasmamembran und somit essentiell für hochentwickeltes eukaryotisches Leben (McMahon und Boucrot 2011). Die für die Erkennung des Vesikelproteins Synaptotagmin zuständigen Adapter rekrutieren das hierfür notwendige Clathrin, ein fibröses Protein, das ein Käfignetz bilden kann (Richter 2013). Jede Clathrinuntereinheit besteht aus drei leichten und drei schweren Polypeptidketten, die gemeinsam eine dreibeinige Struktur aufbauen, die als Triskelion bezeichnet wird (vergleiche Abbildung 16).

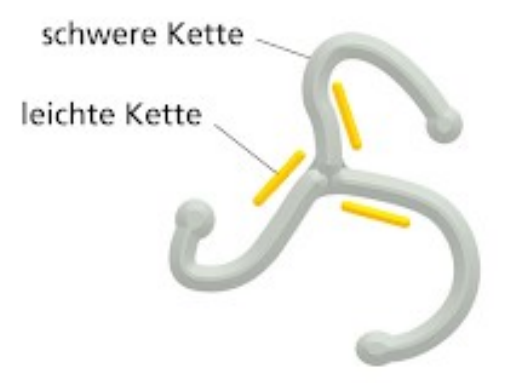

Abbildung 16: Jedes Triskelion besteht aus drei schweren und drei leichten Ketten (entnommen aus (Alberts et al. 2011 Alberts et al. 2011; die Verwendung erfolgt mit freundlicher Genehmigung des Verlags W.W. Norton \& Company). 
Mehrere Clathrin-Triskelions bilden dann durch Zusammenlagerung den sogenannten Coat aus, eine korbähnliche, dreidimensionale Struktur, die sich um die Moleküle des synaptischen Vesikels legt. Abbildung 17 zeigt den Aufbau und anschließenden Zerfall der Clathrinhülle.

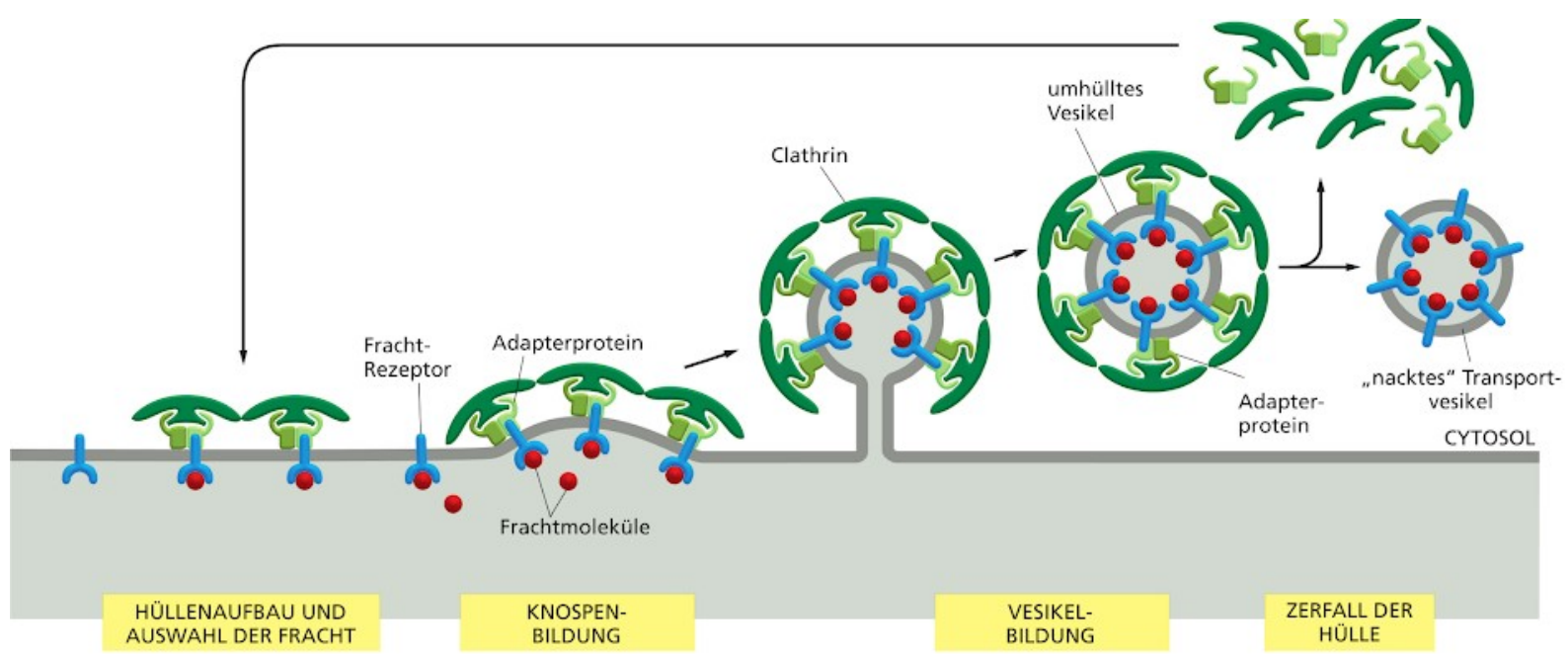

Abbildung 17: Zusammenlagerung und Auflösung einer Clathrinhülle (entnommen aus (Alberts et al. 2011; die Verwendung erfolgt mit freundlicher Genehmigung des Verlags W.W. Norton \& Company)

Nach der vollständigen Ausbildung der clathrinbeschichteten Vesikelknospe muss die Abschnürung dieser von der Plasmamembran erfolgen. Zuständig hierfür sind das zytoplasmatische Protein Dynamin und weitere assoziierte Proteine. Sie lagern sich während des Knospenwachstums um deren Hals an (Alberts et al. 2011). Dynamin enthält eine GTPase-Domäne, die die Geschwindigkeit reguliert, mit der die Vesikel von der Plasmamembran gelöst werden (Alberts et al. 2011).

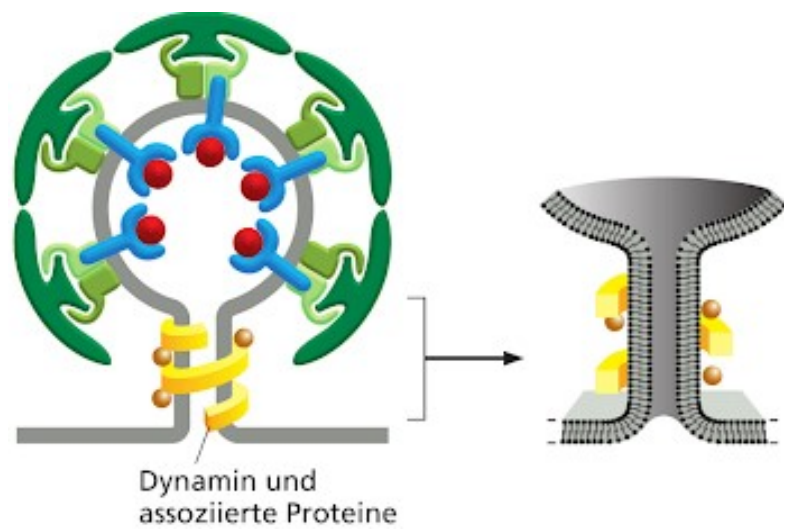

Abbildung 18: Abschnürvorgang des clathrinbeschichteten Vesikels durch Dynamin und assoziierte Proteine (entnommen aus Alberts et al. 2011; die Verwendung erfolgt mit freundlicher Genehmigung des Verlags W.W. Norton \& Company) 
Dieses geschieht vermutlich dadurch, dass Dynamin einen spiralförmigen Ring um den Hals der sich bildenden Vesikel formt und so die beiden extrazellulären Bereiche der Membranen in enge Nähe gebracht werden, fusionieren und das sich bildende Vesikel abdichten (Alberts et al. 2011).

Dieser Mechanismus, der laut Faelber und Kollegen jedoch noch nicht bis in das letzte Detail verstanden wurde, ist in Abbildung 18 abgebildet (Faelber et al. 2012).

Des Weiteren stellt sich die Frage, welche Faktoren oder Ereignisse die Endozytose beeinflussen und in Gang setzen. Ceccarelli und Hurlbut vermuten, dass dieser Prozess durch die Insertion der Vesikelmembran in die Plasmamembran ausgelöst wird (Ceccarelli und Hurlbut 1980). Forschungsergebnisse von Henkel und Betz sowie Zefirov und Kollegen unterstreichen die Bedeutung von extrazellulärem Calcium als Trigger der Endozytose (Henkel und Betz 1995; Zefirov et al. 2006). Dies stimmt mit der Ansicht von Clayton und Kollegen überein, dass der Calciumeinstrom die calciumabhängige Phosphatase Calcineurin aktiviert, was zu einer Dephosphorylierung des Dynamins und weiterer Kofaktoren der Endozytose führt (Clayton et al. 2007).

Nach erfolgter Abschnürung von der Plasmamembran wäre der umhüllte Vesikel nun in der Lage, von der Plasmamembran zu diffundieren, tut dieses aber offensichtlich nicht (Rizzoli 2014a). Stattdessen scheinen die Vesikel, angetrieben durch die Polymerisation von Aktin, von der Plasmamembran entfernt (Merrifield et al. 1999) und in den Bereich des Vesikelclusters transportiert zu werden (Shupliakov et al. 2002; Bloom et al. 2003). Die genaue Bedeutung des Aktins ist noch nicht abschließend geklärt. Die Beeinflussung der Aktinfunktion durch Medikamente führte in Versuchen von Rizzoli und Betz zu einer Störung der Endozytose. Somit lässt sich eine wichtige Funktion des Aktins für diesen Vorgang vermuten (Rizzoli und Betz 2005).

Kurze Zeit nach der Ablösung der Vesikel von der Plasmamembran wird die Clathrinhülle entfernt. Der Bereich, an dem Dynamin den Vesikel abgeschnürt hat, ist frei von Clathrin und kann so von Hsc70 (Heat shock cognate 70) und seinem aktivierenden Kofaktor Auxillin erkannt und gebunden werden (McMahon und Boucrot 2011). Diese Moleküle „schälen“ dann die Clathrinhülle des Vesikels ab (vergleiche Abbildung 19, Rizzoli 2014a). Hsc70 besitzt dabei die Fähigkeit, zahlreiche schwere Ketten gleichzeitig zu binden und zu destabilisieren (Xing et al. 2010; Böcking et al. 2011). Es fungiert bei diesem Prozess als ATPase, die die Energie der ATP-Hydrolyse nutzt, um die Clathrinhülle zu entfernen (Alberts et al. 2011). 
Die nun „enthüllten“ Vesikel besitzen alle SNARE-Moleküle, die für weitere Fusionsgeschehen notwendig wären (Takamori et al. 2006). Somit wäre theoretisch sogar eine Fusion der Vesikel miteinander möglich.

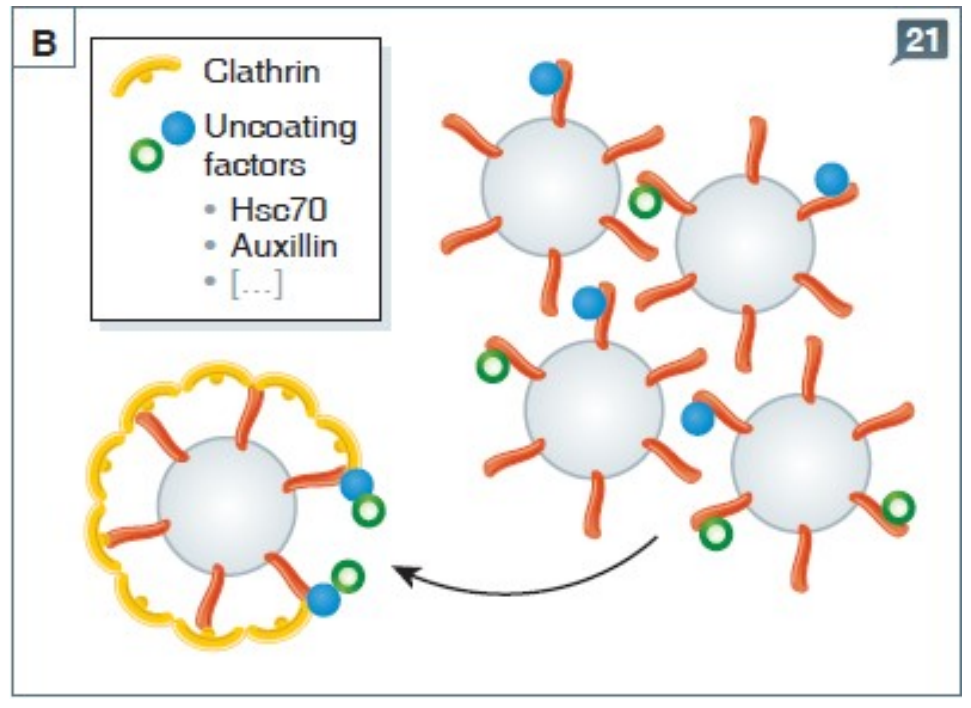

Abbildung 19: Ablösung der Clathrinhülle durch Hsc70 und Auxillin (entnommen aus Rizzoli 2014a; die Verwendung erfolgt mit freundlicher Genehmigung durch Herrn Professor Silvio Rizzoli)

Nach Rizzoli findet dieser Prozess jedoch nicht statt. Gemäß seinen Erkenntnissen kommt es zu einer Fusion mit Endosomen, der ein endosomaler Sortierungs- oder Speicherungsprozess folgt (Rizzoli 2014a). Im Anschluss erfolgt eine erneute „Füllung“ mit Neurotransmittern, wie sie in Kapitel 1.4 beschrieben und in der Abbildung 7 dargestellt ist. Insgesamt dauert der Vesikelzyklus zwischen circa fünf Sekunden (,short-cut") und circa 30 Sekunden (endosomaler Weg) (Draguhn 2014).

Ein abschließender interessanter Punkt ist die Verknüpfung von Exo- und Endozytose. Neher vertritt den Standpunkt, dass die Endozytose notwendig ist, um das Material der synaptischen Vesikel aus dem Bereich der aktiven Zone zu entfernen und diese somit für weitere Fusionsereignisse zu „säubern“ (Neher 2010). Diese Ansicht stimmt mit den Beobachtungen von Miller und Heuser überein, die bereits 1984 herausfanden, dass die Endozytose nicht direkt an der aktiven Zone stattfindet, sondern in einem als „periaktive Zone“ beschriebenen Bereich in der Umgebung der aktiven Zone (Miller und Heuser 1984). Eine Kopplung dieser Prozesse ist laut Rizzoli durch den gemeinsamen Trigger Calcium oder die SNARE-Moleküle möglich. Hosoi und Kollegen sowie auch Xu und Kollegen fanden heraus, dass zum Beispiel aus der enzymatischen Spaltung von Synaptobrevin durch das Tetanustoxin eine Blockade beziehungsweise deutliche 
Verlangsamung der Endozytose resultierte (Hosoi et al. 2009; Xu et al. 2013). Die exakte physikalische Verknüpfung dieser Prozesse ist sicher $\mathrm{zu}$ diskutieren und bleibt somit Gegenstand der aktuellen Forschung (Rizzoli 2014a).

\subsection{Ziel dieser Arbeit}

Ziel dieser vorliegenden Arbeit ist es, anhand von elektronenmikroskopischen Schnittbildern neuronale Zellkulturen aus dem Hippocampus zu untersuchen. Mit Hilfe von Adobe Photoshop CS6 werden die Schnittbilder der einzelnen Ebenen justiert und exakt übereinandergelegt. Anschließend erfolgt eine Auswertung der Bilddateien mit dem Programm MatLab, das eine Markierung und Klassifizierung der einzelnen Zellorganellen ermöglicht und nachfolgend eine dreidimensionale Rekonstruktion der zu untersuchenden Synapsenbereiche erlaubt. Anhand dieser Bilder werden dann Rückschlüsse auf die numerische und räumliche Verteilung der an der Ausbildung von Synapsen beteiligten Zellbereiche und Zellorganellen gezogen.

Mit Hilfe dieser Ergebnisse können Thesen bezüglich der Bedeutung der einzelnen Organellen für die physiologische Funktionalität der Synapse sowie auch über ihre Interaktion untereinander aufgestellt werden.

Die Arbeit soll somit einen Beitrag zu einem besseren Verständnis des realen, dreidimensionalen Aufbaus der Kontakt- und Signalübertragungsstelle zweier Neuronen liefern. Für die Zukunft erhoffen wir uns davon auch ein besseres Verständnis pathologischer Prozesse, die ihren Ursprung im Bereich der Verschaltung an synaptischen Endigungen haben, und die Möglichkeit der medizinischen Intervention an dieser Schnittstelle. 


\section{Material und Methoden}

Die in dieser Arbeit untersuchten Hirnschnitte entstammten aus der Hippocampusregion neugeborener Ratten. Die Tiere wurden von Speziallaboren oder kommerziellen Anbietern beschafft. Der Hippocampus liegt im Temporallappen und ist ein integraler Bestandteil des limbischen Systems. Er erhält sensorischen Input und scheint für das Funktionieren des deklarativen Wissens notwendig zu sein (Lavenex und Amaral 2000). Die Verwendung von Zellkulturen aus dem Hippocampus ist weit verbreitet, da der Aufbau der Neuronen in diesem Bereich des zentralen Nervensystems im Vergleich zu anderen Regionen recht simpel ist (Kaech und Banker 2006). Ein weiterer Vorteil liegt laut Kaech und Banker darin, dass diese Nervenzellen auch in einer Zellkultur ein umfangreiches Netzwerk von Synapsen ausbilden (Kaech und Banker 2006), die in dieser Arbeit untersucht werden sollen. Die Erstellung der Präparate und der elektronenmikroskopischen Bilder erfolgten durch Herrn Prof. Dr. Thomas Schikorski von der Universidad Central del Caribe in Bayamón, Puerto Rico.

\subsection{Konventionelle Zellkultur}

In diesem Kapitel wird der Ablauf zur Herstellung der konventionellen Zellkultur im Detail beschrieben. Die hierfür genutzten Materialien sind in der untenstehenden Tabelle 1 aufgelistet.

Tabelle 1: Auflistung der Materialien für die Herstellung der Zellkultur und deren Anwendung

\begin{tabular}{|c|c|}
\hline Lösung & Bestandteile der Lösung \\
\hline $\begin{array}{l}\text { Aussaatmedium } \\
\text { (Planting-Medium) }\end{array}$ & $\begin{array}{ll}\text { - } & 111 \mathrm{ml} \text { MEM } \\
\text { - } & 66 \mathrm{mg} \text { Glucose }(3,3 \mathrm{mM}) \\
\text { - } & 11 \mathrm{ml} \text { Horse-Serum }(10 \%) \\
\text { - } & 1,1 \mathrm{ml} \text { Glutamine }(2 \mathrm{mM})\end{array}$ \\
\hline
\end{tabular}




\begin{tabular}{|c|c|}
\hline Boratpuffer $\mathrm{pH}=8,5 ; 100 \mathrm{mM}$ & $\begin{array}{l}\text { - Lösung: Base (500 ml) } \\
\rightarrow \mathrm{Na}_{2} \mathrm{~B}_{4} \mathrm{O}_{7} * 10 \mathrm{H}_{2} \mathrm{O}, 19,07 \mathrm{~g} \text {; für längere } \\
\text { Zeit umrühren } \\
\text { - Lösung: Säure (500 ml) } \\
\rightarrow \mathrm{H}_{3} \mathrm{BO}_{3} \text { (Borsäure), 3,09 g } \\
\text { - Mit Reinstwasser vermischen } \\
\text { Herstellung: } \\
\text { Die zweite Lösung wird in ein Becherglas } \\
\text { gegeben. Durch Zugabe der ersten Lösung wird } \\
\text { dann der pH-Wert von 8,5 erzielt. }\end{array}$ \\
\hline Enzymlösung & $\begin{array}{l}\text { - } 2 \mathrm{mg} \text { Cystein } \\
\text { - } 10 \mathrm{ml} \text { DMEM (Dulbecco's Modified Eagle's } \\
\text { Medium; standardisiertes Nährmedium für die } \\
\text { Zellkultur) } \\
\text { - } 0,1 \mathrm{ml} \mathrm{CaCl}(100 \mathrm{mM}) \\
\text { - } \quad 0,1 \mathrm{ml} \text { EDTA (50 mM) } \\
\text { - } 20-25 \quad \text { Einheiten Papain pro Milliliter } \\
\text { Enzymlösung } \\
\text { - Carbogen-Gasgemisch für 10-20 min sieden } \\
\text { Anwendung: } \\
\text { Anschließend wird die Lösung bis zu ihrem } \\
\text { Gebrauch im Wasserbad aufbewahrt. }\end{array}$ \\
\hline Inaktivierungslösung & $\begin{array}{l}\text { - } 25 \mathrm{mg} \text { Albumin } \\
\text { - } 25 \mathrm{mg} \text { Trypsin-Inhibitor } \\
\text { - } 5 \mathrm{ml} 10 \% \text { iges FCS-Medium (Fetales-Kälber- } \\
\text { Serum) } \\
\text { Herstellung: } \\
\text { Die Lösung wird steril filtriert und auf } 37^{\circ} \mathrm{C} \\
\text { erwärmt. }\end{array}$ \\
\hline
\end{tabular}




\begin{tabular}{|c|c|}
\hline 10 \%iges FCS-Medium & $\begin{array}{l}\text { - } 437 \mathrm{ml} \text { DMEM } \\
\text { - } 50 \mathrm{ml} \text { FCS } \\
\text { - } 10 \mathrm{ml} \text { Glutamine } \\
\text { - } 3 \mathrm{ml} \text { Pen-Strep (Penicillin-Streptomycin) }\end{array}$ \\
\hline Neurobasal-A-Medium & $\begin{array}{l}\text { - } 500 \mathrm{ml} \text { Neurobasal-A } \\
\text { - } 10 \mathrm{ml} \mathrm{B-27-Supplement} \\
\text { - } 5 \mathrm{ml} \text { Glutamax 1-Stock } \\
\text { - } 1.000 \mu \mathrm{l} \text { Pen-Strep }\end{array}$ \\
\hline $\begin{array}{l}\text { FUDR zur Hemmung der } \\
\text { Mikroglia }\end{array}$ & $\begin{array}{l}\text { - } 25 \mathrm{mg} 5 \text {-fluor-2'deoxyuridin }(8,1 \mathrm{mM}) \\
\text { - } 62,5 \mathrm{mg} \text { Uridin }(20,4 \mathrm{mM}) \\
\text { - } 12,5 \mathrm{ml} \text { DMEM } \\
\text { Herstellung: } \\
\text { Die Bestandteile werden vermischt, im } \\
\text { Anschluss in den Sterilfilter gegeben und } \\
\text { abschließend im Gefrierschrank in } 500 \mu \mathrm{l} \\
\text { Aliquots gelagert. } \\
\text { Anwendung: } \\
\text { Von dieser Mischung werden dann jeweils } \\
0,02 \mathrm{ml} \quad \text { pro "Well “ (Vertiefung in } \\
\text { Mikrotiterplatte) abgefüllt. }\end{array}$ \\
\hline
\end{tabular}

\subsubsection{Präparation der Deckgläser}

Die Präparation der Deckgläser orientierte sich weitestgehend an dem Protokoll von Kaech und Banker (vergleiche Kaech und Banker 2006). Als Erstes wurden die Deckgläser mit einem Durchmesser von $18 \mathrm{~mm}$ in speziellen säurebeständigen Keramikhaltern platziert, mit Wasser abgespült und anschließend über Nacht in eine Lösung mit einem Salpetersäureanteil von $70 \%$ gebracht und gereinigt. Am darauffolgenden Tag wurden die Gläser so lange mit destilliertem Wasser abgewaschen, bis sich ein $\mathrm{pH}-$ Wert von 7 einstellte. Anschließend erfolgte die vollständige Trocknung der Deckgläser, um verbliebenes Wasser zu entfernen. Im Anschluss wurden sie in ihren Haltern in ein mit 
Alufolie abgedecktes Becherglas gestellt und für 30 Minuten in einen auf $37^{\circ} \mathrm{C}$ erhitzten Wärmeschrank gelegt. Somit wurde sichergestellt, dass die Deckgläser während des Autoklavierens trocken blieben.

Für eine effektive Sterilisation wurden die Coverslips dann für 15 Minuten bei konstantem Druck und einer Temperatur von $121^{\circ} \mathrm{C}$ in den Autoklav gestellt. Nach der Abkühlphase erfolgte die Platzierung der Deckgläser in Zellkultur-Schalen mit einem Durchmesser von $15 \mathrm{~cm}$. Wichtig hierbei war es, dass sich die Deckgläser weder untereinander berührten noch in Kontakt mit der Wand der Zellkultur-Schale kamen. Unter Berücksichtigung dieser Vorschrift konnten jeweils 20 Deckgläser in einer Schale positioniert werden.

Anschließend wurden die Deckgläser mit $1 \mathrm{ml}$ Poly-L-Lysin (PLL) beschichtet, diese wurde im Boratpuffer $(\mathrm{pH}=8,5)$ gelöst und dann steril filtriert. Die Poly-L-Lysin-Lösung hatte eine Konzentration von $1 \mathrm{mg}$ Poly-L-Lysin je Milliliter Boratpuffer. Im Anschluss wurden in die Deckgläser einige Tropfen der Poly-L-Lysin-Lösung gefüllt. Nachdem diese komplett mit der Lösung bedeckt waren, wurden sie vollständig mit Alufolie abgedeckt und bei einer Temperatur von $37^{\circ} \mathrm{C}$ über Nacht (circa 12 Stunden) im Autoklav positioniert.

Am nächsten Tag entfernte man die Poly-L-Lysin-Lösung von den Deckgläsern und bewahrte sie bei $-20^{\circ} \mathrm{C}$ auf. Die Gläser wurden daraufhin zweimal mit sterilem, destilliertem Wasser gespült und in den Well-Platten positioniert, die zuvor ebenfalls mit circa einem Milliliter destilliertem Wasser gespült wurden.

Nach Abschluss des letzten Waschvorgangs wurde möglichst viel Wasser entnommen und die Deckgläser wurden anschließend mit einem Milliliter Aussaatmedium beschichtet. Darauf folgend wurden die Well-Platten bei einer Temperatur von $37^{\circ} \mathrm{C}$ für mindestens drei Tage im Inkubator platziert. 


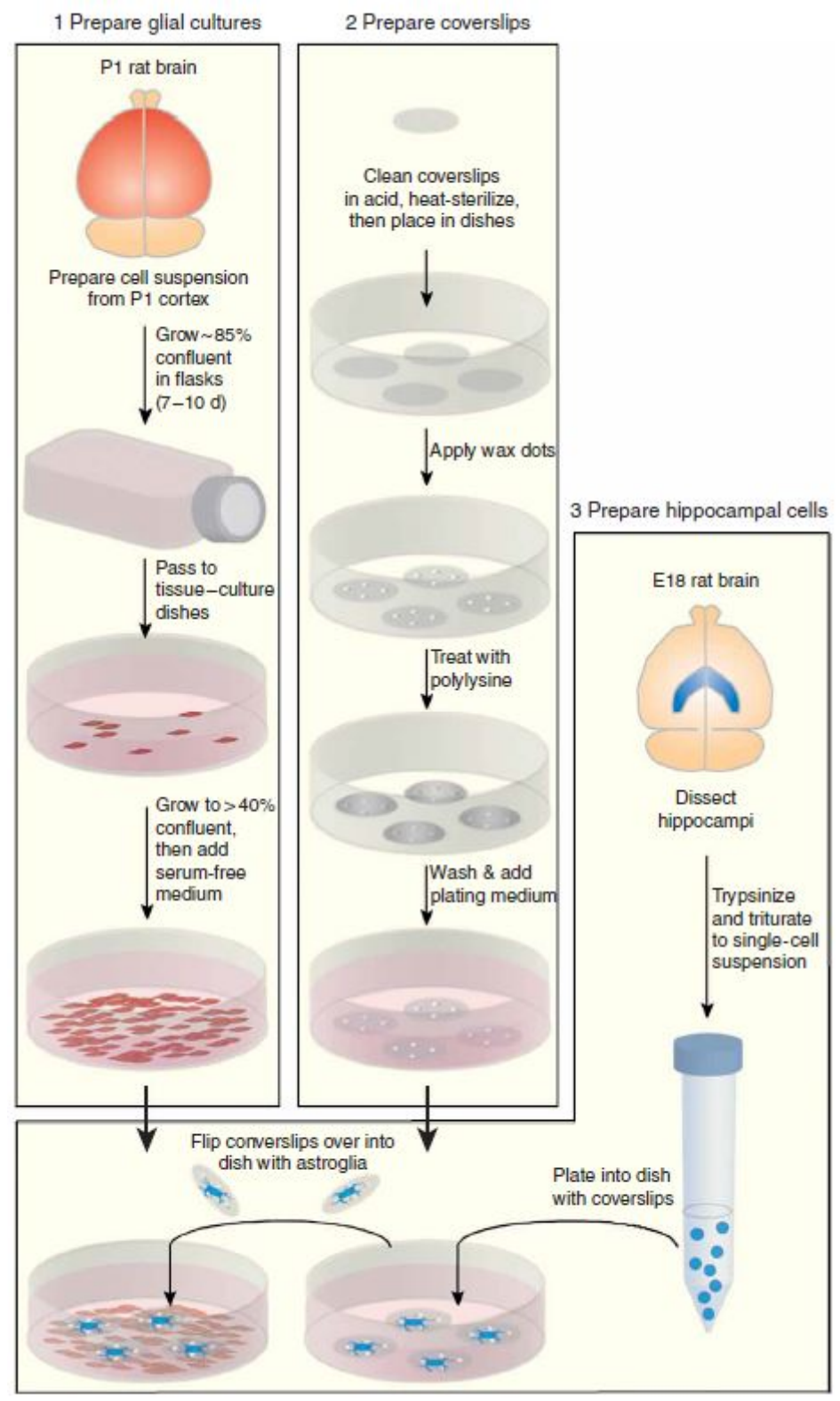

Abbildung 20: Das Flowchart zeigt das dreiteilige Protokoll für die Präparation hippocampaler Zellkulturen nach Kaech und Banker, das in modifizierter Art und Weise auch in dieser Arbeit angewendet wurde (entnommen aus Kaech und Banker 2006; die Verwendung erfolgt mit freundlicher Genehmigung des Springer Nature Verlags).

\subsubsection{Zerteilung und enzymatische Verarbeitung der Hippocampi}

In Vorbereitung der Zerteilung der Hippocampi sollten 10 Milliliter der Enzymlösung (vergleiche Tabelle 1) bereitstehen und in einem Wasserbad auf $37^{\circ} \mathrm{C}$ erwärmt werden. Bevor dann die Gewebeproben in die Lösung gegeben wurden, war eine Sterilisation dieser unbedingt erforderlich. 
Nun konnten die komplett entfernten Gehirne der neugeborenen Ratten in eine Petrischale mit gekühlter Hank's Balanced Salt Solution (HBSS) gelegt und so positioniert werden, dass der Hypothalamus nach oben zeigte.

Mit Hilfe eines Präparationsmikroskops wurden die Hirnhäute vom mittleren Teil der zerebralen Hemisphären entfernt (vergleiche Abbildung 20 für den weiteren Verlauf). Dann erfolgte die Trennung des Hippocampus vom Kortex. Die getrennten Hippocampusteile wurden dann für eine Stunde in die in Tabelle 1 beschriebene Enzymlösung gelegt und bei $37^{\circ} \mathrm{C}$ unter stetigem Rühren inkubiert (vergleiche (Opazo et al. 2010).

Nach Ablauf dieser Zeit wurde die Enzymlösung entfernt und durch fünf Milliliter der ebenfalls in Tabelle 1 beschriebenen Inaktivierungslösung ersetzt. Nach einer Zeit von fünf Minuten wurde dann die Inaktivierungslösung verworfen, gefolgt von der Trituration der Hippocampus-Bestandteile mit Hilfe einer Pasteurpipette in das Neurobasal-A-Medium (vergleiche Tabelle 1). Es folgte die dreimalige Waschung der Zellen in diesem Medium. Während des Pipettierens musste beachtet werden, dass sich die Spitze der Pipette stets am Boden des Gefäßes befand, um die Resuspendierung des Gewebes sicher zu gewährleisten. Durch das kontinuierliche Auf- und Abpipettieren wurden die Hippocampizellen getrennt. Nach der letzten Zugabe des Neurobasal-A-Mediums wurde die Anzahl der Zellen mit Hilfe einer lichtmikroskopischen Auswertung in der „Neubauer Cell Counting Chamber“ gezählt (vergleiche Abbildung 21). Jedes Well wurde mit 80.000 Zellen und dem Aussaatmedium befüllt und dann für mindestens zwei Stunden im Inkubator platziert.

Nach Ablauf dieser Zeit wurde das Aussaatmedium vollständig entfernt und 1,25 Milliliter des Neurobasal-A-Mediums den Neuronen beigefügt. Nach 48 Stunden erfolgte der Austausch eines Teils des Zellkultur-Mediums, indem ein Milliliter des alten Mediums durch einen Milliliter des frischen Mediums ersetzt wurde. Wichtig hierbei war es, nie das komplette Medium zu tauschen (vergleiche Kaech und Banker 2006). 


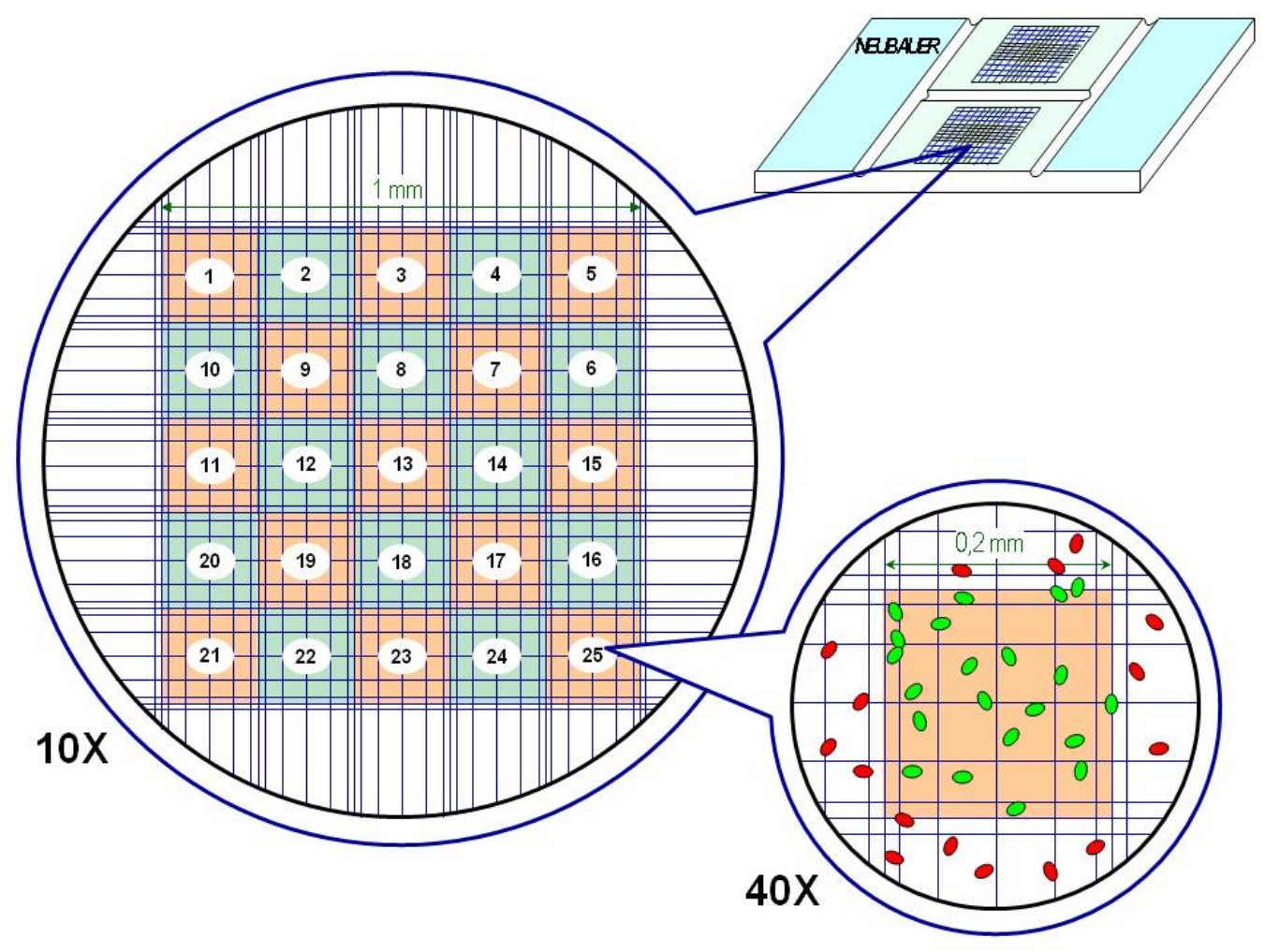

Abbildung 21: Dargestellt ist der beispielhafte Aufbau einer „Neubauer Cell Counting Chamber“ (http://insilico.ehu.eus/counting_chamber/neubauer_improved.php, 2018).

\subsection{Fixation, Elektronenmikroskopie, Adobe Photoshop CS6, MatLab}

\section{Fixation}

Die chemische Fixation der neuronalen Zellkulturen erfolgte zunächst durch das Einlegen der Präparate in 2,5\% Glutaraldehyd in Polybutylensuccinat (PBS), in dem sie für 30 Minuten auf Eis gelegt wurden. Im Anschluss verlief die weitere Fixation für 30 bis 60 Minuten bei Raumtemperatur ebenfalls in 2,5\% Glutaraldehyd. Danach erfolgte das Waschen der Präparate in Polybutylensuccinat und die Abkühlung der Proben mit $100 \mathrm{mM}$ Ammoniumchlorid bei $4{ }^{\circ} \mathrm{C}$. Nach Beendigung des Spülvorgangs wurden die Zellkulturen in $1,5 \mathrm{mg} / \mathrm{ml}$ Diaminobenzidin (DAB) über einen Zeitraum von 30 bis 45 Minuten im Inkubator platziert. 


\section{Postfixation und Färbung der Präparate}

Nach Abschluss der ersten Fixationsschritte mit Hilfe von Polybutylensuccinat erfolgte bei Raumtemperatur die weitere Behandlung der Präparate mit $1 \%$ Osmiumtetroxid zwecks Postfixation und Färbung der neuronalen Zellkulturen. Anschließend erfolgte für 60 Minuten die Dehydrierung der Proben mit verschiedenen Ethanolen und Propylenoxid.

Im Anschluss wurden die Präparate für 12 bis 18 Stunden unter konstantem Rühren in 50 \% Epoxidharz (Epon) in Propylenoxid inkubiert. Um die vollständige Verdunstung des Propylenoxids zu gewährleisten, wurden die Proben zunächst für 8 Stunden in offenen Injektionsfläschchen in $100 \%$ Epoxidharz und abschließend für 36 Stunden bei einer Temperatur von $60^{\circ} \mathrm{C}$ inkubiert.

Zuletzt wurden die Reagenzgläser entfernt und die Präparatsblöcke mit Hilfe eines Ultramikrotoms in $70 \mathrm{~nm}$ starke Schnitte zerteilt. Die Betrachtung der Proben und das Erstellen der elektronenmikroskopischen Bilder erfolgte mit einem Mikroskop der Firma Zeiss (ZEISS EM 902 A), das mit einem CCD-Detektor mit einer Auflösung von 1,024 x 1,024 (Proscan CCD HSS 512/1024, Proscan Electronic Systems) bestückt ist.

\section{Adobe Photoshop CS6}

Mit Hilfe des Programmes Adobe Photoshop CS6 wurden die elektronenmikroskopischen Schnittbilder weiter bearbeitet und ausgewertet. Der im Folgenden beschriebene Arbeitsablauf ist in den Abbildungen 22-25 dargestellt.

Zunächst wurden auf den von Herrn Professor Dr. Thomas Schikorski zur Verfügung gestellten Bildern die Synapsen identifiziert und ausgewählt, die auf möglichst vielen Schnittbildern der Bilderserien zu sehen waren. Die entsprechenden Dateien wurden dann als „.tif“ gespeichert und mit Adobe Photoshop geöffnet (vergleiche Abbildung 22). Schrittweise wurden dann weitere Schnittbilder der gleichen Region ergänzt und mit Hilfe der Bildbearbeitung mit den zuvor bearbeiteten Bildern in Einklang gebracht. Hierfür konnte über das Bedienfeld „Opacity“ die Opazität der jeweils neu ergänzten Schicht so weit reduziert werden (in der Regel auf circa $50 \%$ des Ausgangswertes), dass ein exaktes Übereinanderlegen der einzelnen Ebenen möglich wurde. Mit Hilfe des Befehls „Edit $\rightarrow$ Transform $\rightarrow$ Rotate“ wurden die hinzugefügten Schichten gedreht, bis eine punktgenaue Deckung mit den vorherigen Schichten erreicht werden konnte. Abschließend wurden alle Schnittbilder einer Synapse über den Befehl „Layer $\rightarrow$ Flatten image“ auf eine Ebene gebracht und konnten dann mit Hilfe des Programms MatLab weiter bearbeitet werden. 


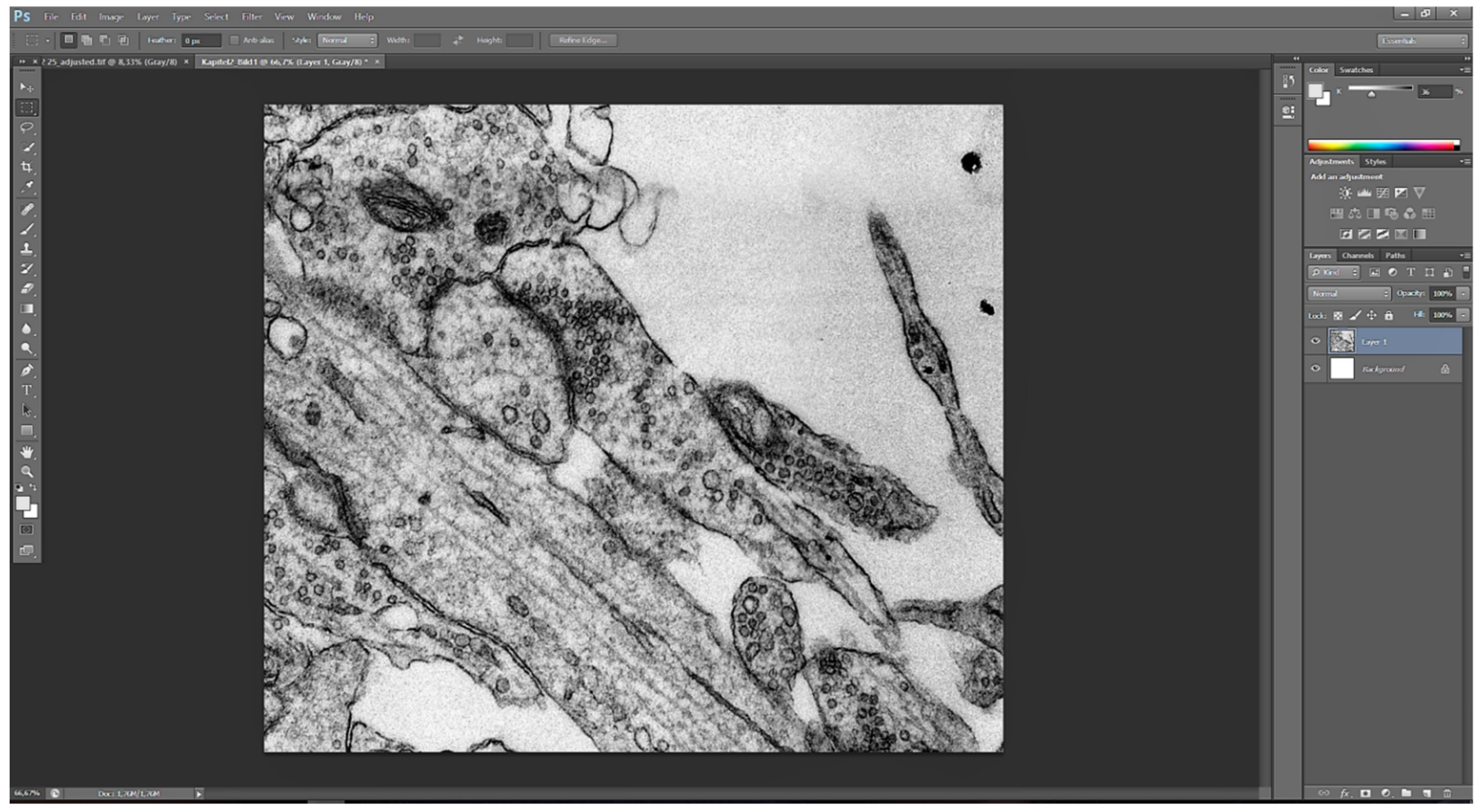

Abbildung 22: Ausschnitt eines elektronenmikroskopischen Bildes, das mit Adobe Photoshop geöffnet wurde und den Bereich der Synapse abbildet

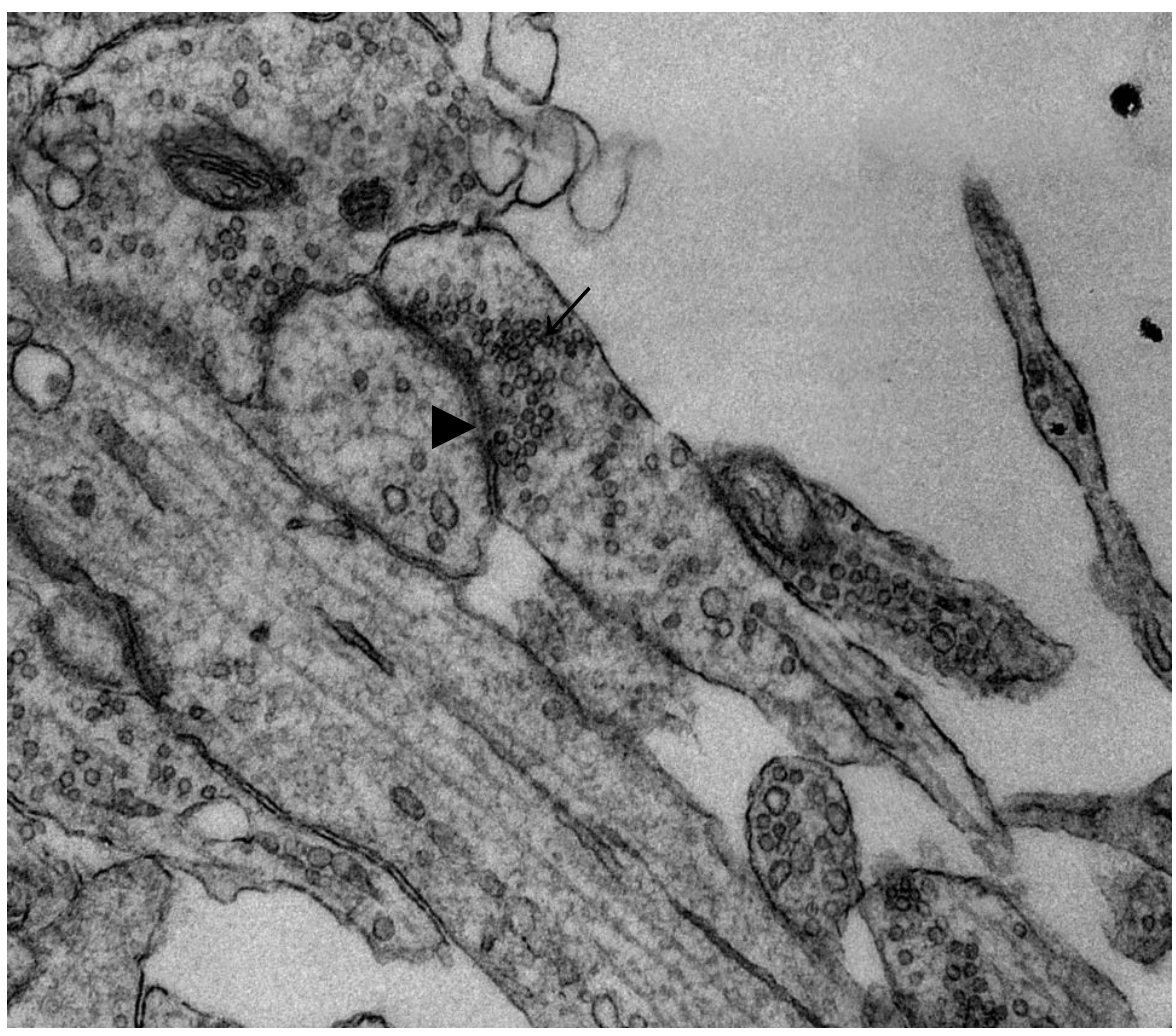

Abbildung 23: Die in Abbildung 22 gezeigte Synapse ist hier im Detail vergrößert dargestellt.

Deutlich zu erkennen sind der dunklere, elektronendichte Bereich der Prä- und Postsynapse ( und die Ansammlung präsynaptischer Vesikel $(\rightarrow)$. 


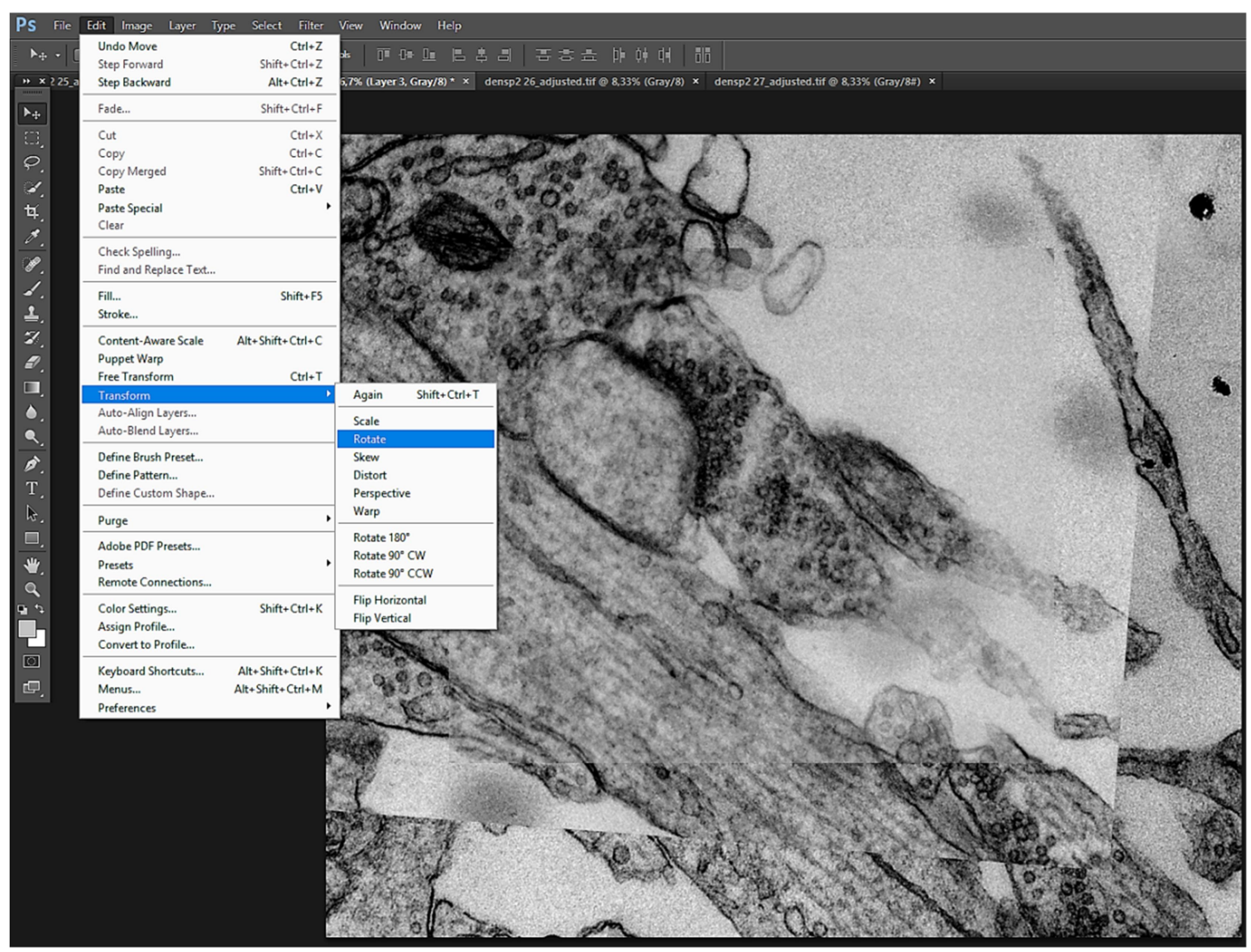

Abbildung 24: Dargestellt ist die Befehlskette „Edit $\rightarrow$ Transform $\rightarrow$ Rotate“, mit deren Hilfe die einzelnen Schichten exakt übereinandergelegt wurden.

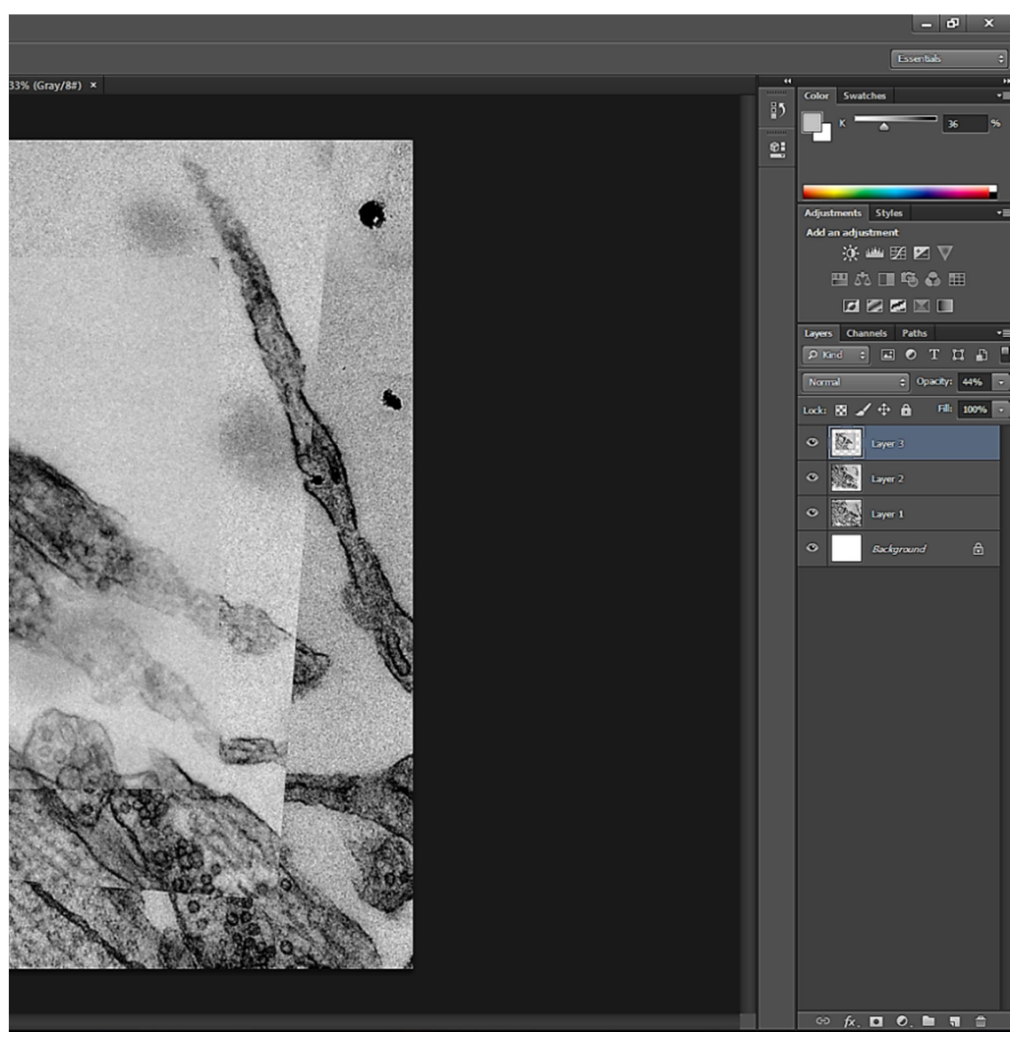

Abbildung 25: Auf der rechten Leiste sind die verschiedenen Ebenen („Layer 1-3“) abgebildet. Ebenfalls zu erkennen ist die Schaltfläche „Opacity“ (in diesem Bild auf 44 \% eingestellt), mit deren Hilfe die Überlagerung der Schnittbilder ermöglicht wurde. 


\section{MatLab}

Die Datenanalyse und Auswertung der erstellten Bilddaten erfolgte durch die Anwendung der MatLab-Software. Hierfür wurden die mit Adobe Photoshop bearbeiteten elektronenmikroskopischen Bilder mit Hilfe einer von Herrn Professor Silvio O. Rizzoli programmierten Software bearbeitet und konnten so in einer dreidimensionalen Darstellung abgebildet werden. Die wichtigsten Arbeitsschritte sind in den Abbildungen 26 und 27 dargestellt.

Zu Beginn wurden die, durch die Bearbeitung mit Photoshop, auf einer Ebene fixierten Schnittbilder mit dem Zeichentool von MatLab geöffnet. Danach erfolgte die Identifikation und das manuelle Zeichnen der präsynaptischen Zellstrukturen, also der Vakuolen, der Mitochondrien und der Vesikel sowie der aktiven Zone und der Membran der präsynaptischen Nervenendigung (vergleiche Abbildung 26). Nachdem dieser Arbeitsschritt für alle Ebenen einer Synapse erfolgt war, konnte über die Befehlskette „File $\rightarrow$ Open $\rightarrow$ for_calculating_the_plotting_lines“ beziehungsweise „for_plotting_the_3D“ die dreidimensionale Rekonstruktion der präsynaptischen Struktur gestartet werden. Abbildung 27 zeigt exemplarisch eine auf diese Weise erstellte dreidimensionale Abbildung der präsynaptischen Nervenendigung.

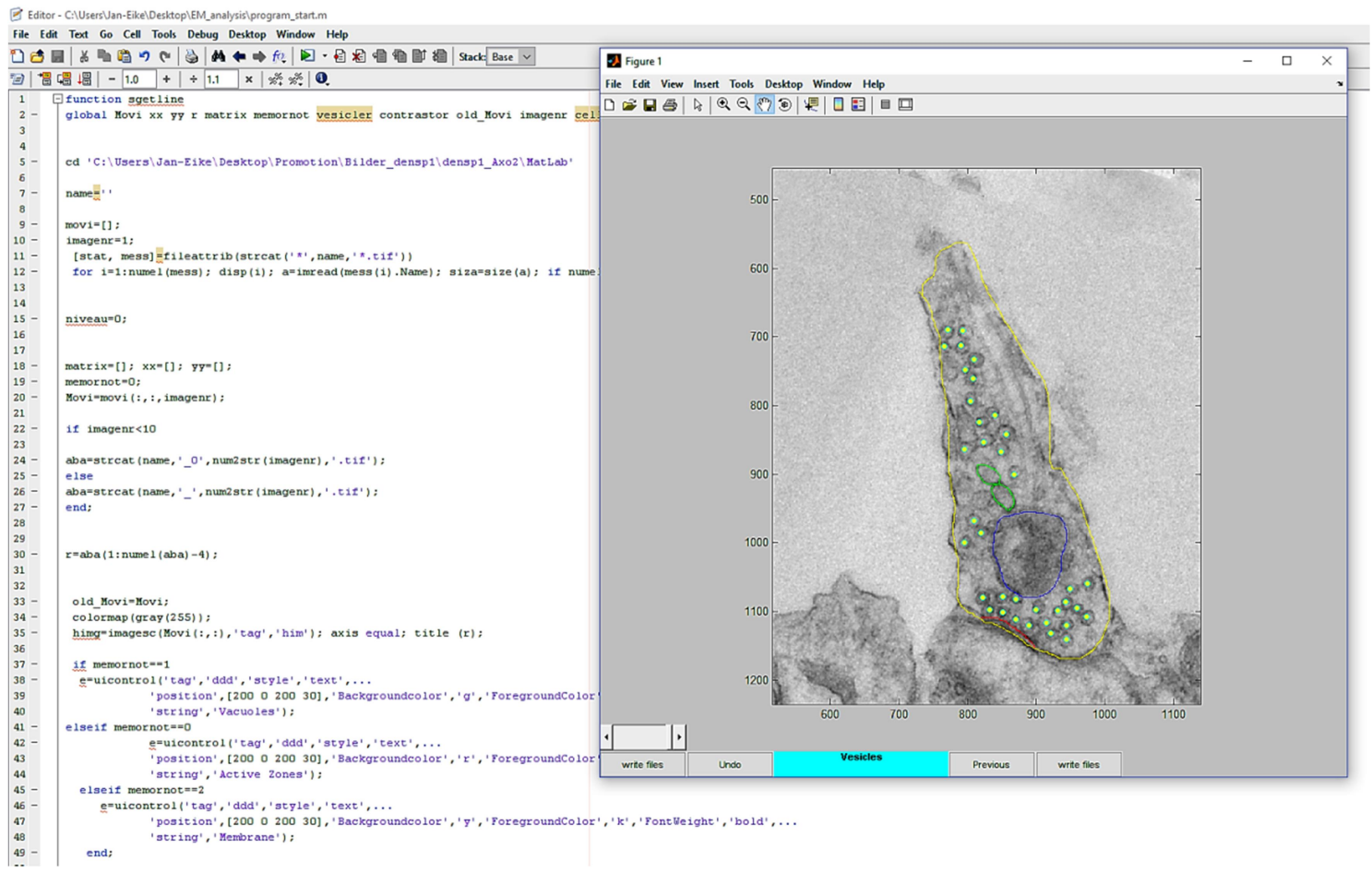

Abbildung 26: Abgebildet ist der Arbeitsschritt des manuellen Zeichnens der synaptischen Strukturen mit dem Programm MatLab. Dargestellt sind der Bereich der aktiven Zone (rot), die Vakuolen (grün), ein Mitochondrium (blau), die Vesikel (hellgrüne Punkte) und die Membran der präsynaptischen Nervenendigung (gelb). 
Die Membran des Neurons ist beige gefärbt, der Bereich der aktiven Zone rot, das Mitochondrium blauviolett und die zahlreichen Vesikel sind grau dargestellt. Vakuolen sind in dieser Darstellung nicht abgebildet (vergleiche Abbildung 27).

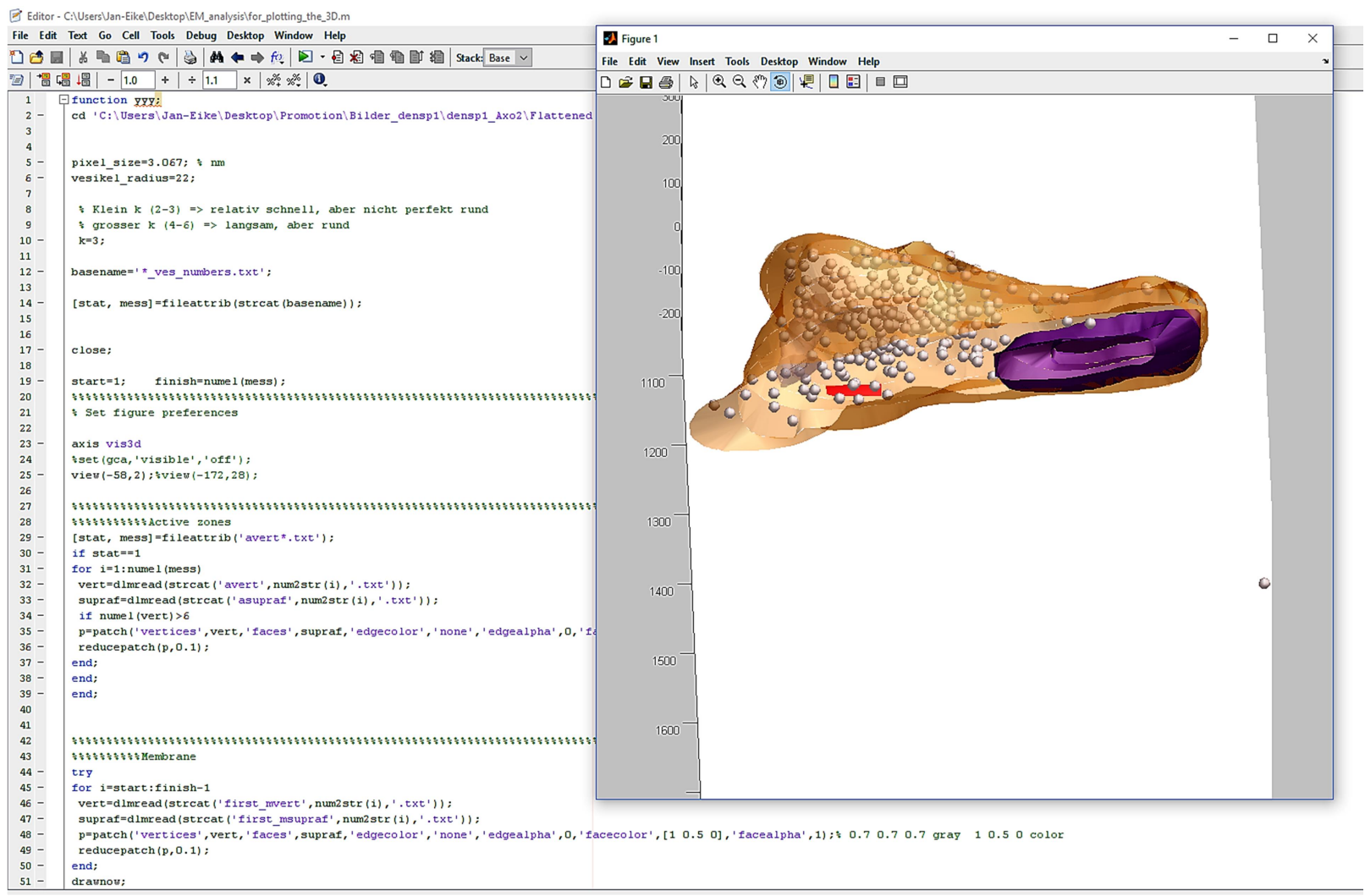

Abbildung 27: Abgebildet ist der Arbeitsschritt der dreidimensionalen Rekonstruktion des präsynaptischen Bereichs. Dargestellt sind die aktive Zone (rot), ein Mitochondrium (blauviolett) und zahlreiche Vesikel (grau). Mit Hilfe der Tools ist das Bild in allen Raumebenen frei zu rotieren und kann somit von allen Seiten betrachtet werden.

\subsection{Statistik: Korrelationskoeffizient nach Bravais-Pearson und Bonferroni-Korrektur}

Die Analyse und graphische Präsentation der erhobenen Daten erfolgte mit Hilfe des Programmes SigmaPlot 10.0.

\section{Korrelationskoeffizient nach Bravais-Pearson}

Korrelation beschreibt den Zustand, wenn zwischen zwei Variablen eine lineare Beziehung vorliegt (Harris et al. 2007). Beschrieben wird das Ausmaß der Korrelation durch den Korrelationskoeffizienten r, der Werte zwischen -1 und 1 annehmen kann. Er ist somit ein Maß für die Stärke einer Korrelation (Harris et al. 2007). In der Statistik wird zwischen einer positiven und einer negativen Korrelation unterschieden. Eine positive Korrelation 
wird dadurch gekennzeichnet, dass der Wert einer Variablen ansteigt, wenn auch der Wert der zweiten Variablen ansteigt. Bei einer negativen Korrelation nehmen die Werte beider Variablen zeitgleich ab. Die graphische Darstellung ist entweder ein von links nach rechts ansteigender Graph (positive Korrelation) beziehungsweise eine von links nach rechts abfallende Gerade (negative Korrelation). Bei einem Wert von $\mathrm{r}=1$ besteht eine perfekte positive Korrelation zweier Variablen, der Wert $\mathrm{r}=-1$ bedeutet dementsprechend eine optimale negative Korrelation, bei $\mathrm{r}=0$ liegt überhaupt keine Korrelation vor, gleichbedeutend mit einer rein zufälligen Verteilung der Punkte in einem Diagramm (Harris et al. 2007). Das bedeutet, dass die Korrelation zweier Variablen umso schwächer wird, je weiter sich der Korrelationskoeffizient $\mathrm{r}$ dem Wert 0 annähert. Mit Hilfe des Korrelationskoeffizienten nach Bravais-Pearson kann somit das Ausmaß einer linearen Beziehung bestimmt werden.

Um eine definitive, verlässliche Interpretation der Graphen zu gewährleisten, müssen diese auf ihre Signifikanz geprüft werden. Hierfür dient in vielen Fällen der p-Wert, ein Resultat eines statistischen Signifikanztests, der die Überprüfung a priori formulierter Hypothesen ermöglicht (Bender und Lange 2001). Er beschreibt die Wahrscheinlichkeit, mit der irgendeine beobachtete Differenz der Messergebnisse zweier Gruppen zufällig auftritt (Harris et al. 2007). Vor einer Datenerhebung wird daher das Signifikanzniveau $\alpha$ festgelegt, das die maximale Irrtumswahrscheinlichkeit beschreibt (Bender und Lange 2001). Ein hierfür häufig gewählter Wert ist $\alpha=0,05$, gleichbedeutend mit $5 \%$. Ist der ermittelte $\mathrm{p}$ Wert dann kleiner als das Signifikanzniveau, liegt statistische Signifikanz vor. Das bedeutet, dass die ermittelten Werte mit hoher Wahrscheinlichkeit (mehr als 95\%) nicht rein zufällig entstanden sind (Bender und Lange 2001). Im Umkehrschluss bedeuten p-Werte größer als 0,05 mangelnde Signifikanz.

\section{Bonferroni-Korrektur}

Die Bonferroni-Korrektur findet Anwendung, wenn gleiche Ausgangsdaten für mehrere statistische Signifikanztests genutzt werden. Sie hebt das Signifikanzniveau $\alpha$ für die einzelnen Testergebnisse an (Rowe und Heinisch 2012). Die Korrektur beziehungsweise das Anheben des Signifikanzniveaus wird erreicht, indem das ursprüngliche Signifikanzniveau $\alpha=0,05$ durch die Anzahl aller durchgeführten Tests dividiert wird (Victor et al. 2010) 
In dieser Arbeit wurde zu Beginn ebenfalls ein Signifikanzniveau von $\alpha=0,05$ angenommen. Da insgesamt zwölf verschiedene Testreihen durchgeführt wurden (vergleiche Kapitel 3) ergab sich folgendes Bonferroni-korrigiertes Signifikanzniveau:

$$
\alpha=0,05 / 12=0,00416666666666667
$$

Somit wurde in dieser Arbeit jedes Testergebnis mit einem p-Wert $<0,00416$ als statistisch signifikant eingestuft. P-Werte $>0,00416$ bedeuteten eine mangelnde Signifikanz des Ergebnisses. 


\section{Ergebnisse}

Durch die in Kapitel 2.2 beschriebene Verarbeitung der Daten ergaben sich die folgenden 30 dreidimensionalen Rekonstruktionen der Synapsen, die in Abbildung 28 dargestellt sind. Abbildung 29 zeigt exemplarisch zwei vergrößerte, im Detail betrachtete und beschriebene Synapsenbilder.

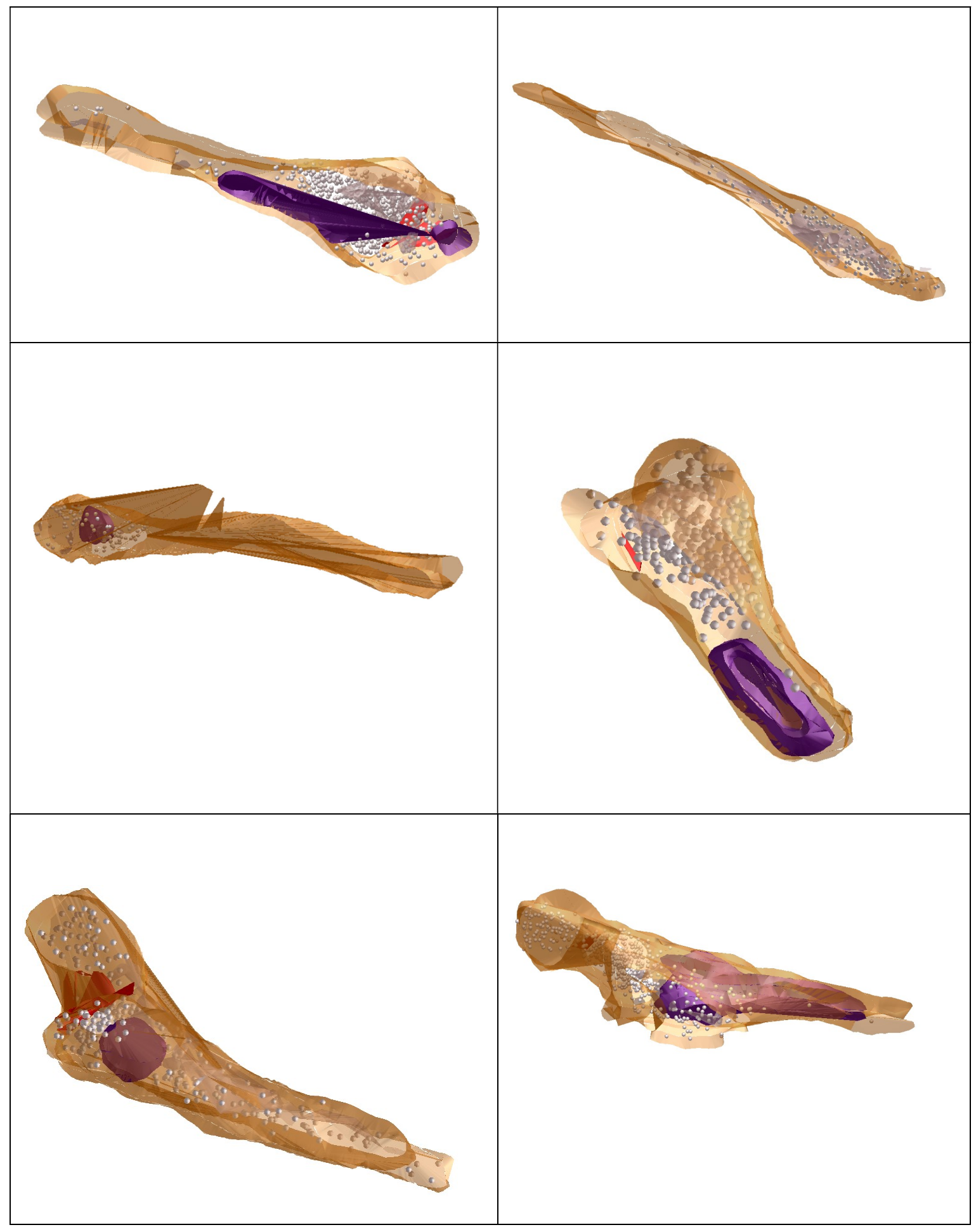




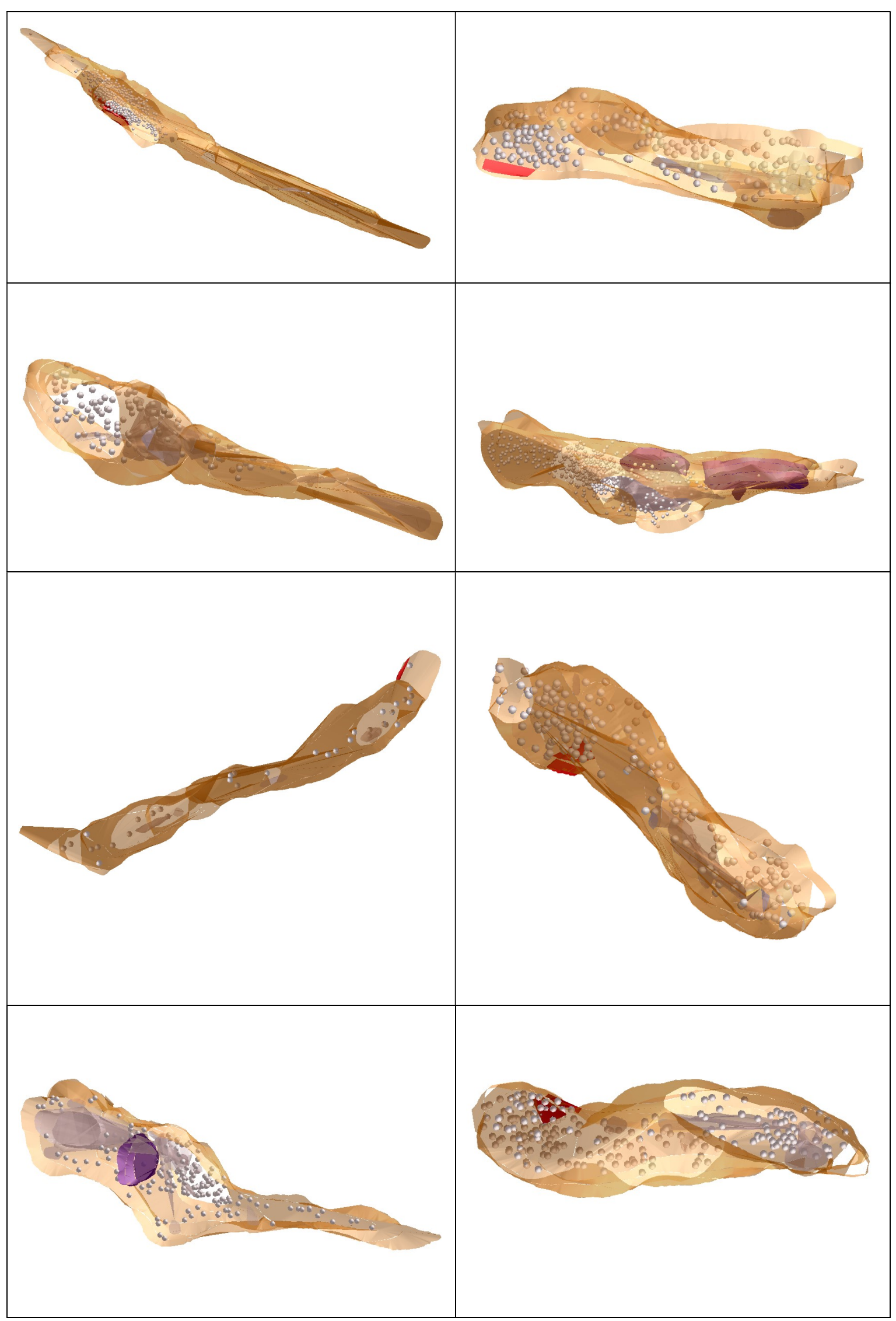




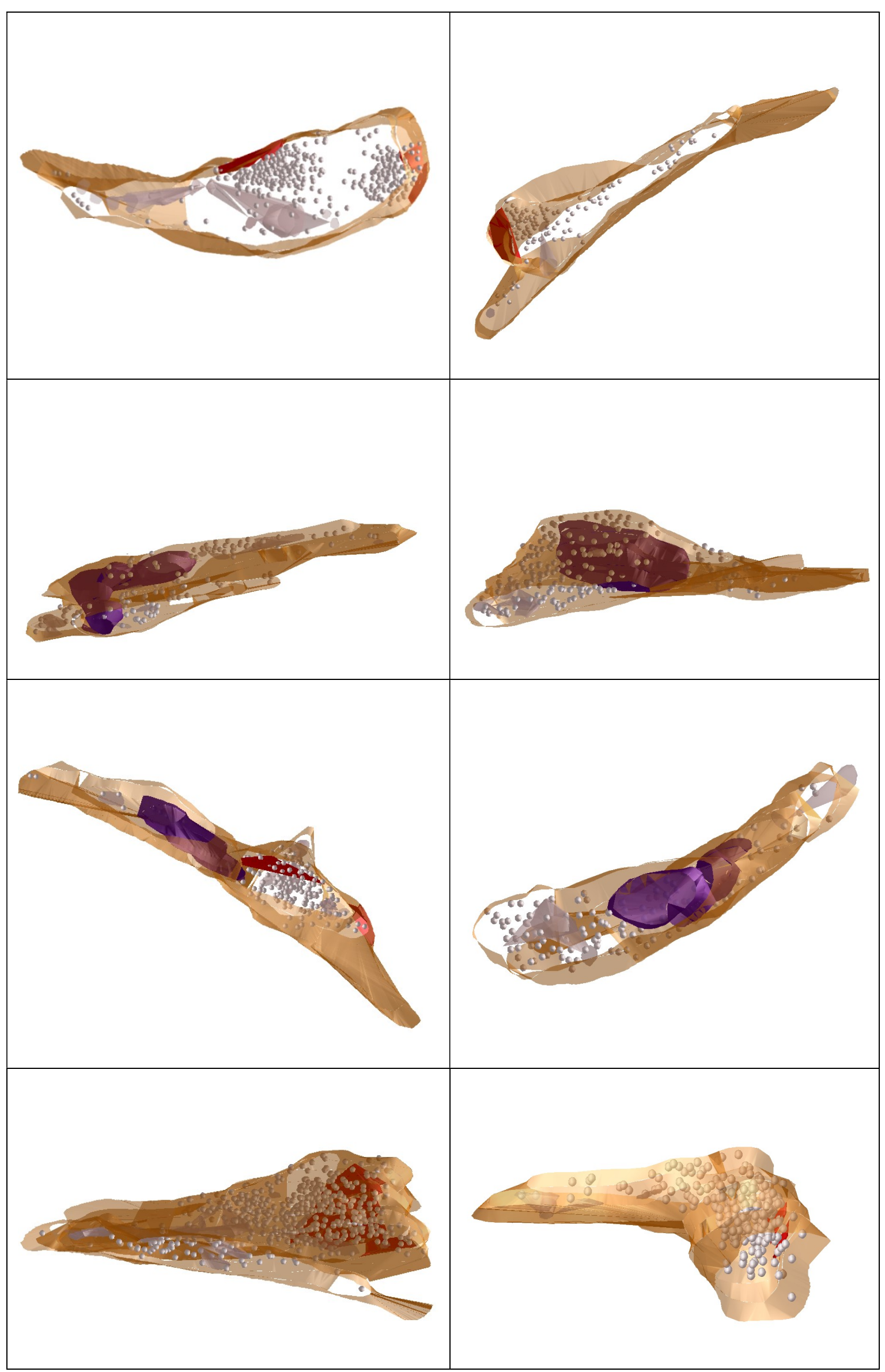




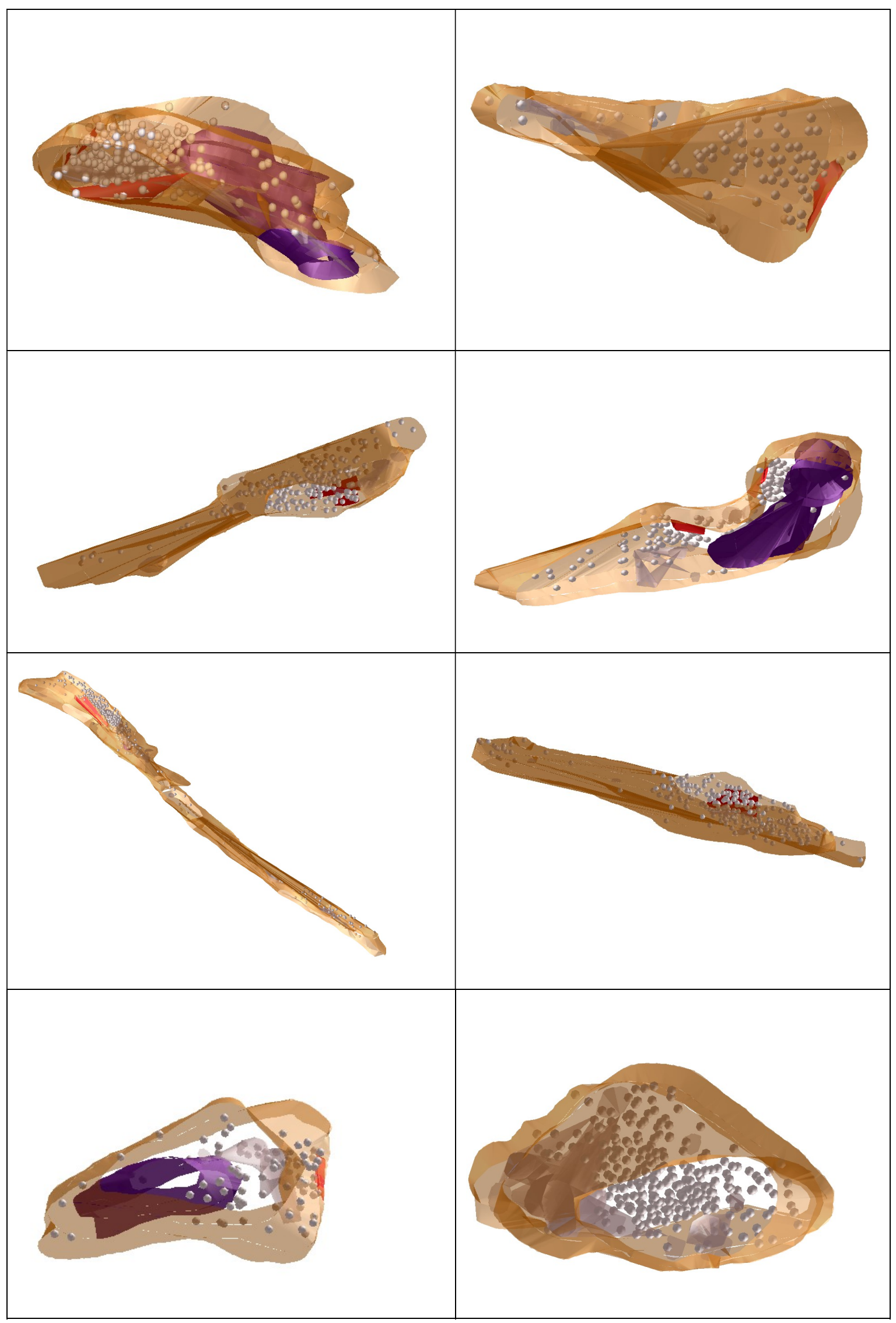

Abbildung 28: Darstellung der 30 dreidimensional rekonstruierten Synapsen. Die Größe eines Vesikels beträgt in allen Bildern einheitlich 42 Nanometer. 

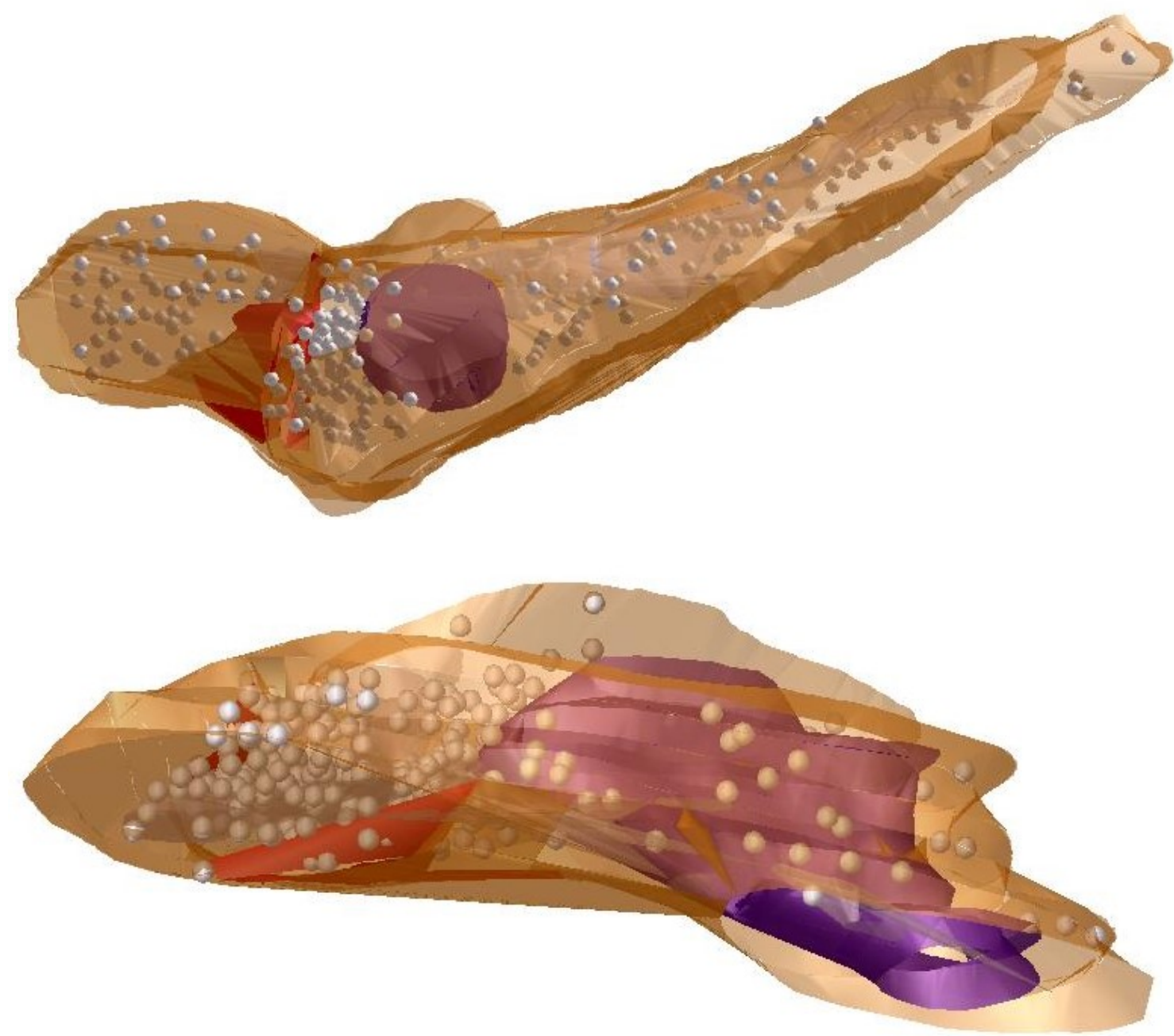

Abbildung 29: Zwei Detailbilder von dreidimensionial rekonstruierten Synapsen. Zu sehen sind die aktive Zone (rot), ein Mitochondrium (blauviolett), Vakuolen (grau) und zahlreiche Vesikel (gräulich weiß).

Die Abbildung 29 zeigt zwei mit Hilfe des Programms Matlab erstellte dreidimensionale Rekonstruktionen einer Synapse. Rot dargestellt ist der Bereich der aktiven Zone, der sich genau wie das blauviolett gefärbte Mitochondrium über mehrere Ebenen erstreckt. Die gräulich weißen Punkte markieren die präsynaptischen Vesikel. Auffällig ist eine lokale Anhäufung/Anreicherung der Vesikel im Bereich der aktiven Zone. Im Hintergrund lassen sich grau gezeichnete Vakuolen erkennen. Der Durchmesser eines Vesikels beträgt einheitlich 42 Nanometer.

Wie in Kapitel 2.3 im Rahmen der Statistikbetrachtung hergeleitet, beträgt der Wert für die Signifikanz einer Aussage nach der Bonferroni-Korrektur in dieser Arbeit $\mathrm{p}=0,0041666666666667$. Anhand dieses Wertes wurden die mit Hilfe von SigmaPlot 10.0 erstellten Statistiken bewertet. In den folgenden Kapiteln werden die Graphen und die daraus gezogenen Schlussfolgerungen dargestellt und erläutert. 


\subsection{Synapsen}

Das durchschnittliche Volumen einer Synapse liegt bei circa $0,73 \mu \mathrm{m}^{3}$. Wie in Abbildung 30 dargestellt, zeigen fünf Synapsen ein verhältnismäßig sehr großes Volumen von $\geq 1,3 \mu \mathrm{m}^{3}$. In den folgenden Kapiteln wird deutlich, dass das Synapsenvolumen in signifikanten Beziehungen zu den einzelnen Zellorganellen steht, die für die physiologische Funktion der Synapse unabdingbar sind.

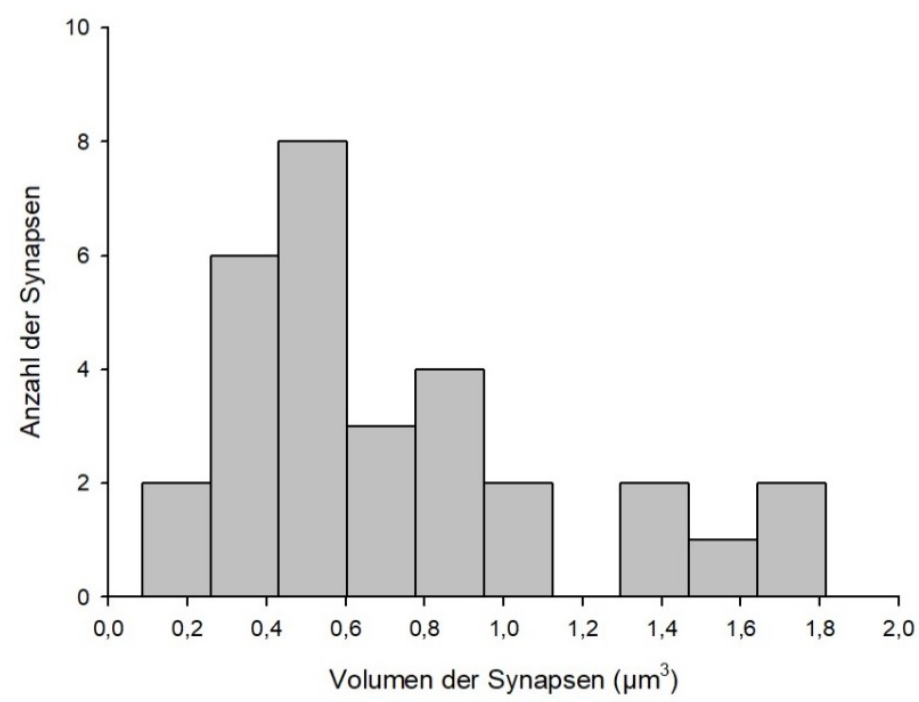

Abbildung 30: Dargestellt ist das Volumen der einzelnen Synapsen.

Aus diesen Ergebnissen lässt sich schlussfolgern, dass das Volumen einer Synapse von großer Bedeutung ist, da es zu fast allen Vergleichsparametern signifikante Beziehungen aufweist.

Die in dieser Arbeit untersuchten Synapsen besitzen im Durchschnitt jeweils 250 Vesikel (vergleiche Abbildung 31). Fünf Synapsen zeigen eine Vesikelanzahl größer als 400 Vesikel. Die Anzahl der Vesikel pro Synapse folgt annähernd einer Gauß-Verteilung. Somit ist ein rein zufälliges Auftreten dieser Ergebnisse unwahrscheinlich und daher zu erwarten, dass sie von Bedeutung für die Funktion der Synapse ist (vergleiche Abbildung 32).

Der durchschnittliche Anteil des Gesamtvolumens der Vesikel am Synapsenvolumen liegt bei ca. 1,41 \% (vergleiche Abbildung 33). Der sehr geringe Standardfehler spricht für ein konstantes Gesamtvesikelvolumen bei allen Synapsen und unterstreicht damit die Wichtigkeit der Vesikel für die Synapsenfunktion. Diese Aussage ist deckungsgleich mit den in Kapitel 3.5 aufgeführten Beobachtungen über die Bedeutung der Vesikel in einer Synapse. 


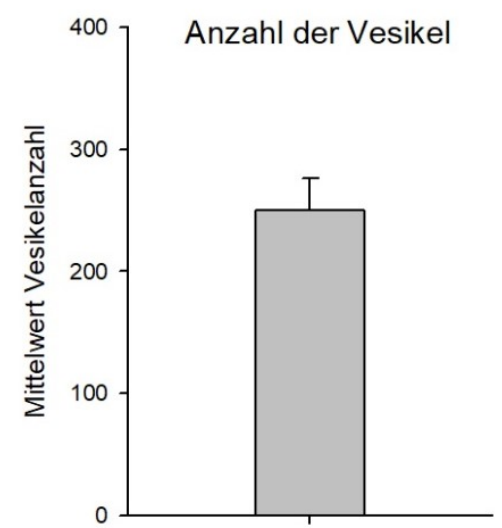

Abbildung 31: Mittelwert der Vesikelanzahl pro Synapse

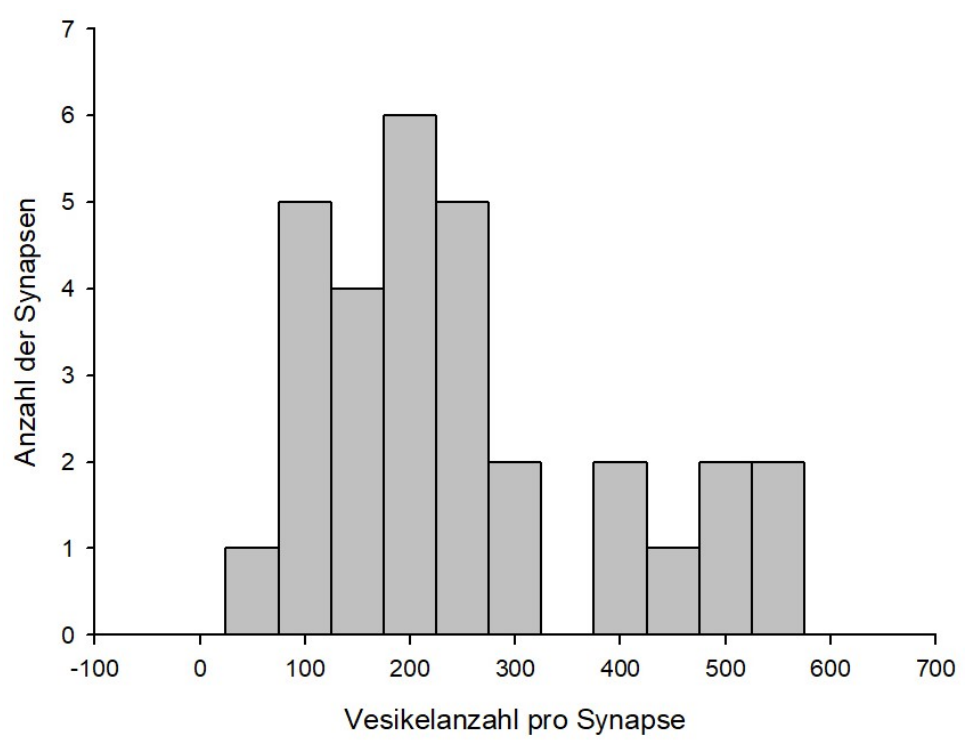

Abbildung 32: Verteilung der Vesikelanzahl pro Synapse

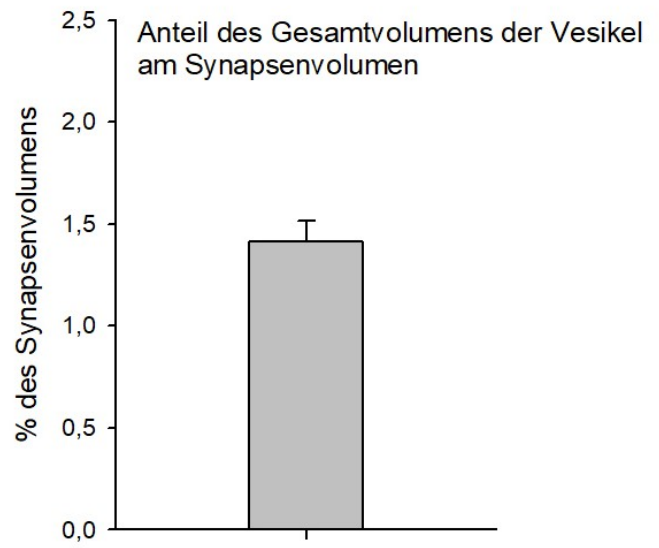

Abbildung 33: Anteil des Gesamtvolumens der Vesikel am jeweiligen Synapsenvolumen 
Die Synapsen in dieser Zellkultur besitzen im Durchschnitt circa 11,6 Vakuolen (vergleiche Abbildung 34). Der ebenfalls geringe Standardfehler kann somit als Hinweis für eine wichtige Funktion der Vakuolen für die Synapse interpretiert werden. Dem Graphen in Abbildung 35 ist zu entnehmen, dass jede Synapse mindestens zwei Vakuolen besitzt. Da somit jede Synapse Vakuolen aufweist, lässt sich deuten, dass Vakuolen einen elementaren Wert für die Funktionalität von Synapsen haben.

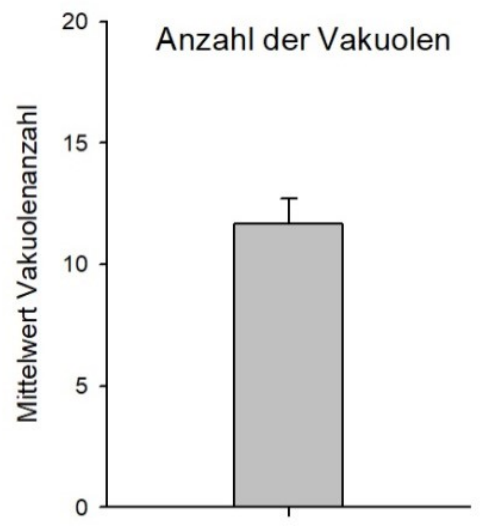

Abbildung 34: Mittelwert der Vakuolenanzahl pro Synapse

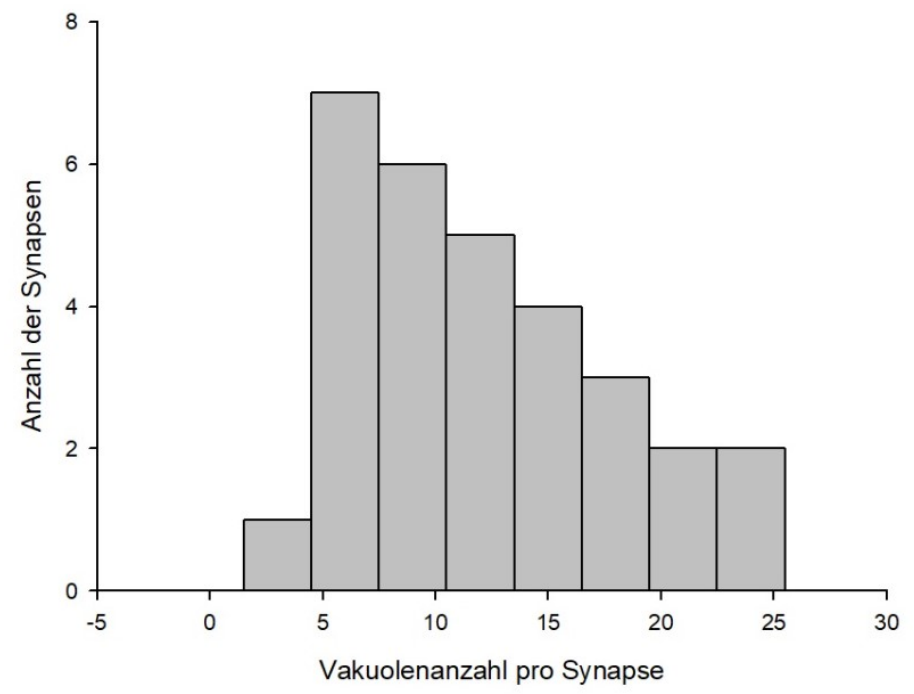

Abbildung 35: Gezeigt ist die Vakuolenanzahl pro Synapse. 


\subsection{Aktive Zone}

Die durchschnittliche Oberfläche einer aktiven Zone liegt bei circa 0,09 $\mu \mathrm{m}^{2}$ (vergleiche Abbildung 36). Ein Großteil der Synapsen zeigt aktive Zonen mit einer relativ kleinen Oberfläche. Acht Synapsen besitzen aktive Zonen mit einer Oberfläche $>0,1 \mu \mathrm{m}^{2}$. Eine Synapse zeigt eine verhältnismäßig sehr große aktive Zone mit einer Oberfläche $>0,4 \mu \mathrm{m}^{2}$. Die Oberflächengrößen der aktiven Zone weisen somit eine recht breite Streuung auf, was zu der Vermutung einer untergeordneten Bedeutung der reinen Größe der Oberfläche einer aktiven Zone führt (vergleiche Abbildung 37). Dieses war anhand der Funktion der aktiven Zone als Ort der Transmitterfreisetzung und Bereich mit einer hohen Dichte an Calciumkanälen und Andockstellen für synaptische Vesikel so nicht zu erwarten.

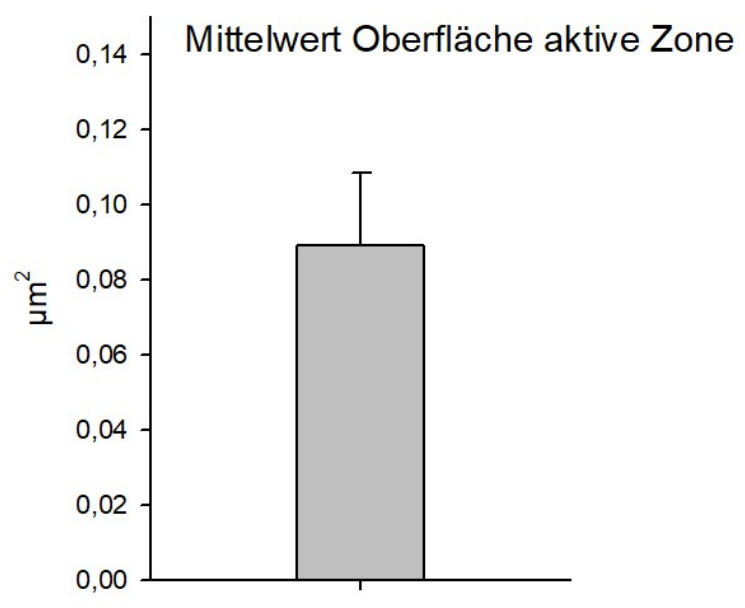

Abbildung 36: Mittelwert der Oberfläche der aktiven Zone

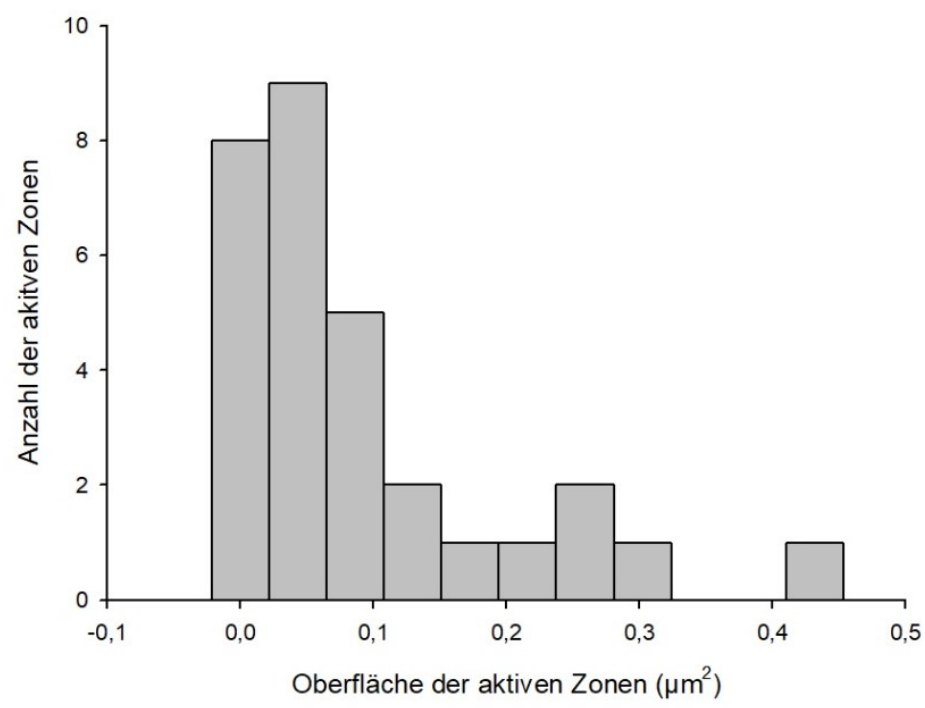

Abbildung 37: Verteilung der Oberflächengrößen der aktiven Zonen 


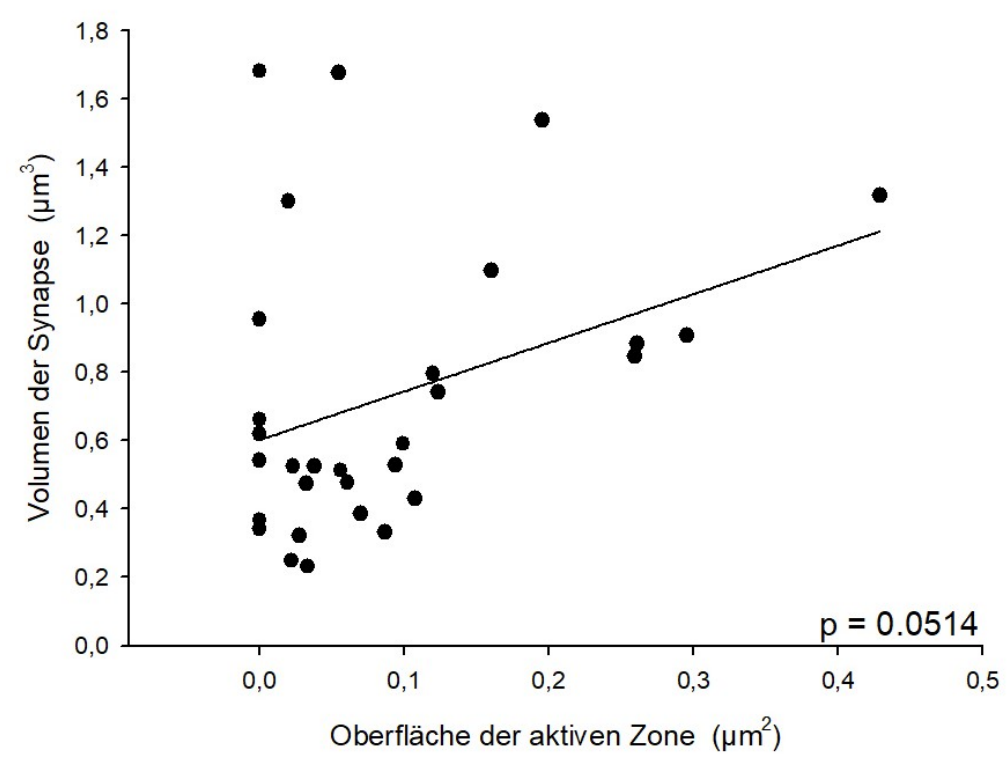

Abbildung 38: Gezeigt ist das Verhältnis vom Volumen der Synapsen zur Oberfläche der aktiven Zonen.

Das Verhältnis vom Volumen der Synapsen zur Oberfläche der aktiven Zonen zeigt keine Signifikanz (vergleiche Abbildung 38). Daraus lässt sich schlussfolgern, dass die Oberfläche der aktiven Zonen unabhängig vom Volumen der jeweiligen Synapse ist. Es wäre zu erwarten gewesen, dass die Oberflächengrößen der aktiven Zonen entsprechend der Zunahme des Gesamtsynapsenvolumens ebenfalls ansteigen.

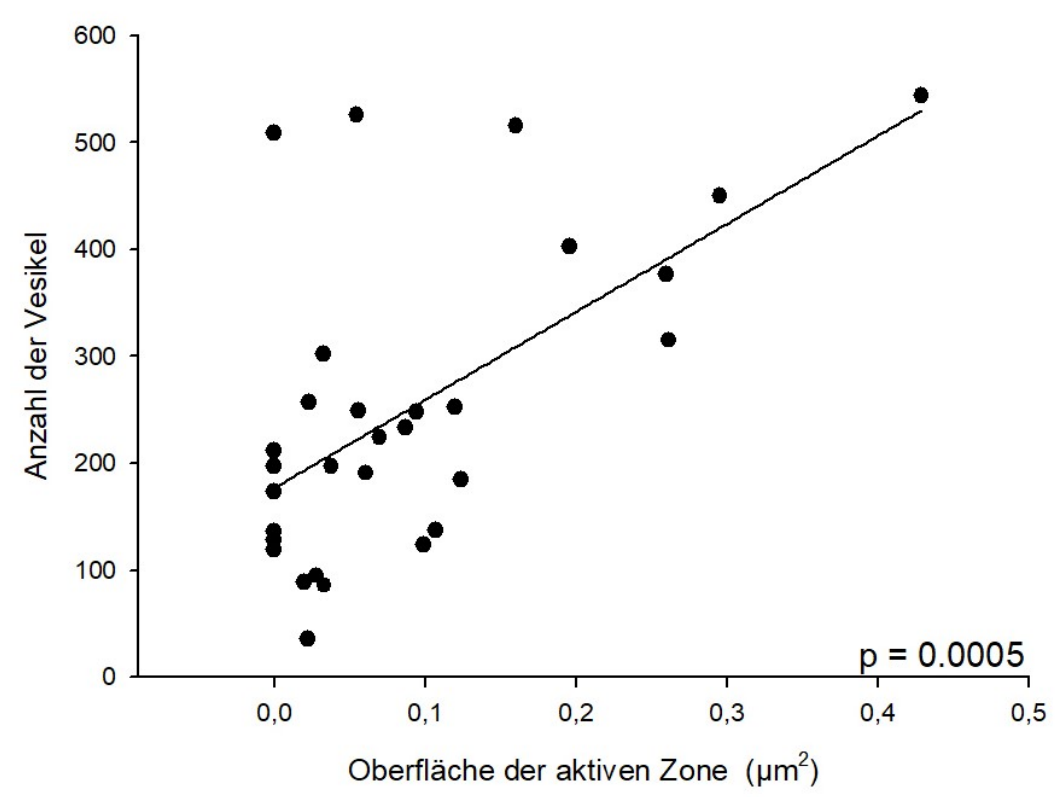

Abbildung 39: Anzahl der Vesikel im Verhältnis zur Oberfläche der aktiven Zone 
Die Anzahl der Vesikel steht hingegen in einem signifikanten Verhältnis zur Oberfläche der aktiven Zone (vergleiche Abbildung 39). Die konstante Verteilung der Vesikel unterstreicht deren Bedeutung für die Funktion der aktiven Zone und der Synapse. Bildgebend unterlegt wird diese Aussage durch die in Abbildung 29 dargestellten 3D- Rekonstruktionen der Synapsen, auf denen eine deutliche Anhäufung von Vesikeln im Bereich der aktiven Zone zu erkennen ist. Diese Beziehung ist auch dahingehend sinnvoll, als dass sich aktive Zonen, wie bereits erwähnt, als Bereiche mit einer Vielzahl von Andockstellen für synaptische Vesikel darstellen. Großen aktiven Zonen stehen somit anscheinend mehr Vesikel für die Signaltransduktion und die Vesikelrezyklierung zur Verfügung als kleinen aktiven Zonen beziehungsweise Synapsen.

Die Anzahl der Vakuolen steht in keinem signifikanten Verhältnis zur Oberfläche der aktiven Zone (vergleiche Abbildung 40). Dieses Ergebnis, also eine untergeordnete Funktion der Vakuolen für die aktive Zone, könnte somit konträr zu den Ergebnissen der Graphen in den Abbildungen 35, 43 und 44 interpretiert werden, die eine hohe Bedeutung der Vakuolen für die Synapse beziehungsweise aktive Zone demonstrieren.

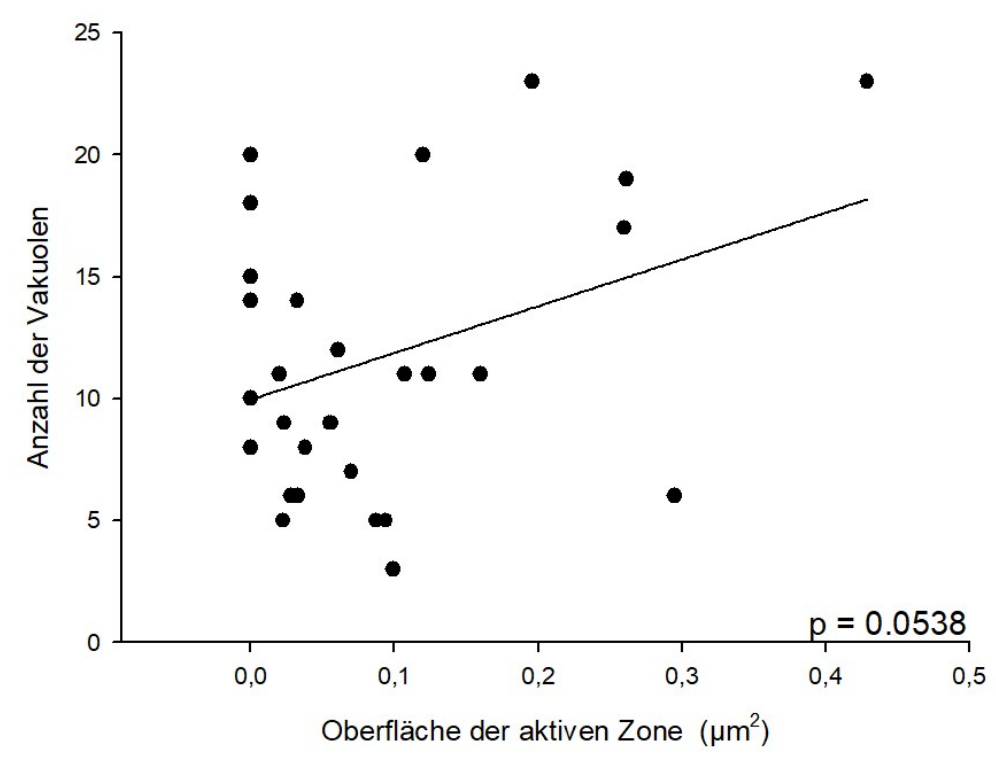

Abbildung 40: Anzahl der Vakuolen im Verhältnis zur Oberfläche der aktiven Zone

Zwischen der Größe der Oberflächen der aktiven Zonen und dem Volumen der Mitochondrien besteht keine signifikante Beziehung (vergleiche Abbildung 40). Mitochondrien scheinen somit von geringerer Bedeutung für die Funktion der aktiven Zonen zu sein. Wie auch die übrigen Beobachtungen bezüglich der untergeordneten 
Bedeutung der Mitochondrien, die in Kapitel 3.4 beschrieben sind, war dieses Resultat so nicht zu erwarten. Möglicherweise sind diese Ergebnisse jedoch nur für eine Zellkultur gültig und unterscheiden sich von denen bei In-vivo-Tests.

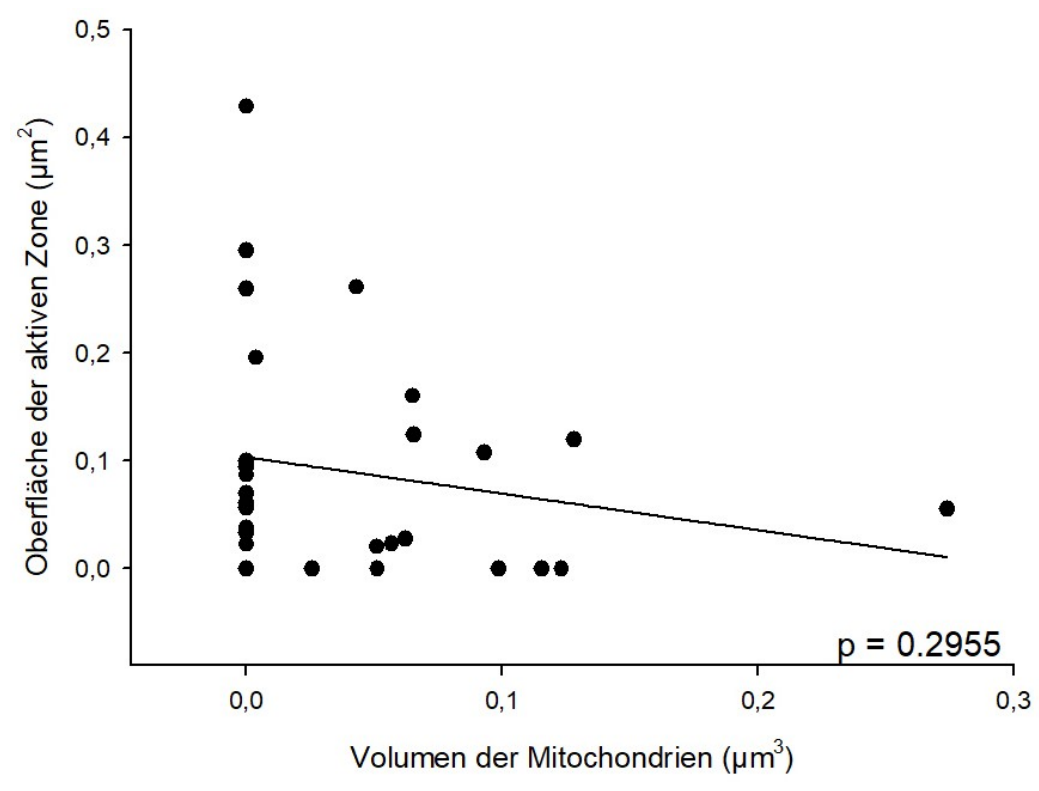

Abbildung 41: Oberfläche der aktiven Zonen im Verhältnis zum Volumen der Mitochondrien

Zusammenfassend wird deutlich, dass die Oberflächengröße der aktiven Zone, außer zu der Anzahl der Vesikel, keine weiteren signifikanten Beziehungen aufweist. Somit ist wahrscheinlich auch die recht breite Streuung der Oberflächengrößen nicht überraschend, sondern bestätigt vielmehr die zuvor aufgestellten Thesen.

\subsection{Vakuolen}

Das durchschnittliche Volumen einer Vakuole liegt bei circa $0,062 \mu \mathrm{m}^{3}$ (vergleiche Abbildung 42). Einzig eine Vakuole zeigt ein verhältnismäßig sehr großes Volumen von $>0,6 \mu \mathrm{m}^{3}$ (vergleiche Abbildung 43). Die Streuung der Vakuolenvolumina entspricht der Normal- oder Gauß-Verteilung. Somit besteht ein hohes Ausmaß einer kontinuierlichen Wahrscheinlichkeitsverteilung und berechtigt zu der Aussage, dass die Ergebnisse nicht rein zufällig entstanden sind. Daraus lässt sich eine wichtige Bedeutung der Vakuolen für eine Synapse ableiten (die in Kapitel 4 noch im Detail beschrieben wird). 


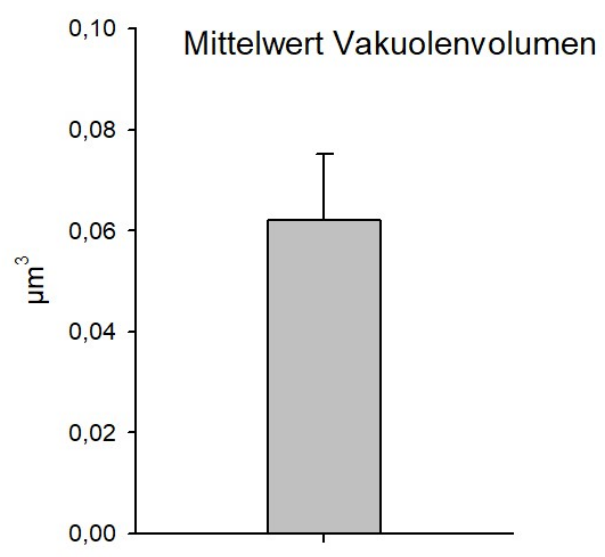

Abbildung 42: Mittelwert der Vakuolenvolumina

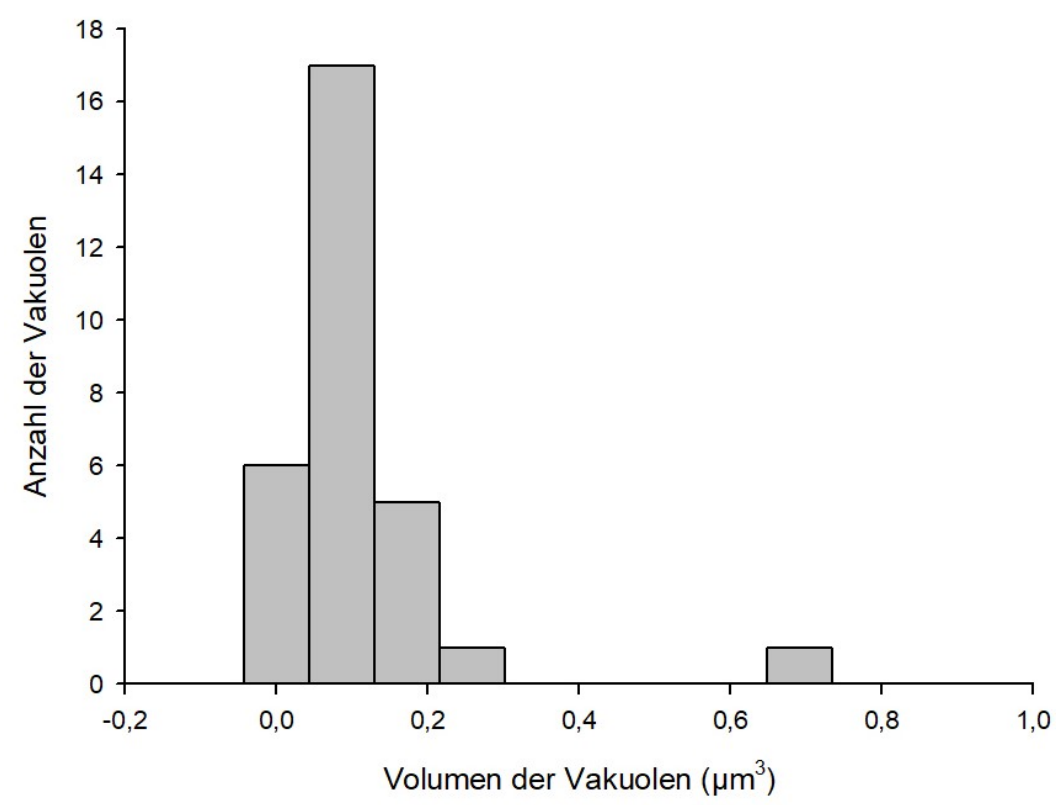

Abbildung 43: Volumenverteilung der Vakuolen

Die Anzahl der Vakuolen steht, wie aus Abbildung 44 ersichtlich, in einem signifikanten Verhältnis zum Volumen der Synapse. Somit wird die Bedeutung der Vakuolen für die Funktion der Synapse unterstrichen. Das Ergebnis dieses Graphen korreliert mit dem in Abbildung 43 dargestellten Graphen des durchschnittlichen Vakuolenvolumens und dem Diagramm in Abbildung 35, das sich auf die Anzahl der Vakuolen in den einzelnen Synapsen bezieht. Im Gegensatz dazu besteht keine signifikante Beziehung zwischen der Größe der Oberfläche einer aktiven Zone und der Vakuolenanzahl (vergleiche Abbildung 40). 


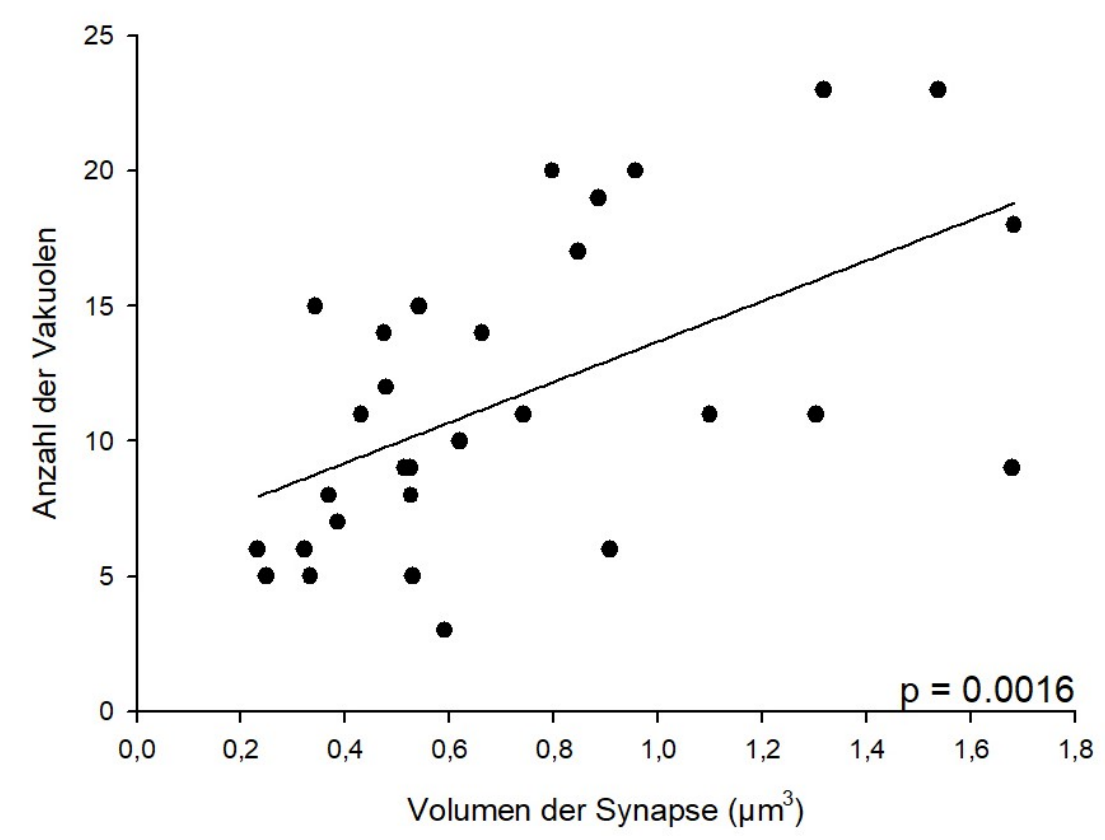

Abbildung 44: Anzahl der Vakuolen im Verhältnis zum Volumen der Synapse

Aus diesen Ergebnissen lässt sich schlussfolgern, dass das Volumen einer Synapse von großer Bedeutung ist, da es mit fast allen Vergleichsparametern signifikante Beziehungen aufweist, wohingegen die übrigen Werte, wie zum Beispiel die Oberfläche der aktiven Zone im Vergleich mit der Vakuolenanzahl, weniger Korrelation zeigen.

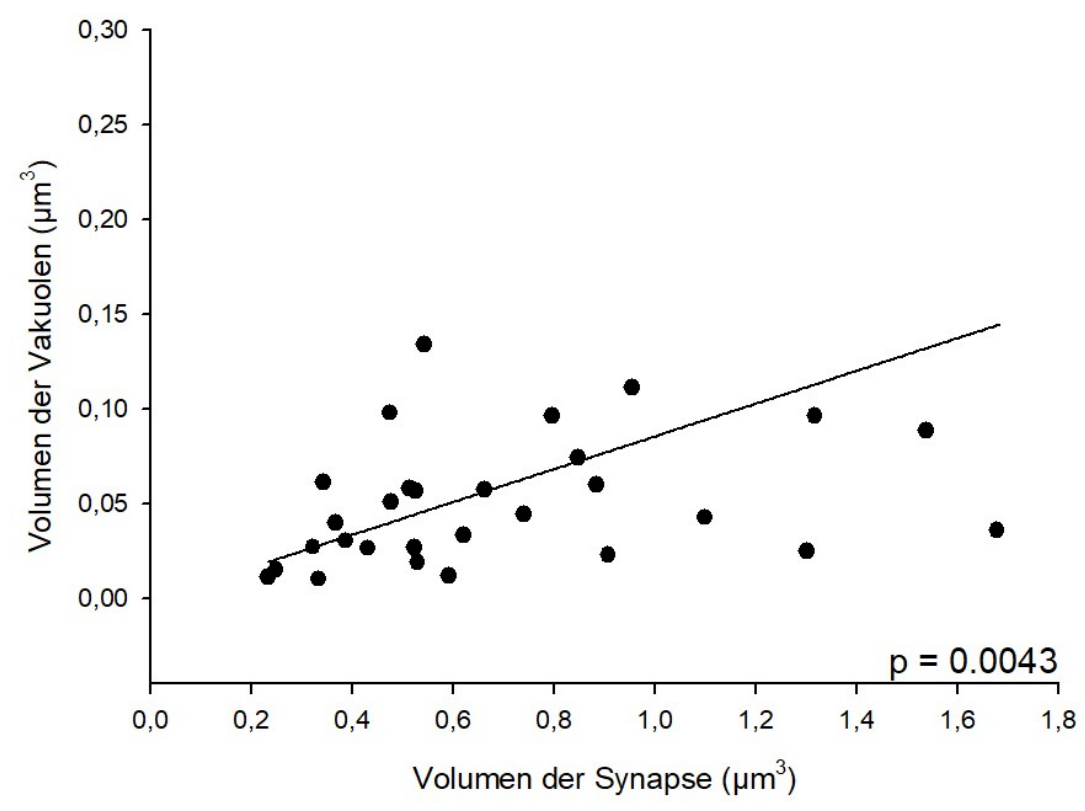

Abbildung 45: Volumen der Vakuolen im Verhältnis zum Volumen der Synapse 
Das Verhältnis des Vakuolenvolumens zum Volumen der Synapse ist grenzwertig signifikant. Im Vergleich zu dem in Abbildung 44 beschriebenen Graphen zeigt sich, dass eher die totale Anzahl der Vakuolen im Verhältnis zum Volumen der Synapse von Bedeutung ist, als das Volumen der einzelnen Vakuolen. Aus dieser Beobachtung lässt sich schlussfolgern, dass das Volumen der Vakuolen weniger wichtig für die Funktion der Synapse ist als das reine Vorhandensein von Vakuolen. Dieses Ergebnis stimmt somit auch mit der bezüglich des Graphen in Abbildung 35 aufgestellten Behauptung überein.

Zwischen der Anzahl der Vakuolen und der Anzahl der Vesikel besteht keine signifikante Beziehung (vergleiche Abbildung 46). Die große Bedeutung des jeweiligen Vorhandenseins der Vakuolen beziehungsweise der Vesikel für die Synapse konnte anhand mehrerer Tests belegt werden. Die totale Anzahl von Vesikeln im Verhältnis zur totalen Anzahl der Vakuolen scheint jedoch für die Funktion der Synapse wenig wichtig.

Die Anzahl der Vesikel steht ebenfalls in keinem signifikanten Verhältnis zum Volumen der Vakuolen (vergleiche Abbildung 47). Die Aussage dieses Graphen ist stimmig mit der Aussage des Graphen in Abbildung 46, der keine direkte Beziehung von Vesikel- und Vakuolenanzahl belegt. Die Deutung ist somit identisch.

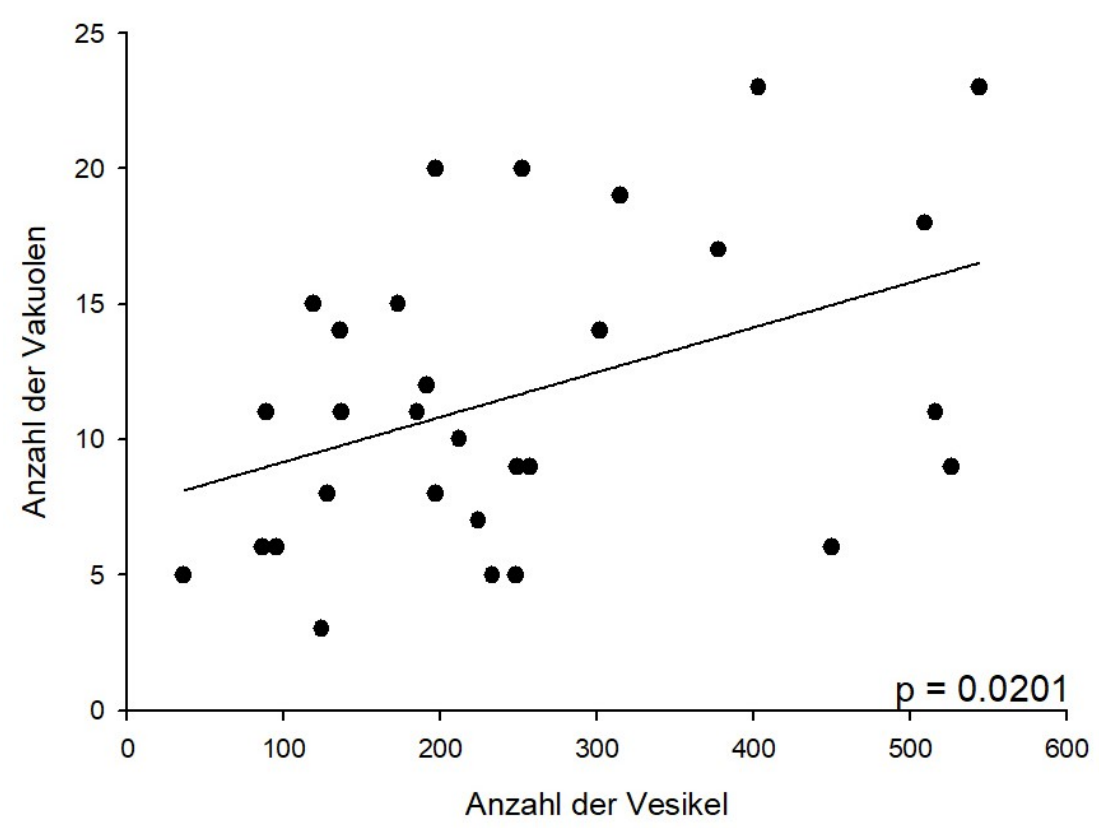

Abbildung 46: Anzahl der Vakuolen im Verhältnis zur Anzahl der Vesikel 


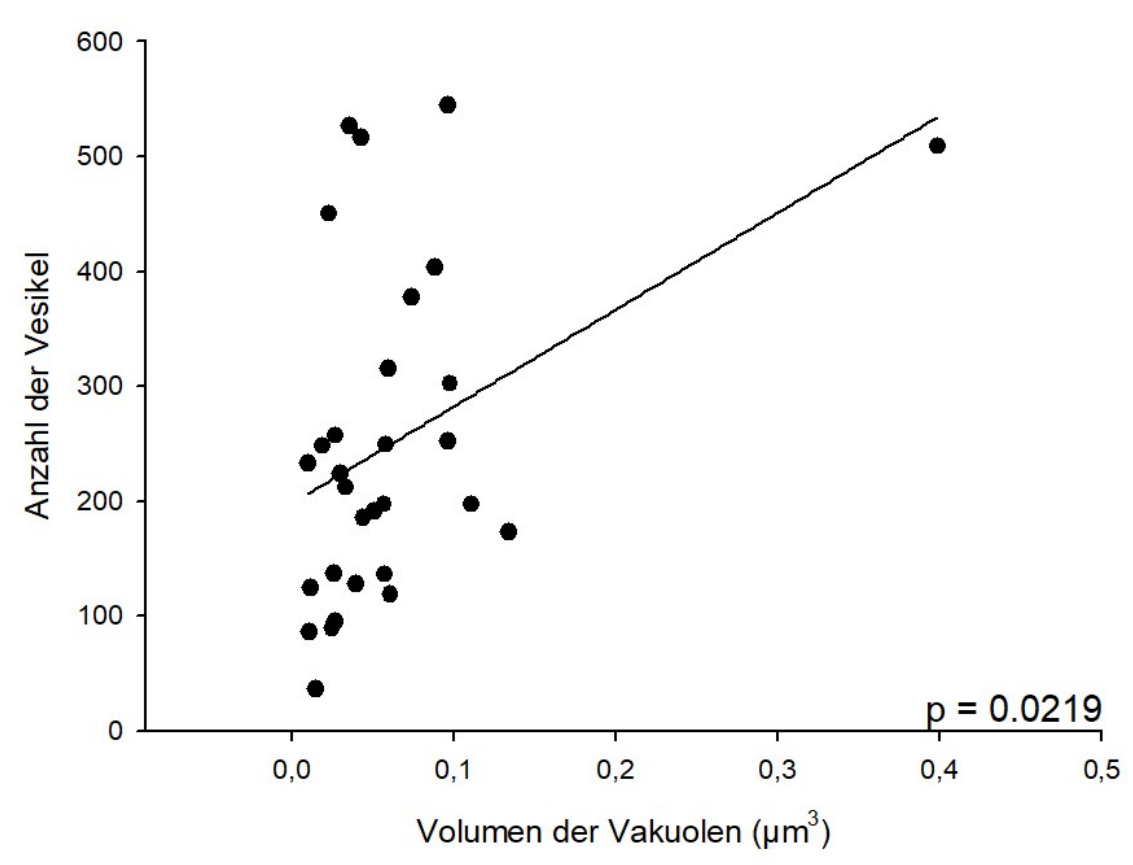

Abbildung 47: Anzahl der Vesikel im Verhältnis zum Volumen der Vakuolen

\subsection{Mitochondrien}

Das durchschnittliche Volumen eines Mitochondriums liegt bei circa $0,042 \mu \mathrm{m}^{3}$ (vergleiche Abbildung 48). Zwei Synapsen zeigen Mitochondrien mit einem Volumen $>0,1 \mu \mathrm{m}^{3}$. Das durchschnittliche Volumen der Mitochondrien ist geringer als das der Vakuolen. Dies ist angesichts des hohen Energieverbrauchs einer Synapse ein nicht unbedingt zu erwartender Wert. Die Verteilung der Mitochondrienvolumina folgt im Gegensatz zu der der Vakuolenvolumina keiner Gauß-Verteilung und entspricht somit einer mehr zufälligen Verteilung (vergleiche Abbildung 49). Dieser Fakt legt eine geringe Bedeutung der Mitochondrien für die Synapsen nahe und bedeutet, dass viele Synapsen mit wenigen oder keinen Mitochondrien überleben können - zumindest in einer Zellkultur. Dieses Ergebnis war so nicht zu erwarten, deckt sich aber mit den Werten in weiteren Statistiken zur Mitochondrienfunktion. 


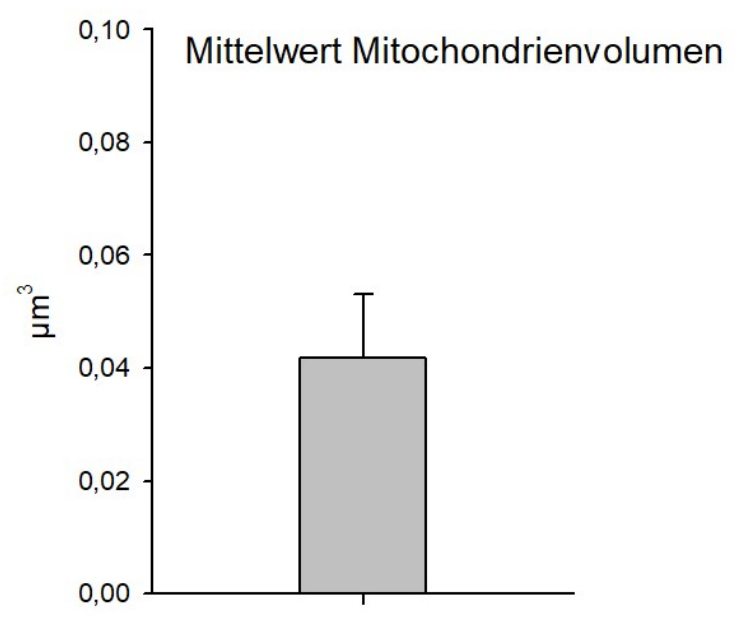

Abbildung 48: Mittelwert der Volumina der Mitochondrien

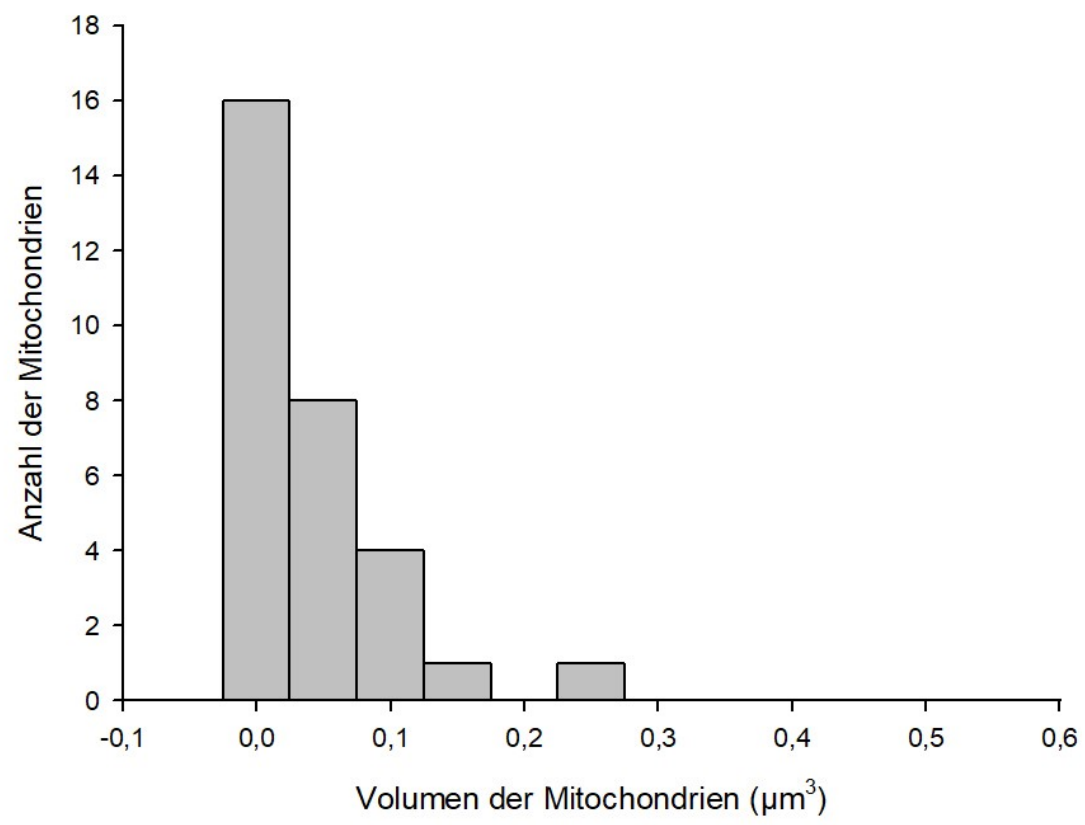

Abbildung 49: Volumina der Mitochondrien 


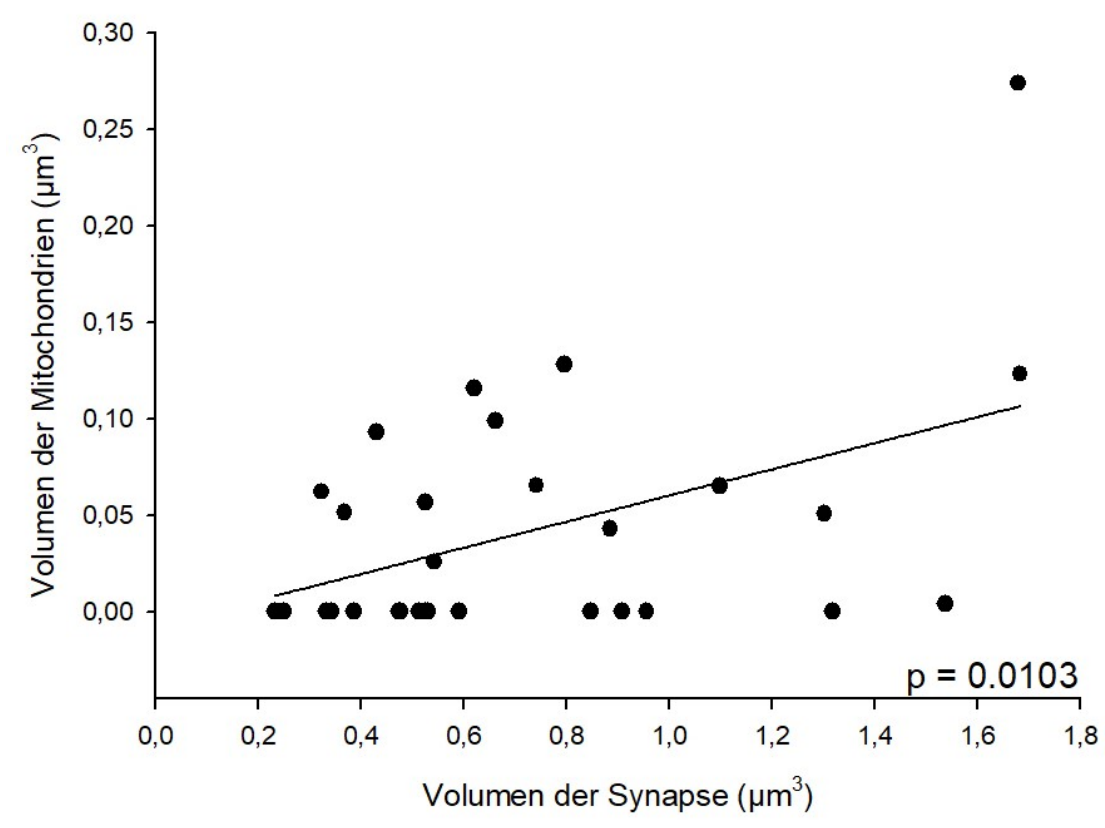

Abbildung 50: Volumen der Mitochondrien im Verhältnis zum Volumen der Synapse

Das Volumen der Mitochondrien hat keine signifikante Beziehung zu dem Volumen der Synapse (vergleiche Abbildung 50). Daraus lässt sich wiederum schlussfolgern, dass Mitochondrien nur eine untergeordnete Bedeutung für die Funktion der Synapse haben. Diese Interpretation ist somit stimmig mit den Ergebnissen des Graphen in Abbildung 49. Anhand des Energieverbrauchs einer Synapse hätte erwartet werden können, dass mit steigendem Volumen der Synapse auch das Volumen der Mitochondrien zunimmt. Die mangelnde Signifikanz ist überraschend und war so nicht zu erwarten.

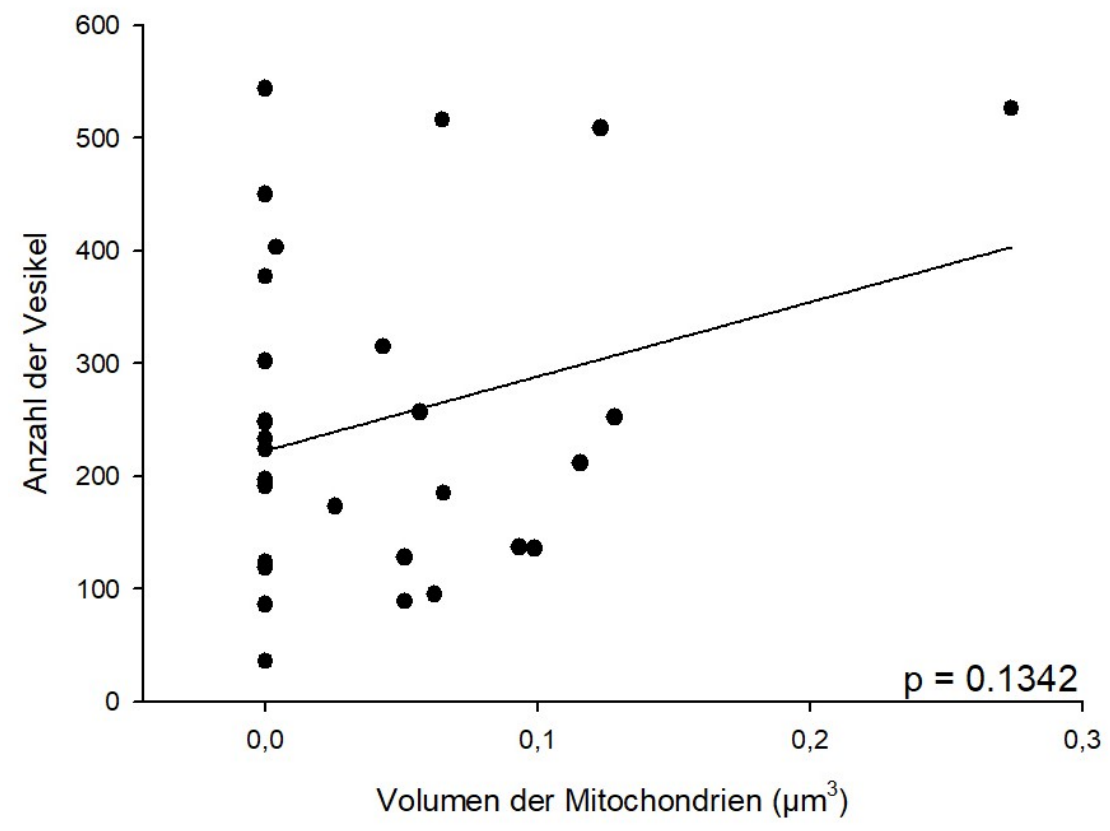

Abbildung 51: Anzahl der Vesikel im Verhältnis zum Volumen der Mitochondrien 
Das Verhältnis der Vesikelanzahl zu dem Volumen der Mitochondrien ist nicht signifikant (vergleiche Abbildung 51). Anhand mehrerer Statistiken konnte die hohe Bedeutung der Vesikel für die Synapsenfunktion gezeigt werden. Vesikel sind augenscheinlich nicht auf Mitochondrien angewiesen. Die Aussage dieses Graphen ist somit stimmig mit bisherigen Ergebnissen, die Vesikeln eine wichtige und Mitochondrien eine untergeordnete Funktion zusprechen.

\subsection{Vesikel}

Wie bereits in Kapitel 3.1 erwähnt, beträgt die durchschnittliche Vesikelanzahl pro Synapse circa 250 Vesikel (vergleiche Abbildung 31). Das durchschnittliche Gesamtvolumen der Vesikel liegt bei circa $0,0097 \mu \mathrm{m}^{3}$ und ist damit sehr klein (vergleiche Abbildung 52). Der Standardfehler ist sehr gering, was für ein konstantes Gesamtvolumen der Vesikel spricht, das 1,41\% des Gesamtvolumens der Synapse ausmacht (vergleiche Abbildung 33). Des Weiteren konnte eine signifikante Beziehung zwischen der Anzahl der Vesikel und der Oberflächengröße der aktiven Zone festgestellt werden (vergleiche Abbildung 39).

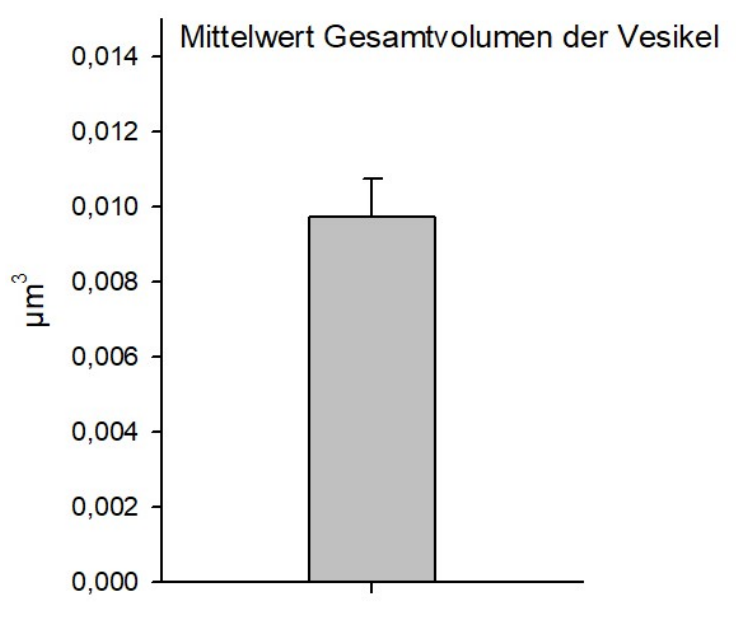

Abbildung 52: Mittelwert des Gesamtvolumens der Vesikel

Die Vesikelanzahl steht in einem signifikanten Verhältnis zum Volumen der Synapse (vergleiche Abbildung 53). Somit wird eine besondere Bedeutung der Vesikel für die Funktion der Synapse herausgestellt. Mit Zunahme des Volumens einer Synapse steigt die Anzahl der enthaltenen Vesikel. Somit stehen in großen Synapsen mehr Vesikel für die Signalübertragung bereit. Dies ist ein zu erwartendes Ergebnis und korreliert mit den weiteren Beobachtungen. 


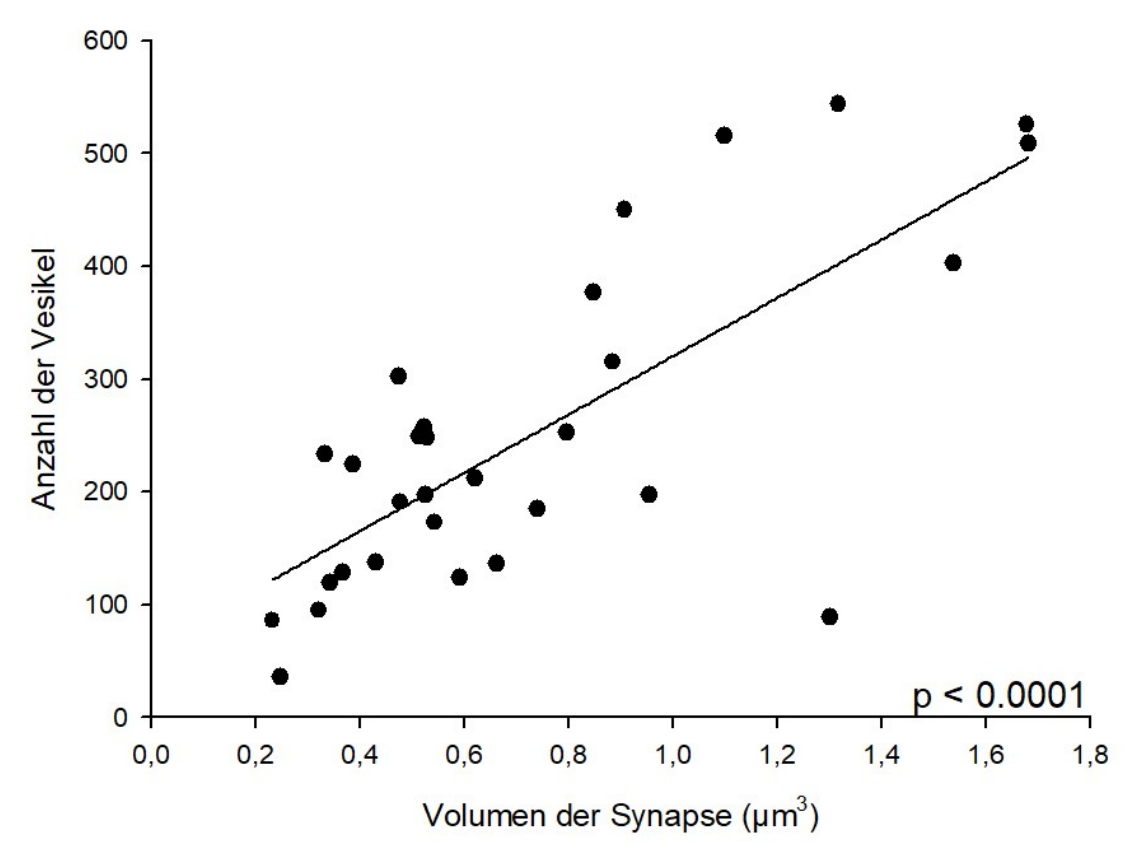

Abbildung 53: Anzahl der Vesikel im Verhältnis zum Volumen der Synapse

Das Gesamtvolumen der Vesikel steht ebenfalls in einem signifikanten Verhältnis zum Volumen der Synapse (vergleiche Abbildung 54). Da mit der Zunahme des Volumens der Synapse auch das Gesamtvolumen der Vesikel steigt, wird die besondere Bedeutung der Vesikel für die Funktionalität einer Synapse erneut belegt. Dieses Ergebnis war aufgrund der in Kapitel 1 beschriebenen Abläufe der Signalübertragung an chemischen Synapsen so zu erwarten.

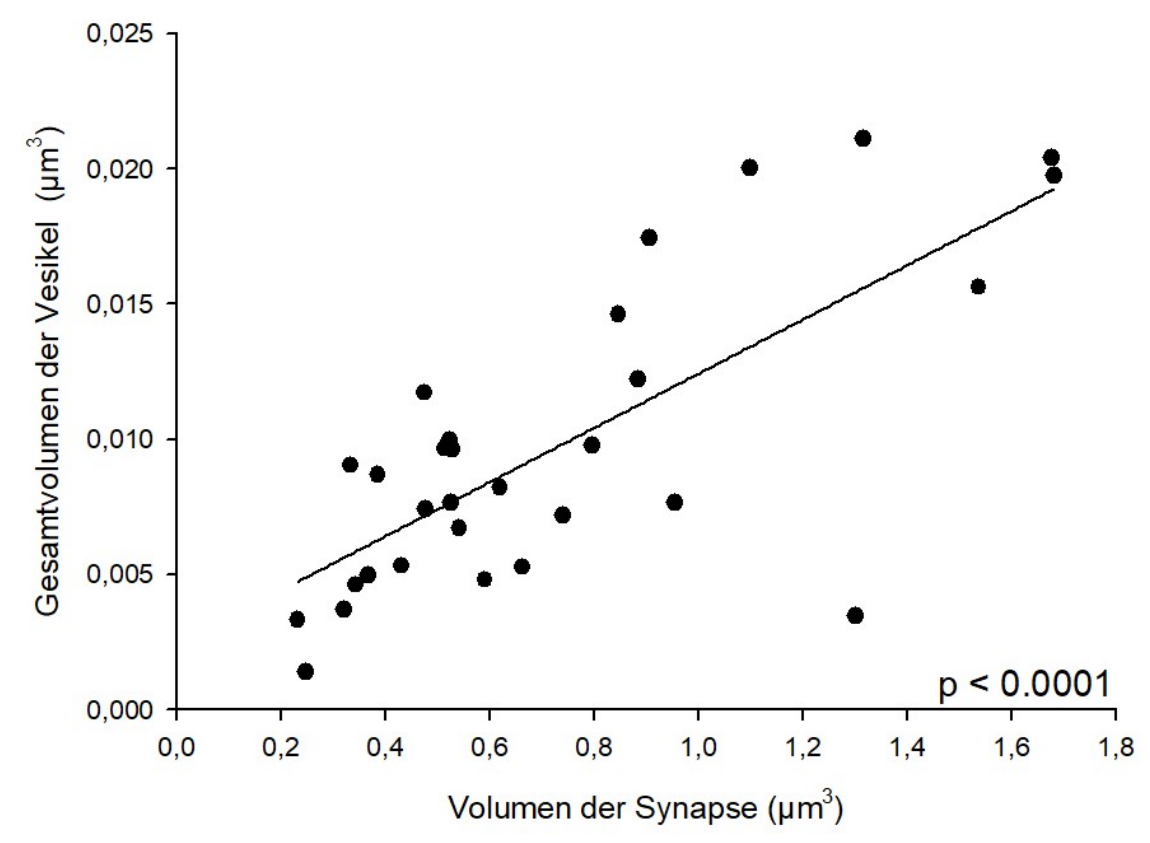

Abbildung 54: Gesamtvolumen der Vesikel im Verhältnis zum Volumen der Synapse 


\section{Diskussion}

Grundlage und Antrieb für die vorliegende Arbeit waren der Wunsch nach einem präziseren Verständnis bezüglich des Aufbaus und der Funktion chemischer Synapsen. Als Untersuchungsgrundlage dienten neuronale Zellkulturen aus dem Hippocampus, die nach ihrer Fixation und Präparation (vergleiche Kapitel 2) ausgewertet wurden. Zu Beginn erfolgte die Identifikation der chemischen Synapse auf den verschiedenen Serien der elektronenmikroskopischen Schnittbilder. Das Ziel dabei war es, Synapsen zu finden, die über möglichst viele Ebenen von Schnittbildern zu erkennen waren, um auf diese Weise ein besseres Verständnis ihrer räumlichen Ausdehnung zu erhalten und eine dreidimensionale Rekonstruktion $\mathrm{zu}$ ermöglichen. Insgesamt konnten 30 Synapsen identifiziert und ausgewertet werden. Im Anschluss daran wurden die Schnittbilder der einzelnen Ebenen mit Hilfe von Adobe Photoshop CS6 justiert und exakt übereinandergelegt.

Die so entstandenen Bilddateien wurden zur weiteren Bearbeitung und Auswertung in das Programm MatLab übernommen. Es folgte die Markierung der aktiven Zonen, der Vakuolen, der Vesikel, der Mitochondrien und der Zellmembran der präsynaptischen Endigung in den verschiedenen Ebenen. Das von Herrn Professor Silvio O. Rizzoli programmierte Tool ermöglichte dann eine dreidimensionale Rekonstruktion der 30 Synapsen, die in Abbildung 28 dargestellt sind. Des Weiteren konnten die Daten der einzelnen Organellen in das Programm SigmaPlot 10.0 übernommen werden, um so eine statistische Auswertung der Ergebnisse vorzunehmen. Somit war es möglich, Rückschlüsse sowohl auf die räumliche als auch auf die numerische Verteilung der einzelnen Zellorganellen zu ziehen, die in Kapitel 3 beschrieben sind und in diesem Kapitel in den Kontext bisheriger Forschungsergebnisse gesetzt werden.

\section{Synapsen}

Das durchschnittliche Volumen der von mir untersuchten Synapsen liegt bei circa $0,73 \mu \mathrm{m}^{3}$. Im Rahmen der statistischen Auswertung wurde deutlich, dass das Synapsenvolumen in signifikanten Beziehungen zu fast allen Zellorganellen steht, die für ihre physiologische Funktion unabdingbar sind. Daher erfolgte die Schlussfolgerung, dass das Volumen einer Synapse von großer Bedeutung für ihre Funktion ist und die Anzahl der jeweiligen Zellorganellen der Größe des Synapsenvolumens folgt.

Aus diesen Ergebnissen lässt sich schlussfolgern, dass das Volumen einer Synapse von großer Bedeutung ist, da es mit fast allen Vergleichsparametern signifikante Beziehungen 
aufweist, wohingegen die übrigen Werte, wie zum Beispiel die Oberfläche der aktiven Zone im Vergleich mit der Vakuolenanzahl, untereinander weniger Korrelation zeigen.

Die 30 betrachteten Synapsen besitzen im Durchschnitt jeweils 250 Vesikel. Die Anzahl der Vesikel pro Synapse folgt annähernd einer Gauß-Verteilung. Die somit nicht rein zufällige Verteilung der Vesikelanzahl unterstreicht die zuvor aufgestellte These, dass die einzelnen Zellorganellen in der Häufigkeit ihres Auftretens dem Synapsenvolumen angepasst sind. Größere Synapsen besitzen daher eine höhere Anzahl an Vesikeln und auch an Vakuolen (siehe unten).

Der durchschnittliche Anteil des Gesamtvolumens der Vesikel am Synapsenvolumen liegt bei circa 1,41\%. Ein sehr geringer Standardfehler bei dieser Auswertung spricht für ein konstantes Gesamtvesikelvolumen bei allen Synapsen und ist somit übereinstimmend mit den zuvor getroffenen Aussagen: größere Synapse korrelieren mit einem größeren Gesamtvolumen der Vesikel.

Die Synapsen in dieser Zellkultur besitzen im Durchschnitt circa 11,6 Vakuolen. Der ebenfalls geringe Standardfehler kann entsprechend als Hinweis auf eine wichtige Funktion der Vakuolen für die Synapse interpretiert werden. Dass jede Synapse mindestens zwei Vakuolen besitzt, lässt den elementaren Wert der Vakuole für die Funktionalität der Synapse erahnen und wird im Fortlauf dieses Kapitels noch weiter beschrieben und gedeutet.

\section{Aktive Zonen}

Die durchschnittliche Oberfläche einer aktiven Zone liegt bei circa 0,09 $\mu^{2}$. Diese Beobachtung ist nahezu deckungsgleich mit den Ergebnissen von Schikorski und Stevens aus dem Jahr 1999 (vergleiche Kapitel 1.2). Die durchschnittliche Oberflächengröße der aktiven Zone betrug bei ihnen $0,095 \mu \mathrm{m}^{2}$ und überschritt nur in Ausnahmen die Größe von $0,4 \mu \mathrm{m}^{2}$. In ihrem 1997 veröffentlichen Artikel waren die Flächen mit durchschnittlich $0,027 \mu \mathrm{m}^{2}$ hingegen kleiner.

Die Oberflächengrößen der aktiven Zone weisen in meiner Arbeit eine recht breite Streuung auf, was zu der Vermutung einer untergeordneten Bedeutung der reinen Größe der Oberfläche einer aktiven Zone führte. Diese breite Verteilung der Oberflächengrößen wurde ebenfalls von Schikorski und Stevens beschrieben. Allerdings standen die Flächen der aktiven Zonen, trotz teils erheblicher Varianz ihrer Größe, stets in einer linearen Beziehung zu dem Volumen ,ihrer“ Synapse. In der vorliegenden Arbeit weist das Verhältnis des Synapsenvolumens im Vergleich zur Größe der Oberfläche der aktiven 
Zone keine Signifikanz auf. Mit Bezug auf die bisherigen Erkenntnisse wäre zu erwarten gewesen, dass größere Synapsen, die eine höhere Anzahl an Zellorganellen besitzen, auch eine größere aktive Zone haben, da diese ja bekanntlich als Andockstelle der synaptischen Vesikel und Ort der Transmitterfreisetzung dient. Im Gegensatz dazu beschrieben Schikorski und Stevens bei ihren Messungen eine signifikante Beziehung zwischen der Oberflächengröße der aktiven Zone und dem Gesamtsynapsenvolumen. Große Synapsen schienen in ihrer Arbeit allerdings dazu zu neigen, eher mehrere aktive Zonen auszubilden, anstatt das erwähnte „Flächenlimit“"von $0,4 \mu \mathrm{m}^{2}$ zu überschreiten.

In Bezug auf das Verhältnis der Oberflächengröße der aktiven Zone im Vergleich zur Anzahl der Vesikel ist die Signifikanz gegeben und auch auf den dreidimensionalen Rekonstruktionen bildlich dargestellt (vergleiche Abbildung 28 und 29). Die räumliche Nähe der synaptischen Vesikel zur aktiven Zone ist eindeutig zu erkennen. Großen aktiven Zonen stehen somit mehr Vesikel für die Signaltransduktion und die Vesikelrezyklierung zur Verfügung als kleinen aktiven Zonen beziehungsweise Synapsen.

Diese Erkenntnisse sind deckungsgleich mit den Beobachtungen von Schikorski und Stevens. Im Durchschnitt waren bei ihnen 10,3 Vesikel an eine der 79 untersuchten aktiven Zonen gebunden. Das Minimum waren zwei, das Maximum 27 angedockte Vesikel. Obwohl die Fläche der aktiven Zone und auch die Menge der Vesikel, die an einer aktiven Zone lagen, sehr unterschiedlich waren, bestand immer eine starke Korrelation dieser beiden Größen an der jeweiligen Synapse. Die Position, an der die Vesikel an die aktive Zone gebunden sind, schien ihrer Meinung nach hingegen zufällig zu sein. Ein Problem bezüglich dieser Beobachtung entstand dadurch, dass es keine präzise Definition „gebundener Vesikel“ im elektronenmikroskopischen Bild gibt. Daher wurde als Kriterium eine enge Lagebeziehung der Vesikel und der Plasmamembran zur Identifikation „gebundener Vesikel“ verwendet. Eine Untersuchung der an der aktiven Zone gebundenen Vesikel ist in meiner Arbeit nicht erfolgt, die dreidimensionalen Rekonstruktionen (vergleiche Abbildungen 28 und 29) geben jedoch hinreichend Grund zu der Annahme, dass tatsächlich eine enge räumliche Nähe zwischen den Vesikeln und der aktiven Zone besteht, was in Betracht der physiologischen Funktion auch zu erwarten war.

Die Anzahl der Vakuolen steht in keinem signifikanten Verhältnis zur Oberfläche der aktiven Zone. Die Vakuolen scheinen somit für die aktive Zone von geringerer Bedeutung zu sein. Die Bedeutung der Vakuolen für das „Gesamtsystem“ Synapse ist jedoch hinreichend belegt und wird zu einem späteren Zeitpunkt gedeutet.

Zwischen der Größe der Oberflächen der aktiven Zonen und dem Volumen der 
Mitochondrien besteht keine signifikante Beziehung, mit der Einschränkung, dass diese Ergebnisse jedoch nur für eine Zellkultur gültig sind und sich gegebenenfalls von Resultaten bei In-vivo-Tests unterscheiden können.

Zusammenfassend besteht also ausschließlich eine signifikante Beziehung zwischen der Oberflächengröße der aktiven Zone und der Vesikelanzahl. Dies ist eine Erkenntnis, die so nicht unbedingt zu erwarten war, da aufgrund des hohen Energieverbrauchs im Bereich der präsynaptischen Endigung zumindest eine Verknüpfung mit dem Mitochondrienvolumen zu vermuten gewesen wäre (siehe unten Abschnitt „Mitochondrien“).

\section{Vakuolen}

Das durchschnittliche Volumen einer Vakuole liegt bei circa 0,062 $\mu \mathrm{m}^{3}$. Die Streuung der Vakuolenvolumina entspricht der Normal- oder Gauß-Verteilung. Daraus lässt sich, wie in Kapitel 3.3 beschrieben, eine große Bedeutung der Vakuolen für eine Synapse ableiten. Da ebenfalls ein signifikantes Verhältnis zwischen Synapsenvolumen und Vakuolenanzahl besteht, wird diese Aussage unterstützt.

Das Verhältnis des Vakuolenvolumens zum Volumen der Synapse ist grenzwertig signifikant. Da, wie bereits beschrieben, jede Synapse mindestens zwei Vakuolen besitzt, scheint eher die totale Anzahl der Vakuolen im Verhältnis zum Volumen der Synapse von Bedeutung zu sein als das jeweilige Volumen der einzelnen Vakuolen.

Sowohl zwischen der Anzahl als auch zwischen dem Volumen der Vakuolen und der Anzahl der Vesikel bestehen keine signifikanten Beziehungen. Wie mehrere Statistiken belegen, sind die beiden Partner für sich genommen jedoch von elementarer Bedeutung für die Funktion der Synapse. Das Verhältnis untereinander scheint hingegen keinen Einfluss auf das Gesamtsystem Synapse zu haben.

Zu klären ist die Frage, was die Vakuolen überhaupt darstellen und welche Funktion sie in der Synapse und der Signalweiterleitung haben. Die Bezeichnung „Vakuole“ ist tendenziell eher eine strukturelle Beschreibung von Zellorganellen, die im elektronenmikroskopischen Bild zu sehen sind. Sie präsentieren sich in ihrem Aussehen ähnlich den Vesikeln, sind jedoch deutlich größer. Höchstwahrscheinlich ist die anatomische Struktur der Vakuole mit der von präsynaptischen Endosomen gleichzusetzen, die wiederum über ihre physiologische Funktion definiert werden. Eine mögliche Definition lautet: „Endosomen sind vakuoläre Zellorganellen, die ein durch Endozytose aufgenommener Stoff durchläuft“ (Lüllmann-Rauch und Paulsen 2012). 
Hier liegt jedoch die Schwierigkeit, die die neurowissenschaftliche Forschung seit Jahren beschäftigt, denn nach wie vor wird die Funktion von Endosomen und endosomähnlichen Strukturen im Bereich der Präsynapse kontrovers diskutiert (Jähne et al. 2015). Das Problem ist, dass es weder einen Konsens bezüglich einer allgemeingültigen Definition endosomaler Strukturen im präsynaptischen Bereich gibt noch bisher eindeutige Marker zur Identifikation dieser Zellorganellen zur Verfügung stehen (Jähne et al. 2015). Somit fällt es schwer, Rückschlüsse auf die physiologische Funktion während der Signalverarbeitung und der Vesikelrezyklierung zu ziehen.

Bereits 1973 entdeckten Heuser und Reese bei der Untersuchung neuromuskulärer Synapsen des Frosches Strukturen, die der Form von Endosomen ähnlich waren (Heuser und Reese 1973). Diese bildeten sich nach einem starken elektronischen Stimulus im Bereich der Zellmembran aus. Ihr Ergebnis wurde jedoch schon im selben Jahr durch Beobachtungen von Ceccarelli und Kollegen angefochten, die bei ähnlichen Versuchen, jedoch mit physiologischen Stimuli, keine Ausbildung derartiger Strukturen erkennen konnten (Ceccarelli et al. 1973). Nachfolgende Untersuchungen sowohl von Gad und Kollegen als auch von Gennaro und Kollegen legen nahe, dass die von Heuser und Reese als endosomähnliche Strukturen beschriebenen Zellorganellen höchstwahrscheinlich Einstülpungen der Plasmamembran und keine Endosomen waren (Gennaro et al. 1978; Gad et al. 1998).

Somit war nach wie vor ungeklärt, ob und in welchem Ausmaß Endosomen oder endosomähnliche Strukturen überhaupt an dem Prozess der Vesikelrezyklierung beteiligt sind. Rizzoli schlussfolgert daher, dass das synaptische Endosom eine der am wenigsten verstandenen Zellorganellen ist (Rizzoli 2014a). In seinem Artikel beschreibt er, dass die frisch „enthüllten“ Vesikel nach der Endozytose nicht untereinander fusionieren, gegebenenfalls aber eine Fusion mit den Endosomen eingehen, woran sich dann ein Sortierungsprozess innerhalb der Endosomen und schließlich die Abspaltung von diesen anschließt (Rizzoli 2014a).

Abbildung 55 zeigt die Position und mögliche Funktion der Endosomen und endosomähnlicher Strukturen im Rahmen der synaptischen Vesikelrezyklierung. Mit Ausnahme der „Kiss and Run“-Endozytose ist für alle Wege die Beteiligung von Endosomen beziehungsweise endosomähnlichen Strukturen im Rahmen von Sortierungsoder Abbauvorgängen der Vesikelproteine beschrieben (Jähne et al. 2015). 


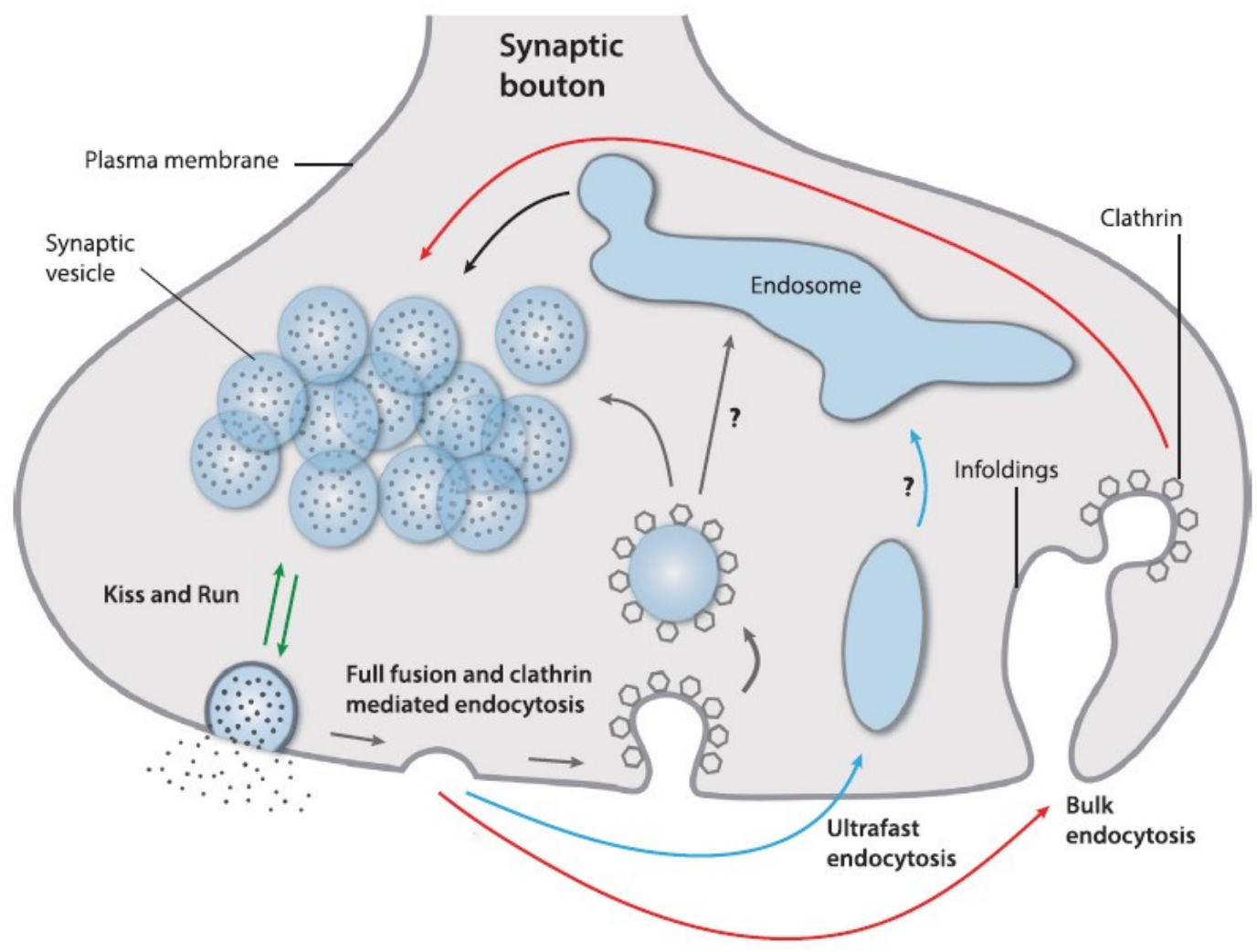

Abbildung 55: Position und mögliche Funktion endosomähnlicher Strukturen im Bereich der Präsynapse. Gezeigt sind die vier Hauptendozytosemodelle synaptischer Vesikel. Dargestellt sieht man den Weg der vollständigen Fusion und der clathrinvermittelten Endozytose (grau), „Kiss and Run“-Endozytose (grün), „Bulk“-Endozytose (rot) und ultraschnellen Endozytose (blau). Mit Ausnahme der „Kiss and Run“-Endozytose sind für alle Wege die Beteiligung von Endosomen beziehungsweise endosomähnlichen Strukturen beschrieben (entnommen aus Jähne et al. 2015; die Verwendung erfolgt mit freundlicher Genehmigung des Elsevier Verlags).

Professor Huttner beschrieb bereits 1995, dass das frühe Endosom der präsynaptischen Axonendigung nicht nur für die Bildung der synaptischen Vesikel verantwortlich ist, sondern darüber hinaus auch die Fähigkeit besitzt, diese nach ihrem Verschmelzen mit der präsynaptischen Membran und der Internalisierung zu regenerieren (Huttner 1995).

Hoopmann und Kollegen erforschten den endosomalen Sortiervorgang als einen schnellen Vorgang, der anscheinend am Vesikelrecycling der initial freigesetzten Vesikel, also Vesikel des „Readily Releasable Pools“, beteiligt ist. Sie fanden heraus, dass sich die Zusammensetzung der Vesikelproteine nach der Endozytose verändert.

Diese werden dafür sowohl in der Plasmamembran als auch in den Endosomen in Clustern gespeichert und dann den neu entstehenden Vesikeln beigefügt (Hoopmann et al. 2010). Fernandes und Kollegen beschreiben die Bedeutung der Endosomen im Rahmen des 
Endosom-Lysosom-Verkehrs, eines Mechanismus, der dem Abbau vesikelassoziierter Proteine dient (Fernandes et al. 2014). Obwohl Endosomen und endosomähnliche Strukturen auch im Ruhezustand der Synapse beobachtet werden können, treten sie besonders nach einem starken Stimulus in Erscheinung (Jähne et al. 2015). Diese Beobachtung von Jähne und Kollegen deckt sich mit der Beschreibung von Wucherpfennig, dass synaptische Endosomen ihre Morphologie während der synaptischen Stimulation verändern und dann im Rahmen der Endozytose aufgenommene Membranbestandteile durch die endosomalen Kompartimente verkehren (Wucherpfennig et al. 2003). Durch den starken Stimulus kommt es zur Bildung großer Einstülpungen der Plasmamembran, von denen ausgehend die clathrinvermittelte Endozytose beobachtet werden konnte (Jähne et al. 2015). Clayton und Kollegen erforschten, dass sich im Rahmen der sogenannten Bulk-Endozytose diese Einstülpungen von der Plasmamembran abschnüren (Clayton et al. 2007). Zu beobachten war dieser Vorgang wiederum nach einem starken Stimulus der Synapse. Aufgrund dieser Erkenntnisse ist es nicht verwunderlich, dass die synaptische Vesikelrezyklierung durch Störungen von Molekülen, die an der Fusion mit dem Endosom (Hoopmann et al. 2010) oder dem Sortiervorgang in dessen Kompartimenten (Uytterhoeven et al. 2011) beteiligt sind, beeinträchtigt wird. Rizzoli gibt jedoch zu bedenken, dass der Mangel an Informationen bezüglich der Funktionsweise der endosomalen Sortierung das Verständnis der Formation synaptischer Vesikel vom Endosom beeinflusst (Rizzoli 2014a).

Zusammenfassend bleibt das Problem, ob die Einstülpungen der Membran im Bereich der aktiven Zone, die nach einem starken Stimulus entstehen, wirklich Endosomen entsprechen oder fälschlicherweise in vielen Studien nur als solche interpretiert wurden (Jähne et al. 2015). Das überwiegende Auftreten dieser Strukturen nach einem unphysiologisch starken Stimulus lässt die Frage offen, ob diese Beobachtungen auch unter physiologischen In-vivo-Bedingungen so gemacht worden wären. Rizzoli gibt zu bedenken, dass der Mangel an Informationen bezüglich der Funktionsweise der endosomalen Sortierung das Verständnis der Formation synaptischer Vesikel vom Endosom beeinflusst (Rizzoli 2014a). Jähne und Kollegen fordern daher, dass zunächst eine klare Definition und einheitliche Marker für Endosomen gefunden und Prozesse wie die „Bulk“-Endozytose weiter erforscht werden (Jähne et al. 2015). Aktuell wird die Ansicht vertreten, dass die frisch endozytierten Vesikel ein mögliches Ziel für die Fusion mit dem Endosom darstellen (Rizzoli 2014a).

Wie bereits erwähnt, konnte in dieser Arbeit mit Hilfe mehrerer statistischer Erhebungen die Bedeutung der Vakuole beziehungsweise des Endosoms für die Synapse und die 
Vesikelrezyklierung belegt werden. Eine Beteiligung an den erklärten Fusions- und Sortierungsprozessen sowie der Bestückung synaptischer Vesikel mit entsprechenden Proteinen ist somit $\mathrm{zu}$ vermuten, bedarf aber noch weiterer Untersuchungen. Diesbezüglich sind die von Jähne und Kollegen aufgestellten Forderungen nach einheitlichen Markern und Definitionen sicherlich hilfreich.

Ein Vergleich mit bisherigen Ergebnissen von Schikorski und Stevens ist im Hinblick auf die Vakuolen nicht möglich, da diese Organellen in ihrer Arbeit nicht untersucht wurden.

\section{Mitochondrien}

Das durchschnittliche Volumen eines Mitochondriums liegt bei circa $0,042 \mu \mathrm{m}^{3}$ und ist somit geringer als das durchschnittliche Vakuolenvolumen. Darüber hinaus folgt die Verteilung der Mitochondrienvolumina im Gegensatz zu denen der Vakuolen keiner GaußVerteilung und scheint somit eher zufällig. Diese Ergebnisse sind, angesichts des hohen Energieverbrauchs einer Synapse, ein nicht unbedingt erwartetes Resultat. Es wäre anzunehmen, dass die Mitochondrienanzahl und das Mitochondrienvolumen mit steigendem Synapsenvolumen ebenfalls ansteigen, da größere Synapsen einen erhöhten Energiebedarf aufweisen. Das Neuron benötigt Energie unter anderem für die Synthese von Neurotransmittern und die Informationsweiterleitung. Beckervordersandforth und Kollegen beschreiben Mitochondrien als Kraftwerke der Zellen, die eine wichtige Rolle in der Steuerung von Stammzellen im Gehirn und in der Entstehung neuer Nervenzellen spielen. Eine Verbesserung der Mitochondrienfunktion stellt ihrer Meinung nach einen neuen möglichen Therapieansatz zur Behandlung von Alterserscheinungen im Gehirn dar (Beckervordersandforth et al. 2017). Weitere Studien von Zeng und Kollegen heben die Bedeutung einer mitochondrialen Dysfunktion im Rahmen der Entstehung der neurodegenerativen Erkrankung Morbus Parkinson hervor und stellen somit die wichtige Funktion für Nervenzellen heraus (Zeng et al. 2018). Gleiche Aussagen treffen Tyumentsev und Kollegen, die Störungen der Mitochondrienfunktion als ein frühes Symptom der Alzheimer Erkrankung ansehen (Tyumentsev et al. 2018). Die Ergebnisse dieser Arbeit legen hingegen eine geringere Bedeutung der Mitochondrien für die Synapsen nahe und ergeben, dass zumindest in einer Zellkultur viele Synapsen mit wenigen, kleinen oder keinen Mitochondrien überleben können.

Ein Vergleich mit den Arbeiten von Schikorski und Stevens ist erneut nicht möglich, da Mitochondrien in ihren Untersuchungen nicht berücksichtigt wurden. 


\section{Vesikel}

Wie bereits im Abschnitt „Synapsen“ erwähnt, beträgt die durchschnittliche Vesikelanzahl pro Synapse circa 250 Vesikel mit einem durchschnittlichen Gesamtvolumen von circa 0,0097 $\mu \mathrm{m}^{3}$. Schikorski und Stevens differenzierten bei ihren Untersuchungen im Jahr 1999 zwischen den einzelnen Hippocampusschichten und zählten die jeweiligen Vesikel in den Schichten $1 \mathrm{a}$ und $1 \mathrm{~b}$ (vergleiche Kapitel 1.2). Sie fanden in der Schicht 1a $354 \pm 436$ Vesikel pro Synapse und in der Schicht 1b $656 \pm 423$. Ihre Tests aus dem Jahr 1997 zeigten im Mittel 270 Vesikel pro Synapse, ein Ergebnis, das sehr gut mit der Anzahl der Vesikel in dieser Arbeit korreliert.

Die Vesikelanzahl steht in den untersuchten Synapsen in der hier vorliegenden Arbeit in einem signifikanten Verhältnis zum Volumen der Synapse und der Oberflächengröße der aktiven Zone. Somit wird eine besondere Bedeutung der Vesikel für die Funktion der Synapse herausgestellt. Mit Zunahme des Volumens einer Synapse steigt die Anzahl der enthaltenen Vesikel und somit auch deren Gesamtvolumen im Vergleich zum Synapsenvolumen. Somit stehen in großen Synapsen mehr Vesikel für die Signalübertragung bereit, was so zu erwarten war und die in Kapitel 1 beschriebenen Abläufe der Signalübertragung an chemischen Synapsen widerspiegelt. Das signifikante Verhältnis der Vesikelverteilung pro aktive Zone wurde so auch schon von Schikorski und Stevens beschrieben und kann somit als Fakt angesehen werden. 


\section{$5 \quad$ Zusammenfassung}

Die hier vorliegende Arbeit soll einen Beitrag zu einem besseren Verständnis des realen dreidimensionalen Aufbaus der Kontakt- und Signalübertragungsstelle zweier Neuronen, der Synapse, liefern. Durch die Detektion und Klassifizierung der wichtigsten Bereiche und Zellorganellen, nämlich der aktiven Zone, der Vesikel, Mitochondrien und der Vakuolen, konnte eine räumliche Vorstellung der Synapsenstruktur rekonstruiert und dreidimensional dargestellt werden (vergleiche Abbildung 28 und 29). Durch die zusätzliche Darstellung der Mitochondrien und Vakuolen konnte im Vergleich zu den Pionierarbeiten von Schikorski und Stevens (vergleiche Abbildung 3) eine noch detailreichere Abbildung der Synapsenstruktur erzielt werden. Dadurch war es auch möglich, Rückschlüsse hinsichtlich der Beziehungen der einzelnen Organellen untereinander zu ziehen, die für ein tieferes Verständnis der physiologischen Funktion der Synapse und der Interaktion der daran beteiligten Zellorganellen von Nutzen sein könnten.

\subsection{Limitationen dieser wissenschaftlichen Arbeit}

Als limitierender Faktor dieser Arbeit ist sicherlich zu erwähnen, dass sowohl die funktionellen Beziehungen innerhalb der Synapse als auch zwischen den einzelnen Zellorganellen keine Berücksichtigung fanden. Es wurde eine strukturelle Beschreibung des dreidimensionalen Aufbaus vorgenommen. Anschließend erfolgten Auswertungen hinsichtlich der Relationen der einzelnen Synapsenbestandteile. Davon ausgehend wurden dann Schlussfolgerungen bezüglich der Bedeutung und der Interaktion der einzelnen Zellorganellen für das Gesamtsystem Synapse gezogen.

Diese reine Herleitung und Beschreibung des anatomischen Aufbaus hätte durch fluoreszenzmikroskopische Betrachtungen oder elektrophysiologische Messmethoden, wie zum Beispiel die „Patch-Clamp-Technik“, weiter sinnvoll ergänzt werden können. Auf diese Art und Weise wären Veränderungen der Aktivitätszustände der einzelnen Komponenten während der synaptischen Übertragung zu messen, der Synapsenanatomie zuzuordnen und in einen Gesamtkontext zu bringen gewesen.

Des Weiteren hätte man durch die Untersuchung einer größeren Anzahl als der in dieser Arbeit beschriebenen 30 Synapsen gegebenenfalls eine höhere Signifikanz bezüglich der gemessenen Werte erzielen und somit auch die Schlussfolgerungen deutlicher belegen 
können. Beispielsweise waren speziell die Ergebnisse hinsichtlich der untergeordneten Funktion der Mitochondrien (vergleiche Kapitel 3.4) trotz des zweifelsohne vorhandenen Energieverbrauchs einer Synapse so nicht zu erwarten. An diesem Punkt hätte eine größere Stichprobe vielleicht hilfreich sein können, um die in dieser Arbeit getroffenen Aussagen zu stützen und gegebenenfalls durch die Verknüpfung mit elektrophysiologischen Messungen zu belegen.

\subsection{Ausblick für zukünftige Foschungsvorhaben}

Vorausschauend erhoffen wir uns, für weitere Forschungsvorhaben einen Beitrag zur Entschlüsselung des realen Synapsenaufbaus geleistet zu haben. Da die funktionellen Beziehungen der einzelnen Organellen nicht primär im Fokus dieser Arbeit standen, wäre dieses ein Ansatzpunkt für weitere Forschungsvorhaben. Eine Verknüpfung des anatomischen Aufbaus mit Erkenntnissen bezüglich der Interaktion der beschriebenen Zellorganellen wäre daher ein weiterer Schritt zur vollständigen Entschlüsselung der Funktion der einzelnen Organellen sowie der Synapse insgesamt. Somit könnte in Zukunft aufgrund dieser neuen Erkenntnisse auch ein besseres Verständnis pathologischer Prozesse, die ihren Ursprung im Bereich der Verschaltung an synaptischen Endigungen nehmen, erzielt werden. Dadurch bestünde die Möglichkeit einer effektiven medizinischen Intervention an genau dieser Schnittstelle zwischen zwei Neuronen, die gerade bei neurodegenerativen Erkrankungen von großer Bedeutung zu sein scheint. 


\section{Literaturverzeichnis}

Ahnert-Hilger G, Bigalke H (1995): Molecular aspects of tetanus and botulinum neurotoxin poisoning. Prog Neurobiol 46, 83-96

Alberts B, Johnson A, Lewis J, Raff M, Roberts K, Walter P: Molecular biology of the cell. 5. Auflage; Garland Science, New York 2008

Alberts B, Johnson A, Lewis J, Raff M, Roberts K, Walter P: Molekularbiologie der Zelle. Hrsg. v. Schäfer U, übers. v. Häcker B u. a. 5. Auflage; Wiley-VCH-Verlag, Weinheim 2011

Bar-On D, Gutman M, Mezer A, Ashery U, Lang T, Nachliel E (2009): Evaluation of the Heterogeneous Reactivity of the Syntaxin Molecules on the Inner Leaflet of the Plasma Membrane. J Neurosci 르, 12292-12301

Bar-On D, Wolter S, van de Linde S, Heilemann M, Nudelman G, Nachliel E, Gutman M, Sauer M, Ashery U (2012): Super-resolution imaging reveals the internal architecture of nanosized syntaxin clusters. J Biol Chem 287, 27158-27167

Beckervordersandforth R, Ebert B, Schäffner I, Moss J, Fiebig C, Shin J, Moore DL, Ghosh L, Trinchero MF, Stockburger C, et al. (2017): Role of Mitochondrial Metabolism in the Control of Early Lineage Progression and Aging Phenotypes in Adult Hippocampal Neurogenesis. Neuron 93, 560-573.e6

Bender R, Lange S (2001): Was ist der p-Wert? DMW - Dtsch Med Wochenschr 126, T 39-T 40

Bloom O, Evergren E, Tomilin N, Kjaerulff O, Löw P, Brodin L, Pieribone VA, Greengard P, Shupliakov O (2003): Colocalization of synapsin and actin during synaptic vesicle recycling. J Cell Biol 161, 737-747

Böcking T, Aguet F, Harrison SC, Kirchhausen T (2011): Single-molecule analysis of a molecular disassemblase reveals the mechanism of Hsc70-driven clathrin uncoating. Nat Struct Mol Biol 18, 295-301

Boujard D, Anselme B, Cullin C, Raguénès-Nicol C, Lechowski S: Zell- und Molekularbiologie im Überblick. Springer Spektrum, Berlin 2014

Burgalossi A, Jung S, Meyer G, Jockusch WJ, Jahn O, Taschenberger H, O'Connor VM, Nishiki T, Takahashi M, Brose N, Rhee J-S (2010): SNARE protein recycling by $\alpha$ SNAP and $\beta S N A P$ supports synaptic vesicle priming. Neuron $\underline{68}, 473-487$

Ceccarelli B, Hurlbut WP (1980): Vesicle hypothesis of the release of quanta of acetylcholine. Physiol Rev 60, 396-441

Ceccarelli B, Hurlbut WP, Mauro A (1973): Turnover of transmitter and synaptic vesicles at the frog neuromuscular junction. J Cell Biol $\underline{57}, 499-524$

Chapman ER (2008): How does synaptotagmin trigger neurotransmitter release? Annu Rev Biochem 그, 615-641

Clayton EL, Evans GJO, Cousin MA (2007): Activity-dependent control of bulk endocytosis by protein dephosphorylation in central nerve terminals. J Physiol $\underline{585}$, 687-691 
Di Giovanni J, Boudkkazi S, Mochida S, Bialowas A, Samari N, Lévêque C, Youssouf F, Brechet A, Iborra C, Maulet Y, et al. (2010): V-ATPase membrane sector associates with synaptobrevin to modulate neurotransmitter release. Neuron $\underline{67}, 268-279$

Draguhn A: Membranpotenzial und Signalübertragung in Zellverbänden; in: Pape H-C, Kurtz A, Silbernagl S, Klinke R (Hrsg.): Physiologie, 7., vollstädnig überarb. und erw. Auflage; Georg Thieme Verlag, Stuttgart / New York 2014, 86-132

Dudel J, Heckmann M: Erregungsleitung und synaptische Übertragung; in: Schmidt RF, Lange F, Thews G (Hrsg.): Physiologie des Menschen mit Pathophysiologie, 29., vollständig neu bearb. und aktual. Auflage; Springer Medizin, Heidelberg 2005, 85-146

Edwards RH (2007): The neurotransmitter cycle and quantal size. Neuron $\underline{55}, 835-858$

Faelber K, Held M, Gao S, Posor Y, Haucke V, Noé F, Daumke O (2012): Structural insights into dynamin-mediated membrane fission. Structure 20, 1621-1628

Fernandes AC, Uytterhoeven V, Kuenen S, Wang Y-C, Slabbaert JR, Swerts J, Kasprowicz J, Aerts S, Verstreken P (2014): Reduced synaptic vesicle protein degradation at lysosomes curbs TBC1D24/sky-induced neurodegeneration. J Cell Biol 207, 453-462

Fernández-Chacón R, Südhof TC (1999): Genetics of synaptic vesicle function: toward the complete functional anatomy of an organelle. Annu Rev Physiol 61, 753-776

Gad H, Löw P, Zotova E, Brodin L, Shupliakov O (1998): Dissociation between Ca2+-triggered synaptic vesicle exocytosis and clathrin-mediated endocytosis at a central synapse. Neuron $\underline{21}, 607-616$

Galli T, McPherson PS, De Camilli P (1996): The V0 sector of the V-ATPase, synaptobrevin, and synaptophysin are associated on synaptic vesicles in a Triton X-100-resistant, freezethawing sensitive, complex. J Biol Chem 271, 2193-2198

Gennaro JF, Nastuk WL, Rutherford DT (1978): Reversible depletion of synaptic vesicles induced by application of high external potassium to the frog neuromuscular junction. J Physiol $\underline{280}, 237-247$

Harlow ML, Szule JA, Xu J, Jung JH, Marshall RM, McMahan UJ (2013): Alignment of synaptic vesicle macromolecules with the macromolecules in active zone material that direct vesicle docking. PloS One $\underline{8}$, e69410

Harris M, Taylor G, Taylor J, Zillgitt M: Startwissen Mathematik und Statistik: Ein Crash-Kurs für Studierende der Biowissenschaften und Medizin. (Startwissen); Elsevier/Spektrum, München 2007

Haucke V, Neher E, Sigrist SJ (2011): Protein scaffolds in the coupling of synaptic exocytosis and endocytosis. Nat Rev Neurosci 12, 127-138

Henkel AW, Betz WJ (1995): Monitoring of black widow spider venom (BWSV) induced exo- and endocytosis in living frog motor nerve terminals with FM1-43. Neuropharmacology $\underline{34}$, 1397-1406

Heuser JE, Reese TS (1973): Evidence for recycling of synaptic vesicle membrane during transmitter release at the frog neuromuscular junction. J Cell Biol 57, 315-344

Hoopmann P, Punge A, Barysch SV, Westphal V, Bückers J, Opazo F, Bethani I, Lauterbach MA, Hell SW, Rizzoli SO (2010): Endosomal sorting of readily releasable synaptic vesicles. Proc Natl Acad Sci U S A 107, 19055-19060 
Hosoi N, Holt M, Sakaba T (2009): Calcium dependence of exo- and endocytotic coupling at a glutamatergic synapse. Neuron $\underline{63}, 216-229$

Jahn R, Fasshauer D (2012): Molecular machines governing exocytosis of synaptic vesicles. Nature 490, 201-207

Jähne S, Rizzoli SO, Helm MS (2015): The structure and function of presynaptic endosomes. Exp Cell Res $\underline{335}, 172-179$

Kaech S, Banker G (2006): Culturing hippocampal neurons. Nat Protoc 1, 2406-2415

Kawasaki F, Mattiuz AM, Ordway RW (1998): Synaptic physiology and ultrastructure in comatose mutants define an in vivo role for NSF in neurotransmitter release. J Neurosci $\underline{18}, 10241-$ 10249

Kühnel W: Taschenatlas Histologie: 750 mikroskopische Aufnahmen mit ausführlichen Bildbeschreibungen. 12., vollst. überarb. Auflage; Thieme, Stuttgart 2008

Lavenex P, Amaral DG (2000): Hippocampal-neocortical interaction: a hierarchy of associativity. Hippocampus $10,420-430$

Littleton JT, Barnard RJO, Titus SA, Slind J, Chapman ER, Ganetzky B (2001): SNARE-complex disassembly by NSF follows synaptic-vesicle fusion. Proc Natl Acad Sci USA 무, 1223312238

Liu KSY, Siebert M, Mertel S, Knoche E, Wegener S, Wichmann C, Matkovic T, Muhammad K, Depner H, Mettke C, et al. (2011): RIM-binding protein, a central part of the active zone, is essential for neurotransmitter release. Science $\underline{34}, 1565-1569$

Lüllmann-Rauch R, Paulsen F: Taschenlehrbuch Histologie. 4., vollständig überarb. Aufl; Thieme, Stuttgart 2012

Ma C, Su L, Seven AB, Xu Y, Rizo J (2013): Reconstitution of the vital functions of Munc18 and Munc13 in neurotransmitter release. Science $\underline{339}, 421-425$

Matz J, Gilyan A, Kolar A, McCarvill T, Krueger SR (2010): Rapid structural alterations of the active zone lead to sustained changes in neurotransmitter release. Proc Natl Acad Sci USA $\underline{107}, 8836-8841$

McMahon HT, Boucrot E (2011): Molecular mechanism and physiological functions of clathrinmediated endocytosis. Nat Rev Mol Cell Biol 12, 517-533

Merrifield CJ, Moss SE, Ballestrem C, Imhof BA, Giese G, Wunderlich I, Almers W (1999): Endocytic vesicles move at the tips of actin tails in cultured mast cells. Nat Cell Biol 1,72 74

Miller TM, Heuser JE (1984): Endocytosis of synaptic vesicle membrane at the frog neuromuscular junction. J Cell Biol 모, 685-698

Murthy VN, Stevens CF (1999): Reversal of synaptic vesicle docking at central synapses. Nat Neurosci 2, 503-507

Neher E (2010): What is Rate-Limiting during Sustained Synaptic Activity: Vesicle Supply or the Availability of Release Sites. Front Synaptic Neurosci $\underline{2}, 144$

Opazo F, Punge A, Bückers J, Hoopmann P, Kastrup L, Hell SW, Rizzoli SO (2010): Limited intermixing of synaptic vesicle components upon vesicle recycling. Traffic Cph Den $\underline{11}$, 800-812 
Reiner A, Dragatsis I, Dietrich P (2011): Genetics and neuropathology of Huntington`s disease. Int Rev Neurobiol 98, 325-372

Richter D (2013): Skript zur Vorlesung Neurophysiologie „Synapsen und synaptische Interaktion“, Wintersemester 2013/14, Göttingen.

Rizzoli SO (2014a): Synaptic vesicle recycling: steps and principles. EMBO J $\underline{33}$, 788-822

Rizzoli SO (2014b): Skript zur Vorlesung Neurophysiologie „Neuronen und Synapsen“, Wintersemester 2014/15, Göttingen.

Rizzoli SO, Betz WJ (2005): Synaptic vesicle pools. Nat Rev Neurosci $\underline{6}$, 57-69

Rizzoli SO, Tabares L (2016): Editorial: Molecular Nanomachines of the Presynaptic Terminal. Front Synaptic Neurosci 8:27

Rosenmund C, Stevens CF (1996): Definition of the readily releasable pool of vesicles at hippocampal synapses. Neuron $\underline{16}, 1197-1207$

Rossetto O, Deloye F, Poulain B, Pellizzari R, Schiavo G, Montecucco C (1995): The metalloproteinase activity of tetanus and botulism neurotoxins. J Physiol-Paris $\underline{89}, 43-50$

Rowe P, Heinisch C: Statistik für Mediziner und Pharmazeuten. Wiley-VCH-Verlag, Weinheim 2012

Ryu J-K, Min D, Rah S-H, Kim SJ, Park Y, Kim H, Hyeon C, Kim HM, Jahn R, Yoon T-Y (2015): Spring-loaded unraveling of a single SNARE complex by NSF in one round of ATP turnover. Science $\underline{347}, 1485-1489$

Sandell JH, Masland R (1988): Photoconversion of some fluorescent markers to a diaminobezidine product. J Histochem Cytochem $\underline{36}, 555-559$

Scarlatos A, Welt BA, Cooper BY, Archer D, DeMarse T, Chau KV (2005): Methods for Detecting Botulinum Toxin with Applicability to Screening Foods Against Biological Terrorist Attacks. J Food Sci 0ㅡ, r121-r130

Schikorski T, Stevens CF (1997): Quantitative ultrastructural analysis of hippocampal excitatory synapses. J Neurosci $\underline{17}, 5858-5867$

Schikorski T, Stevens CF (1999): Quantitative fine-structural analysis of olfactory cortical synapses. Proc Natl Acad Sci 므, 4107-4112

Schikorski T, Stevens CF (2001): Morphological correlates of functionally defined synaptic vesicle populations. Nat Neurosci 4 , 391-395

Schmidt RF, Lang F, Thews G (Hrsg.): Physiologie des Menschen: mit Pathophysiologie. 29., vollst. neu bearb. und aktual. Auflage; Springer Medizin, Heidelberg 2005

Shupliakov O, Bloom O, Gustafsson JS, Kjaerulff O, Low P, Tomilin N, Pieribone VA, Greengard P, Brodin L (2002): Impaired recycling of synaptic vesicles after acute perturbation of the presynaptic actin cytoskeleton. Proc Natl Acad Sci U S A $\underline{99}, 14476-14481$

Sieber JJ, Willig KI, Kutzner C, Gerding-Reimers C, Harke B, Donnert G, Rammner B, Eggeling C, Hell SW, Grubmüller H, Lang T (2007): Anatomy and dynamics of a supramolecular membrane protein cluster. Science $\underline{317}, 1072-1076$

Takamori S, Holt M, Stenius K, Lemke EA, Grønborg M, Riedel D, Urlaub H, Schenck S, Brügger B, Ringler P, et al. (2006): Molecular anatomy of a trafficking organelle. Cell $\underline{127}$, 831-846 
Tyumentsev MA, Stefanova NA, Muraleva NA, Rumyantseva YV, Kiseleva E, Vavilin VA, Kolosova NG (2018): Mitochondrial Dysfunction as a Predictor and Driver of Alzheimer's Disease-Like Pathology in OXYS Rats. J Alzheimers Dis $\underline{63}$, 1075-1088

Uytterhoeven V, Kuenen S, Kasprowicz J, Miskiewicz K, Verstreken P (2011): Loss of skywalker reveals synaptic endosomes as sorting stations for synaptic vesicle proteins. Cell $\underline{145}, 117-$ 132

Veit M (1999): Molecular biology of neurosecretion and its inhibition by tetanus and botulinum toxins. Berl Munch Tierarztl Wochenschr 112, 186-191

Victor A, Elsäßer A, Hommel G, Blettner M (2010): Judging a Plethora of p-Values. Dtsch Arzteblatt Int 107, 50-56

Wucherpfennig T, Wilsch-Bräuninger M, González-Gaitán M (2003): Role of Drosophila Rab5 during endosomal trafficking at the synapse and evoked neurotransmitter release. J Cell Biol 161, 609-624

Xing Y, Böcking T, Wolf M, Grigorieff N, Kirchhausen T, Harrison SC (2010): Structure of clathrin coat with bound $\mathrm{Hsc} 70$ and auxilin: mechanism of Hsc70-facilitated disassembly. EMBO J 29, 655-665

Xu J, Luo F, Zhang Z, Xue L, Wu X, Chiang H-C, Shin W, Wu L-G (2013): SNARE proteins synaptobrevin, SNAP-25 and syntaxin are involved in rapid and slow endocytosis at synapses. Cell Rep $\underline{3}, 1414-1421$

Zefirov AL, Abdrakhmanov MM, Mukhamedyarov MA, Grigoryev PN (2006): The role of extracellular calcium in exo- and endocytosis of synaptic vesicles at the frog motor nerve terminals. Neuroscience 143 , 905-910

Zeng X-S, Geng W-S, Jia J-J, Chen L, Zhang P-P (2018): Cellular and Molecular Basis of Neurodegeneration in Parkinson Disease. Front Aging Neurosci $\underline{10}$

\section{Internetquellen}

- http://insilico.ehu.eus/counting chamber/neubauer improved.php; Zugriff am 13.5.2018

- https://www.mpg.de/synapse, Jahn R (2016): Wie Nervenzellen miteinander reden; Zugriff am 1.5.2018

- https://www.uni-heidelberg.de/uni/presse/rc9/4.html, Huttner W (1995):

Blitzschnelle Boten; Zugriff am 21.4.2018 


\section{Danksagung}

Mein spezieller Dank gilt Herrn Prof. Dr. Silvio O. Rizzoli für die freundliche Überlassung dieses Dissertationsthemas. Seine stets zuverlässige, motivierende und zeitnahe Korrektur meiner Arbeit hat maßgeblich zu dem erfolgreichen Gelingen beigetragen.

Des Weiteren möchte ich mich bei allen Personen bedanken, die mich in den vergangenen Monaten und Jahren immer unterstützt und begleitet haben. 